\title{
Recovery Act: Multi-Objective Optimization Approaches for the Design of Carbon Geological Sequestration Systems
}

\author{
FINAL SCIENTIFIC/TECHNICAL REPORT
}

Reporting Period: December 01, 2009 to May 31, 2013

Principal Author

Professor Domenico Bau

dabau@engr.colostate.edu

Date Report Issued

August 31, 2013

DOE Award Number

DE-FE0001830

Submitting Organization

Colorado State University

1372 Campus Delivery

Fort Collins, CO 80523-1372

USA 


\section{Disclaimer}

This report was prepared as an account of work sponsored by an agency of the United States Government. Neither the United States Government nor any agency thereof, nor any of their employees, makes any warranty, express or implied, or assumes any legal liability or responsibility for the accuracy, completeness, or usefulness of any information, apparatus, product, or process disclosed, or represents that its use would not infringe privately owned rights. Reference herein to any specific commercial product, process, or service by trade name, trademark, manufacturer, or otherwise does not necessarily constitute or imply its endorsement, recommendation, or favoring by the United States Government or any agency thereof. The views and opinions of authors expressed herein do not necessarily state or reflect those of the United States Government or any agency thereof. 


\begin{abstract}
The main objective of this project is to provide training opportunities for two graduate students in order to improve the human capital and skills required for implementing and deploying carbon capture and sequestration (CCS) technologies. The graduate student effort will be geared towards the formulation and implementation of an integrated simulation-optimization framework to provide a rigorous scientific support to the design CCS systems that, for any given site: (a) maximize the amount of carbon storage; (b) minimize the total cost associated with the CCS project; (c) minimize the risk of $\mathrm{CO} 2$ upward leakage from injected formations.

The framework will stem from a combination of data obtained from geophysical investigations, a multiphase flow model, and a stochastic multi-objective optimization algorithm. The methodology will rely on a geostatistical approach to generate ensembles of scenarios of the parameters that are expected to have large sensitivities and uncertainties on the model response and thus on the risk assessment, in particular the permeability properties of the injected formation and its cap rock. The safety theme will be addressed quantitatively by including the risk of $\mathrm{CO}_{2}$ upward leakage from the injected formations as one the objectives that should be minimized in the optimization problem.

The research performed under this grant is significant to academic researchers and professionals weighing the benefits, costs, and risks of $\mathrm{CO}_{2}$ sequestration. Project managers in initial planning stages of CCS projects will be able to generate optimal tradeoff surfaces and with corresponding injection plans for potential sequestration sites leading to cost efficient preliminary project planning.

In addition, uncertainties concerning CCS have been researched. Uncertainty topics included Uncertainty Analysis of Continuity of Geological Confining Units using Categorical Indicator Kriging (CIK) and the Influence of Uncertain Parameters on the Leakage of $\mathrm{CO}_{2}$ to Overlying Formations. Reductions in uncertainty will lead to safer CCS projects.
\end{abstract}




\section{Table of Contents}

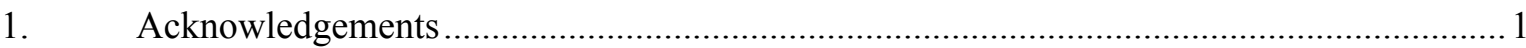

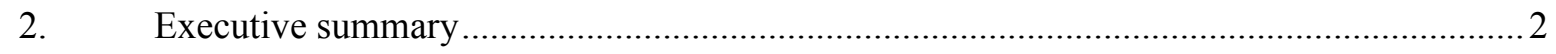

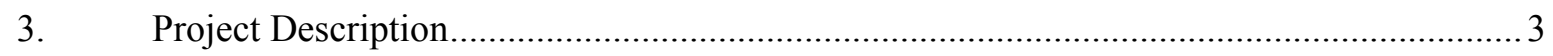

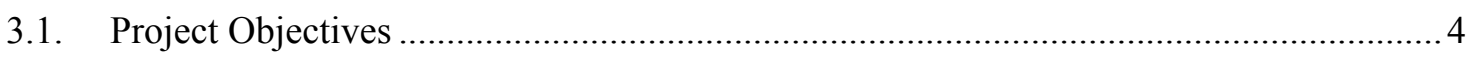

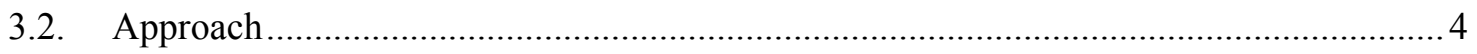

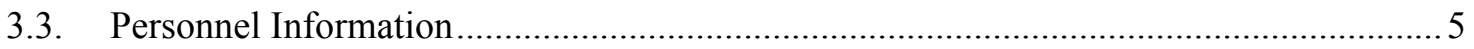

4. Semi-Analytical Modeling of Multi-phase Subsurface Plume and Pressure Migration ....... 6

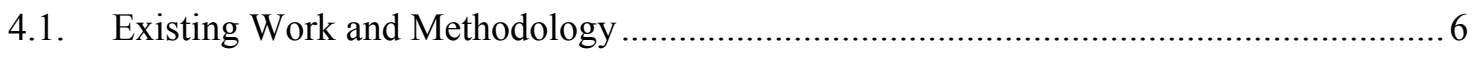

4.2. Semi-analytical Modeling Improvements …........................................................ 7

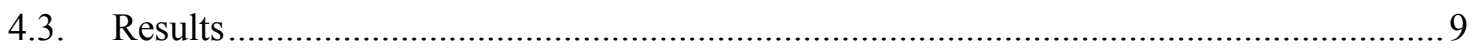

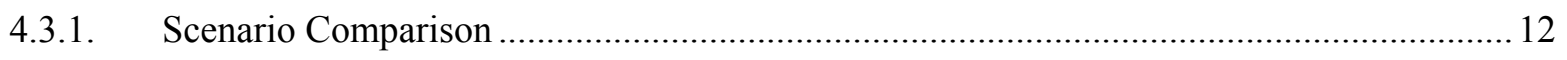

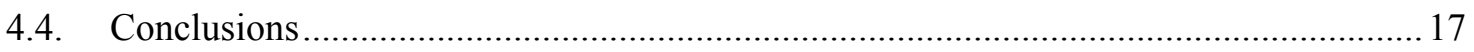

5. Multi-objective Optimization of $\mathrm{CO}_{2}$ Sequestration using Evolutionary Algorithms ......... 18

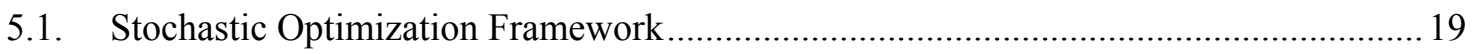

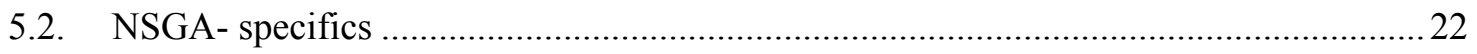

5.3. Case Study: Hypothetical Optimization of $\mathrm{CO}_{2}$ sequestration at the Michigan

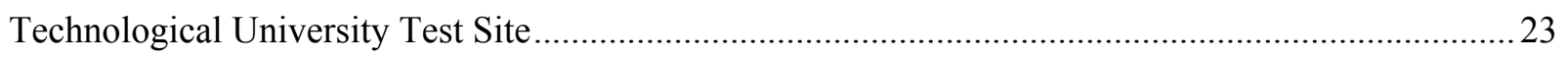

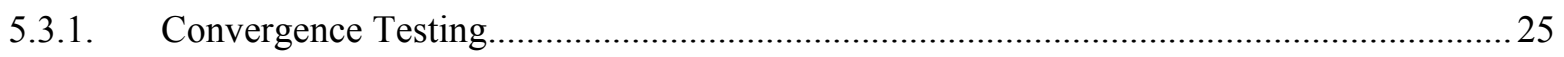

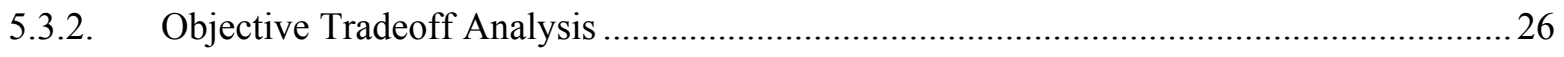

6. Influence of Uncertain Parameters on the Leakage of $\mathrm{CO}_{2}$ to Overlying Formations........ 28

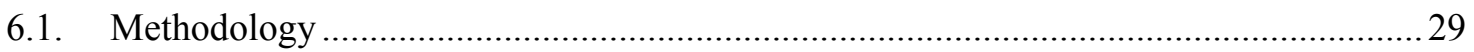

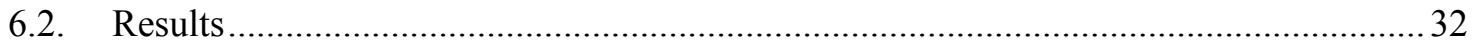

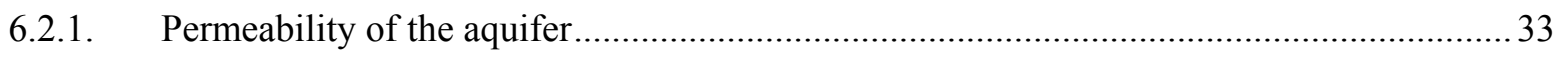

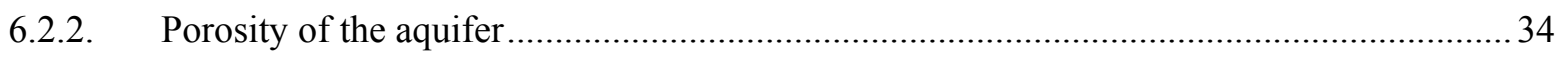

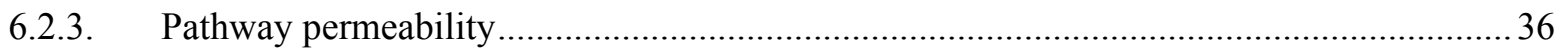




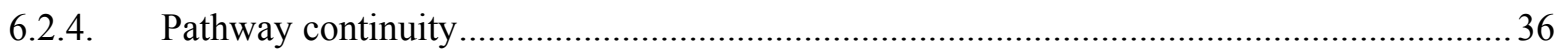

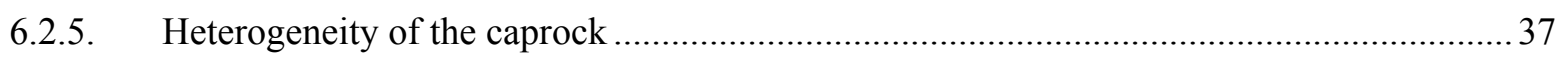

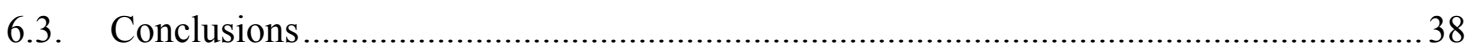

7. Uncertainty Analysis of Continuity of Geological Confining Units using Categorical

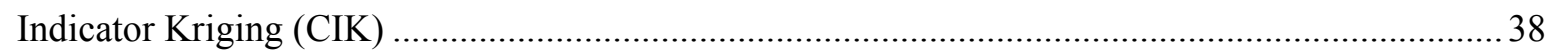

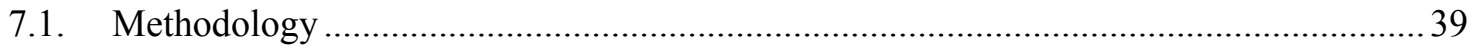

7.1.1. Categorical Indicator Kriging applied to MTU-site ........................................................... 39

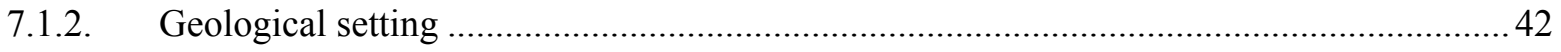

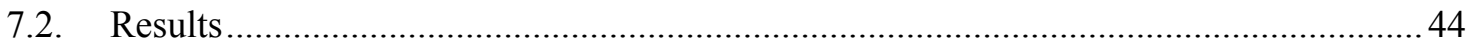

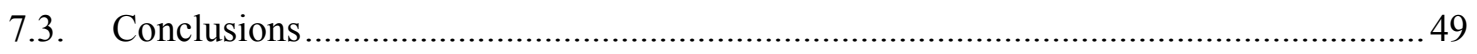

8. Characterization of geophysical properties and lithology of MTU test site......................50

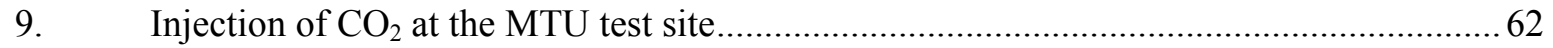

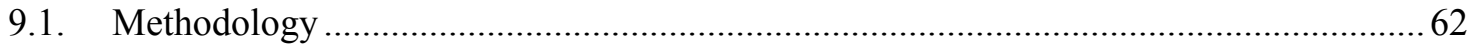

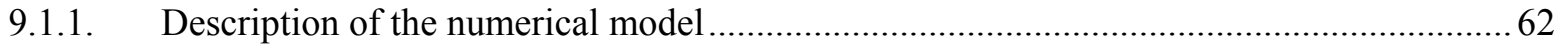

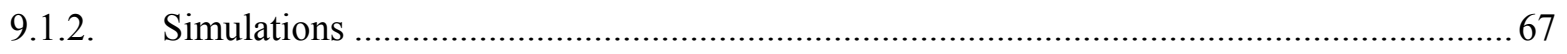

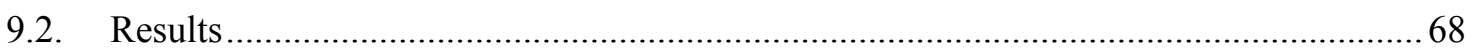

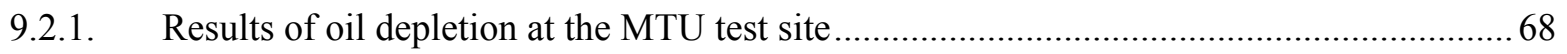

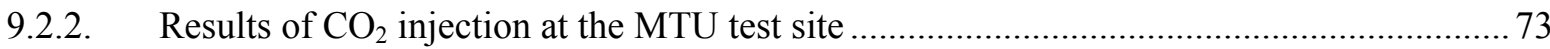

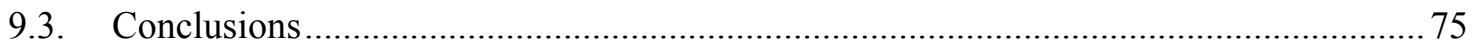

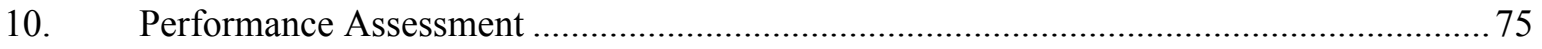

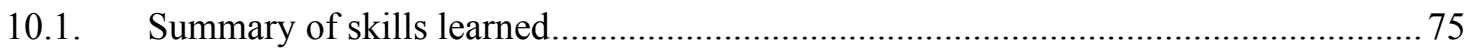

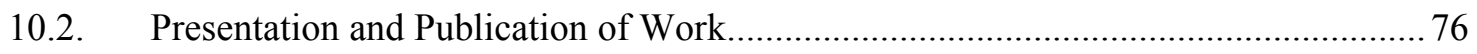

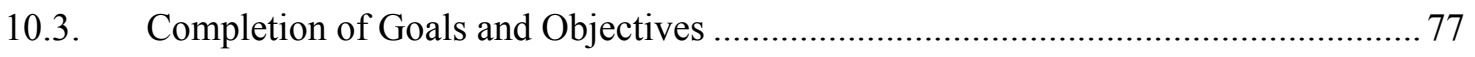

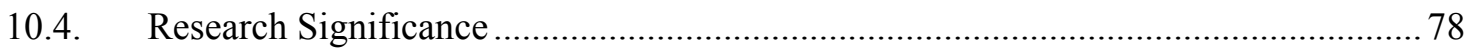

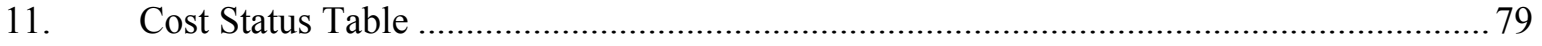

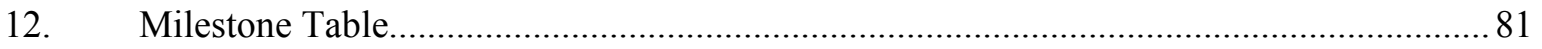

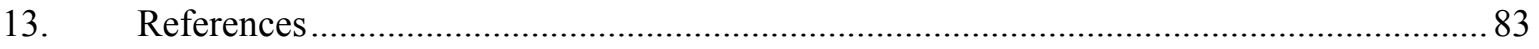




\section{Acknowledgements}

The members of this research team including Dr. Domenico Baú, Brent Cody and Ana GonzalezNicolas would like to thank the U.S. Department of Energy-NETL Office (Grant DE-FE0001830) for their interest and funding of this project. 


\section{Executive summary}

The main research goal pursued in this project consists of the formulation and implementation of an integrated simulation-optimization framework to provide rigorous scientific support to the design of cost-optimal, effective and safe carbon capture and sequestration (CCS) systems. From an educational perspective, this project provides training opportunities for two graduate students in order to improve the human capital and skills required for implementing and deploying CCS technologies.

The members of the research team working on this project are the PI, Dr. Domenico Baú, and two $\mathrm{PhD}$ students, Brent Cody and Ana Gonzalez-Nicolas. Both students have completed their $\mathrm{PhD}$ coursework and are dedicated to full-time research.

In this quarter, the research team has focused on the project tasks "CCS Multi-objective Framework" and "Application to the MTU test site" as planned in the milestone log of the PMP.

The aim of this report is to model uncertainty on the sealing properties of the Gray Niagaran formation at the MTU-site (Michigan) for geological carbon storage. A Categorical Indicator Kriging (CIK) technique is used to study the uncertainty on the continuity of the geological unit overlying the Gray Niagaran. The CIK creates binary fields of caprock (low permeability) and inclusions (high permeability). Inclusions are areas where $\mathrm{CO}_{2}$ could leak. Inclusions having relatively similar spatial locations are grouped and considered as a cluster to reduce the number of leaky points used by the semianalytical multiphase flow model CO2FLOW, thus improving computational efficiency. Simulations of

the MTU-site are also carried out with a numerical code to understand the limitations of the semianalytical model. 


\section{Project Description}

In the last 250 years, the average concentration of atmospheric carbon dioxide $\left(\mathrm{CO}_{2}\right)$ has increased from about $280 \mathrm{ppm}$ to $385 \mathrm{ppm}$. Estimates show that two thirds of this increase has occurred in the last 50 years (Keeling and Whorf, 2000), mainly due the use of fossil fuels as primary source of energy. The current carbon emissions from fossil fuels account for about $95 \%$ of the total emissions, with about $75 \%$ coming from solid and liquid fuels and $20 \%$ originating from natural gases. Increased greenhouse gas emission have long been recognized as one of the major causes of global warming, which has been estimated to be between 0.3 and $0.6^{\circ} \mathrm{C}$ during the last 150 years (Ledley et al., 1999). The Kyoto protocol [UNFCCC, 1997], which was ratified in 1997 by most of the industrialized countries, already included a program for reducing future carbon emissions.

In more recent years, the Intergovernmental Panel on Climate Change (IPCC, 2005; 2007) has indicated that global warming is unequivocal and measures are needed that reduce anthropogenic carbon emissions. Pacala and Socolow (2004) indicate that current global carbon emissions are increasing at a rate of about 0.14 Giga tons per year (GtC/year), and that, under this trend, these emissions will double in about 50 years. Over this period, this is likely produce an increase of the preindustrial concentrations of $\mathrm{CO}_{2}$ of 280 ppm, of about three times (Socolow et al., 2004), which will certainly impact on human health, ecological systems, global temperature and climate. A proposed goal for the next 50 years is to limit $\mathrm{CO}_{2}$ concentrations to about $500 \mathrm{ppm}$. This goal will require the application of technologies that limit carbon emission rates to the current levels of about $7 \mathrm{GtC} /$ year, which is equivalent to cutting a total of $175 \mathrm{GtC}$ over 50 years.

The IPCC (2007) has indicated that multiple synergistic approaches are necessary to achieve this goal. Geological storage in deep saline aquifers of liquid or supercritical $\mathrm{CO}_{2}$ produced from power plants, hydrogen plants, and synthetics fuel plants is seen as a technology that, if applied on a global scale, has the potential of ridding about $25 \mathrm{GtC}$ over the 50 years (Pacala and Socolow, 2004; NETL, 2007). While geological sequestration (GS) seems to be technically feasible (Herzog, 2001), it must be 
carefully examined with regard to the possible environmental side effects. A particular concern is the risk of potential carbon leakage from the injected geologic formations upwards into shallow aquifers or to the atmosphere, which may negatively impact on environmental and human health. Carbon leakage pathways may include permeable areas of cap rock formations, fractures and faults, as well as abandoned oil/gas production wells and exploration boreholes (Celia et al., 2004). Although it is well recognized that the carbon leakage problem is complex and potentially catastrophic, no framework has been advanced to assess the effectiveness, safeness and environmental soundness of the deep formations proposed for carbon GS. . This proposed study will consist of the formulation of an integrated monitoring-modeling multi-objective optimization framework to provide a rigorous scientific support to the design of low-cost, effective and safe GS systems.

\subsection{Project Objectives}

There are two major objectives associated with this project.

1) Formulate and implement an integrated simulation-optimization framework to provide rigorous scientific support to the design of cost-optimal, effective and safe carbon capture and sequestration (CCS) systems.

2) Provide training opportunities for two graduate students in order to improve the human capital and skills required for implementing and deploying CCS technologies.

\subsection{Approach}

As of the period covered by this Project Progress Report (PPR), both of the graduate students involved in this project, Brent Cody and Ana Gonzalez-Nicolas, have completed all required coursework at Colorado State University necessary to fulfill the requirements of the doctoral graduate program in Civil and Environmental Engineering.

The two students and the PI have continued their work regarding the simulation of geological sequestration of $\mathrm{CO}_{2}$ into domains having uncertain parameters, as well as the development of a 
simulation/optimization framework that can be used to: (a) investigate the sensitivity of different site parameters and injection strategies on the risk of carbon leakage; (b) assist the design of cost-optimal, effective and safe carbon injection schemes.

\subsection{Personnel Information}

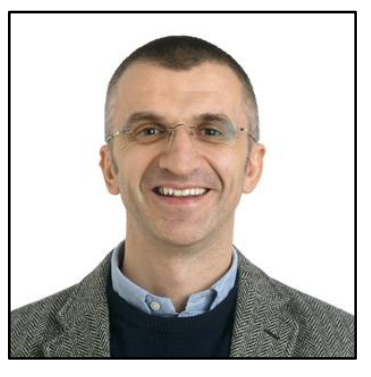

Domenico Baú, Ph.D., (PI), is an Assistant Professor of Civil and Environmental Engineering at Colorado State University. He has extensive experience in the development and implementation of mathematical models applied to flow and transport hydrogeological processes and land subsidence geomechanical analyses and optimization algorithms for planning and management of groundwater resources, and in conducting geostatistical analyses of physical properties of porous media for this project.

Doctoral candidate Ana González-Nicolás achieved dual Masters Degrees in both Chemical Engineering and Groundwater Hydrology from Universitat Politecnica de Catalunya (UPC), Barcelona, Spain. During this doctoral study she has focused upon numerical techniques, gaining experience in modeling $\mathrm{CO}_{2}$ sequestration using Eclipse, Petrel, and CO2FLOW.
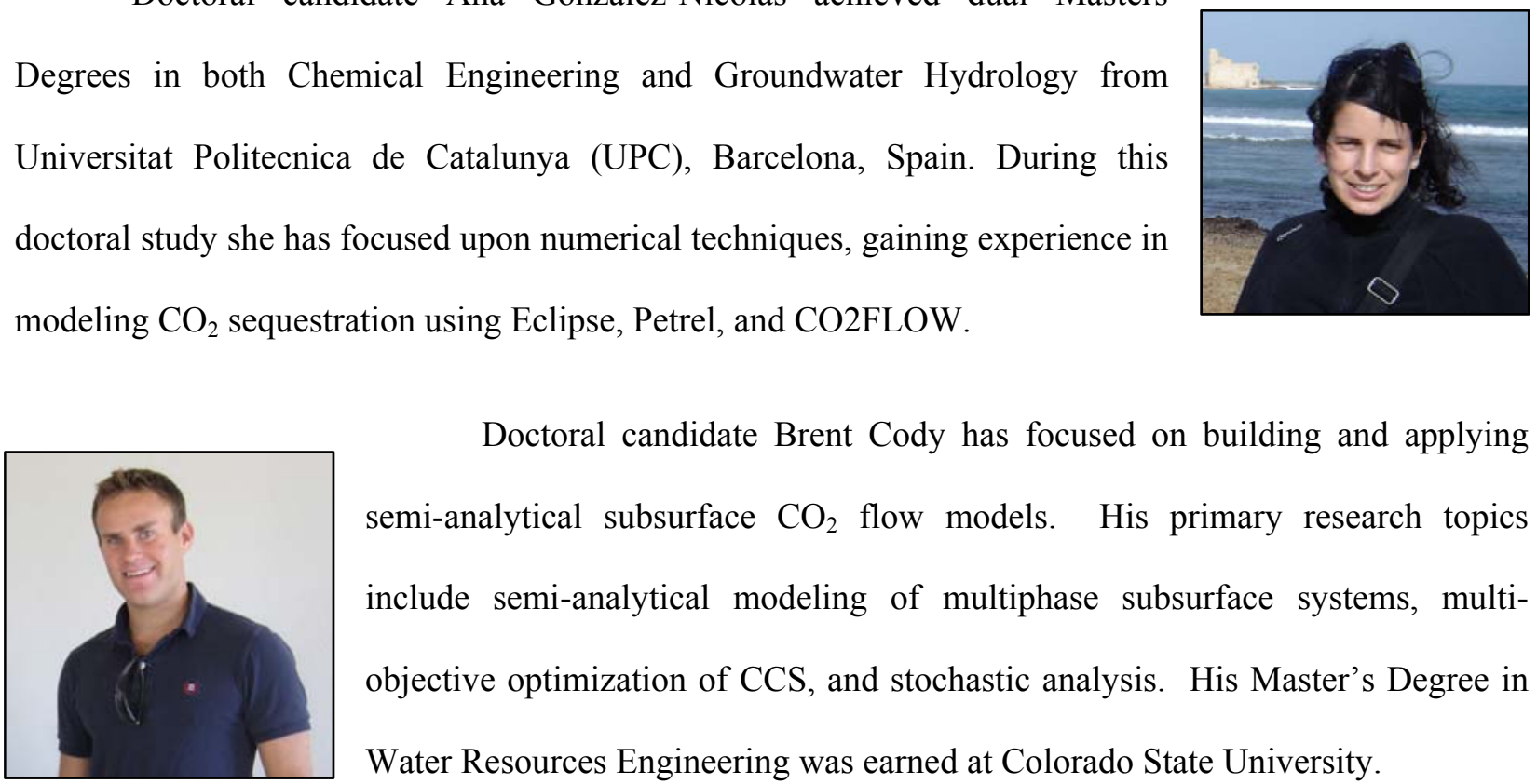

Doctoral candidate Brent Cody has focused on building and applying semi-analytical subsurface $\mathrm{CO}_{2}$ flow models. His primary research topics include semi-analytical modeling of multiphase subsurface systems, multiobjective optimization of CCS, and stochastic analysis. His Master's Degree in Water Resources Engineering was earned at Colorado State University. 


\section{Topics Researched}

\section{Semi-Analytical Modeling of Multi-phase Subsurface Plume and Pressure Migration}

\subsection{Existing Work and Methodology}

Referred to as ELSA (Estimating Leakage Semi-analytically) when used by Nogues et al. (2012) to estimate the maximum probable leakage along abandon oil wells, the semi-analytical algorithm focused upon estimates both brine and $\mathrm{CO}_{2}$ flux through permeable caprock locations caused by GCS. Permeable caprock locations are conceptualized as segments of abandoned wells and represent cylindrical portions of the aquitard layers having permeability values greater than or equal to zero. These are referred to as 'passive wells' and are the only pathways for fluid flux between aquifer layers. Users of this model are able to specify the number and spatial location of injection wells $(M)$, passive wells $(N)$, and aquifer/aquitard layers $(L)$.

The domain is structured as a horizontal stack of aquifer/aquitard layers perforated by injection and passive wells. Aquifers are assumed to be horizontally level, homogenous, and isotropic. Aquitards are impermeable, except where perforated by passive wells. Injection wells are able to inject into any layer. Initially, fluid is not flowing through any of the passive wells because the entire domain is assumed to be saturated with brine at hydrostatic pressure. Additional assumptions made by this model include:

- Aquifers exhibit horizontal flow

- Capillary pressure is negligible resulting sharp fluid interface

- $\mathrm{CO}_{2}$ plume thickness at any given location is assumed to be the maximum plume thickness from any given source or sink in the aquifer

- Pressure response from sources and sinks are superimposed in each aquifer 


\subsection{Semi-analytical Modeling Improvements}

The $\mathrm{CO}_{2}$ pressure response function (1) was derived for sources or sinks having constant flow rate. Passive well fluxes occur as a response to pressure differentials across caprock layers and therefore change with time. Fluid pressure response from a variable flow rate may be estimated by using an average flow rate. The following is very important to understand about the established algorithm: for each time step, the established semi-analytical leakage algorithm estimates the total pressure change thus far (not the pressure change over the time step) at well $w$ resulting from fluid flux at well ws by multiplying the current time step's instantaneous passive well flow rate by a Green's function constant calculated using the average flow rate over all previous time steps.

$$
\Delta p_{w, l, w s}=G_{w, l, w s}\left(Q_{a v g, w s, l}^{t-1}\right) \cdot Q_{w s, l}^{t}
$$

This work proposes estimating this pressure change by multiplying the average passive well flow rate of all previous time steps by its corresponding Green's function constant.

$$
\Delta p_{w, l, w s}=G_{w, l, w s}\left(Q_{a v g, w s, l}^{t-1}\right) \cdot Q_{a v g, w s, l}^{t}
$$

Figure 4-1 shows an example of a passive well's flux (represented by the blue line) increasing with time. In this case, multiplying $Q_{w s, l}^{t}$ (represented by the orange line) by the injection duration $(t)$ overestimates the volume of fluid transferred and therefore the change in pressure from the source or sink ws.

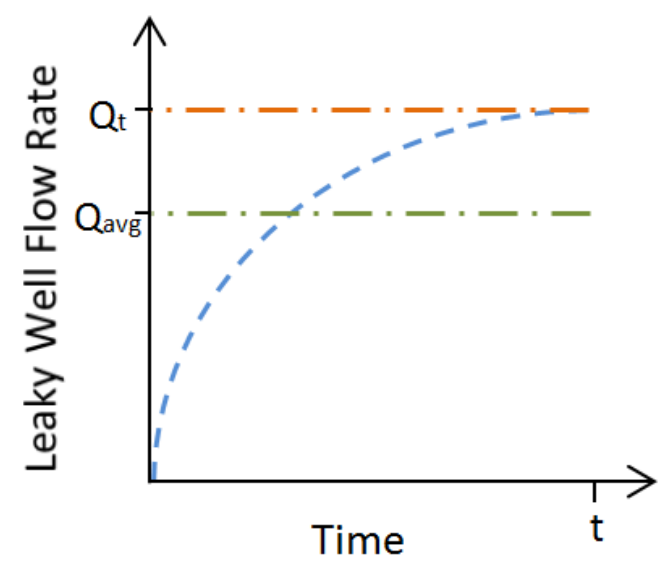

Figure 4-1. Passive well flow rate vs. time 
To apply this modification, the local pressure equation needs to be rewritten with respect to $Q_{\text {avg,ws }}$.

$$
\begin{aligned}
p_{w, l}=p_{\text {int }, l}+ & \sum_{w s=1}^{M} G_{w, l, w s} Q_{a v g, w s, l}+\sum_{w s=M+1}^{M+N} G_{w, l, w e l l}\left\{Q_{a v g, w s, l}-Q_{a v g, w s, l+1}\right\} \\
& +F\left(h_{\text {max }}^{\prime}\right)\left(\rho_{b}-\rho_{c}\right) g H
\end{aligned}
$$

Next, unknown passive well flow rates are isolated for the current time step. The average volumetric flow rate is equal to the total fluid mass transferred by the passive well segment, $M_{w s, l}^{t}$, divided by the effective fluid density, $\rho_{\text {eff }}$, divided by the time, $t$.

$$
Q_{a v g, w s, l}^{t}=M_{w s, l}^{t} / \rho_{e f f} t
$$

Effective fluid densities are needed in this case because $M_{w s, l}^{t}$ may be composed of both $\mathrm{CO}_{2}$ and brine. The total fluid mass transferred through the current time step between aquifers by a passive well segment may be defined as

$$
M_{w s, l}^{t}=M_{w s, l}^{t-\Delta t}+\Delta t \cdot 0.5\left(Q_{w s, l}^{t-\Delta t}+Q_{w s, l}^{t}\right) \rho_{e f f}
$$

where $M_{w s, l}^{t-\Delta t}$ is total fluid mass transferred by the well segment during all previous time steps, $\Delta t$ is time-step duration, and $0.5\left(Q_{w s, l}^{t-\Delta t}+Q_{w s, l}^{t}\right) \rho_{e f f}$ is the average mass flux over the current time step. Substituting (4-5) into (4-4) gives

$$
Q_{w s, a v g, l}^{t}=\left[M_{w s}^{t-\Delta t, l}+0.5 \Delta t\left(Q_{w s}^{t-\Delta t, l}+Q_{w s}^{t, l}\right) \rho_{e f f}\right] / \rho_{e f f} t
$$

Subtracting the bottom by the top layer average flow rates gives

$$
\begin{aligned}
Q_{w s, a v g, l}-Q_{w s, a v g, l+1} \\
=\left[M_{w s}^{t-\Delta t, l}-M_{w s}^{t-\Delta t, l+1}+\Delta t\right. \\
\left.\cdot 0.5\left\{\left(Q_{w s}^{t-\Delta t, l}+Q_{w s}^{t, l}\right)-\left(Q_{w s}^{t-\Delta t, l+1}+Q_{w s}^{t, l+1}\right)\right\} \rho_{e f f}\right] / \rho_{e f f} t
\end{aligned}
$$


The preceding equation may be simplified by defining $c_{c}$ and $c_{2}$ as

$$
\begin{gathered}
c_{1}=\frac{M_{w s}^{t-\Delta t, l}-M_{w s}^{t-\Delta t, l+1}+0.5 \Delta t\left(Q_{w s}^{t-\Delta t, l}-Q_{w s}^{t-\Delta t, l+1}\right) \rho_{e f f}}{\rho_{e f f} t} \\
c_{2}=\frac{0.5 \Delta t}{t}
\end{gathered}
$$

Using $c_{1}$ and $c_{2}$, (4-7) may be written concisely as

$$
Q_{w s, a v g, l}-Q_{w s, a v g, l+1}=c_{2}\left(Q_{w s, l}-Q_{w s, l+1}\right)+c_{1}
$$

Substituting (4-10) into (4-3) gives the pressure equation for the modified method.

$$
\begin{aligned}
p_{w, l}=p_{\text {int }, l}+ & \sum_{w s=1}^{M}\left[G_{w, l, w s} Q_{w s, l}\right] \\
& +\sum_{w s=M+1}^{M+N}\left[c _ { 2 } G _ { w , l , w s } \left\{\pi r_{p w_{w s, l}^{2} k_{w s, l} \frac{k_{r, e f f, w s, l}}{\mu_{e f f} B_{l}}\left(p_{w s, l-1}-\rho_{b} g B_{l}-g H_{l-1}\left(\rho_{b}\right.\right.}\right.\right. \\
& \left.\left.-\rho_{b} h_{w, l-1}^{\prime}+\rho_{c} h_{w, l-1}^{\prime}\right)-p_{w s, l}\right) \\
& -\pi r_{p w_{w s, l+1}^{2}} k_{w s, l+1} \frac{k_{r, e f f, w s, l+1}}{\mu_{e f f} B_{l+1}}\left(p_{w s, l}-\rho_{b} g B_{l+1}-g H_{l}\left(\rho_{b}-\rho_{b} h_{w, l}^{\prime}\right.\right. \\
& \left.\left.\left.\left.+\rho_{c} h_{w, l}^{\prime}\right)-p_{w s, l+1}\right)\right\}+c_{1} G_{w, l, w s}\right]+F\left(h_{\max }^{\prime}\right)\left(\rho_{b}-\rho_{c}\right) g H
\end{aligned}
$$

\subsection{Results}

Due to the complexity of the underlying concepts we attempt to keep the simulation domains as simple as possible. The following parameters are constant for all simulations: 1 injection well, 1 passive well, 2 - $20 \mathrm{~m}$ thick aquifers each having an isotropic permeability of $10 \mathrm{mD}$ separated by a $10 \mathrm{~m}$ thick aquitard, $\lambda=4.1, S_{b}^{r e s}=2.5 \%, c_{e f f}=4.6 \times 10^{-10} \mathrm{~m}^{2} / \mathrm{N}, g=9.81 \mathrm{~m} / \mathrm{s}^{2}, \rho_{b}=1045 \mathrm{~kg} / \mathrm{m}^{3}, \rho_{c}=479 \mathrm{~kg} / \mathrm{m}^{3}, \mu_{b}$ $=0.2935 \mathrm{mPa} \mathrm{s}$, and $\mu_{c}=0.0395 \mathrm{mPa}$. In addition, the bottom of the lower aquifer is at a depth of 2000 m (Figure 3). 
Mathematical justification of the proposed modification has been given above however the following is a graphical validation of the proposed improvement. The existing and modified semianalytical algorithms are used to simulate two injection schemes having identical domain characteristics; a $500 \mathrm{~m}$ separation distance between the injection and passive well, $k_{p w}=100 \mathrm{mD}$, and $r_{p w}=0.2 \mathrm{~m}$. Both scenarios involve the injection of $10 \mathrm{~kg} / \mathrm{s}$ for a period of 1 year however the first scheme begins injecting immediately (start at $\mathrm{t}=0$ yrs.) while the second begins injection at the start of the last year of a 50 year simulation (start at $\mathrm{t}=49 \mathrm{yrs}$.). The second scenario may be representative of a variable rate injection well or a passive well that encounters a pressure pulse near the end of simulation. Dimensionless leakage is the mass of $\mathrm{CO}_{2}$ leakage into the upper aquifer divided by the total mass injected. The relative leakage error is defined as

$$
\text { Rel. Error }=\frac{a b s\left(M_{\text {leak }} k_{E S A}-M l e a k_{E L S A r}\right)}{\text { Mleak }_{E L S A r}} * 100 \%
$$

where Mleak is the mass of $\mathrm{CO}_{2}$ that has leaked into the upper layer and ELSAr referred to the revised methodology. Based upon the hydrostatic initial condition assumption, semi-analytical results for each injection scheme should be identical and similar to numerical results. However, the established semi-analytical algorithm drastically underestimates leakage mass for the 50 year simulation. Figure 4-2 shows leakage estimation for the 1 year simulation and the last year of the 50 year simulation. 


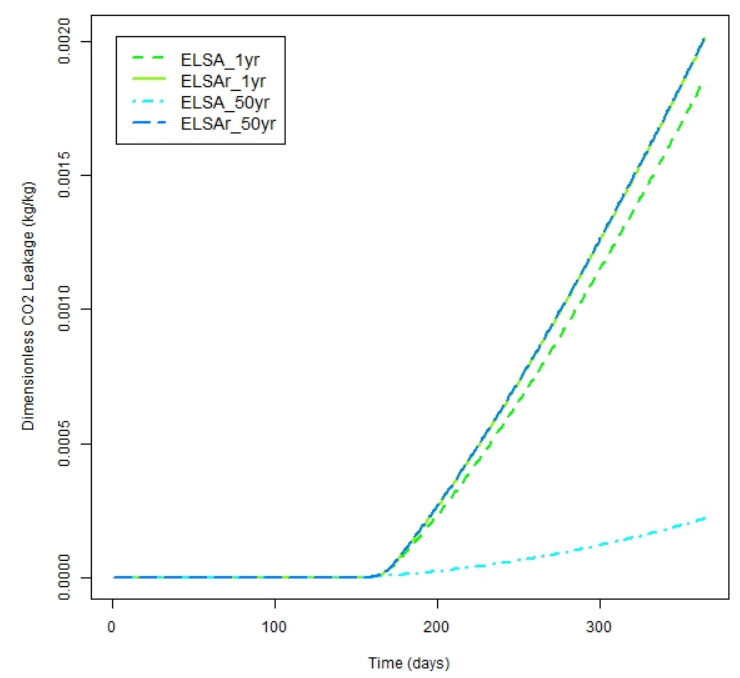

Figure 4-2. Dimensionless leakage vs. time for the 1 year simulations and last year of the 50 year simulations

All semi-analytical results are very similar except those given by the established method for the 50 year simulation. The reason why the established semi-analytical model underestimates leakage in this case is as follows: The change in aquifer fluid pressure is equal to the product of the Green's function and the source or sink flow rate. In this case, the instantaneous flow rate $\left(Q_{t}\right)$ is much greater than the average flow rate $\left(Q_{\text {avg }}\right)$. The change in pressure resulting from caprock leakage calculated by $G^{*} Q_{t}$ is therefore greater than the change in pressure calculated by $G^{*} Q_{\text {avg. }}$. Hence, the pressure differential between the two aquifers is assumed to equalize with less fluid transfer using ELSA and therefore results in less cumulative leakage mass. Figure 4-3 shows the relative error for the last year of the 50 year simulation using ELSA. There are no data before $\mathrm{t}=156$ days because $\mathrm{CO}_{2}$ did not begin leaking before this time. 


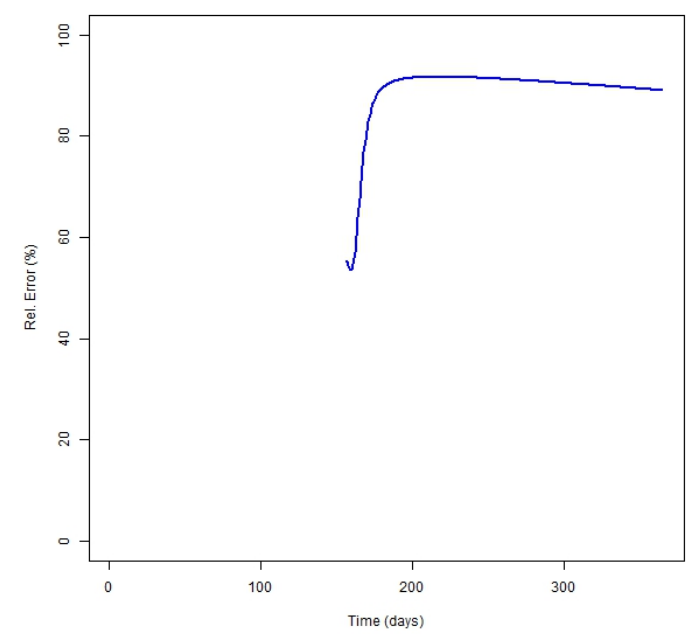

Figure 4-3. Relative error vs. time for the last year of the established algorithm's 50 year simulation

\subsubsection{Scenario Comparison}

It is evident that average and instantaneous leakage flow rates are greatly different for the $50 \mathrm{yr}$. simulation as the injection well has been dormant for 49 years before starting injection. Let us now compare fluid leakage estimation between the existing and modified semi-analytical algorithms for more realistic injection schemes and domain characteristics. A hypothetical base case was established with a 40 year injection rate of $30 \mathrm{~kg} / \mathrm{s}$, a $4000 \mathrm{~m}$ separation distance (SepDist) between the injection and passive well, $k_{p w}=100 \mathrm{mD}$, and $r_{p w}=0.4 \mathrm{~m}$. Sets of scenarios were created by altering each one of these four parameters. Leakage estimates of these scenarios were compared to determine the significance of the proposed modification. Table 4-1 displays the parameters used in this study with the base case highlighted light grey.

Table 4-1. Study parameters

\begin{tabular}{|c|c|c|c|}
\hline $\begin{array}{c}\text { Injection Rate } \\
(\mathrm{kg} / \mathrm{s})\end{array}$ & $\begin{array}{c}\text { Distance btw. } \\
\text { IW and PW (m) }\end{array}$ & $\begin{array}{c}\text { Passive well } \\
\text { Permeability } \\
(\mathrm{mD})\end{array}$ & $\begin{array}{c}\text { Passive well } \\
\text { Radius (m) }\end{array}$ \\
\hline 10 & 1000 & 10 & 0.2 \\
\hline 30 & 4000 & 100 & 0.4 \\
\hline 50 & 7000 & 1000 & 0.6 \\
\hline
\end{tabular}


Figure 4-4 and Figure 4-5 show dimensionless leakage and relative error versus time for the set of scenarios in which the injection rate was altered from the base case. Both dimensionless leakage and maximum relative error increased with increased injection rate. The final values of relative error were lower in cases with higher injection rates because the $\mathrm{CO}_{2}$ plume arrived at the passive well earlier and had more time to adjust.

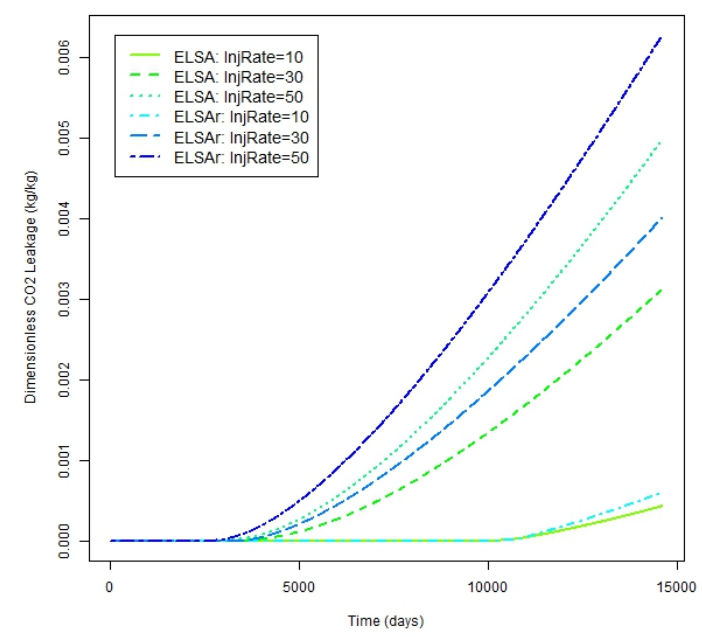

Figure 4-4. Dimensionless leakage vs. time for scenarios having altered injection rate

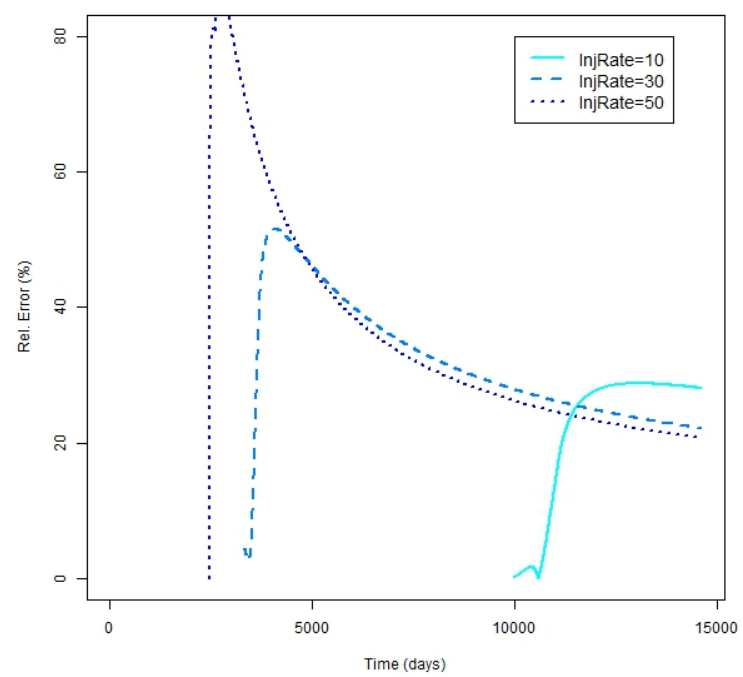

Figure 4-5. Relative error vs. time for scenarios having altered injection rate 
The following two figures show dimensionless leakage and relative error versus time for the set of scenarios in which the separation distance was altered from the base case. As expected, dimensionless leakage decreased with increased separation distance. The maximum relative error was relatively the same for these three simulations but dropped off faster in case of increased separation distance. Final relative error at the end of simulation were greater in cases of larger separation distance due to longer passive well dormant periods.

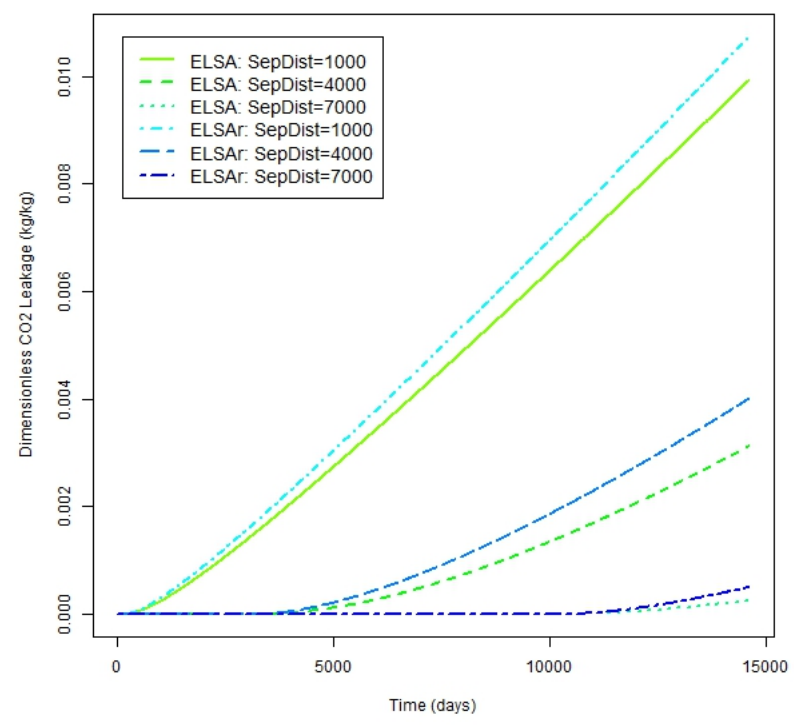

Figure 4-6. Dimensionless leakage vs. time for scenarios having altered separation distance 


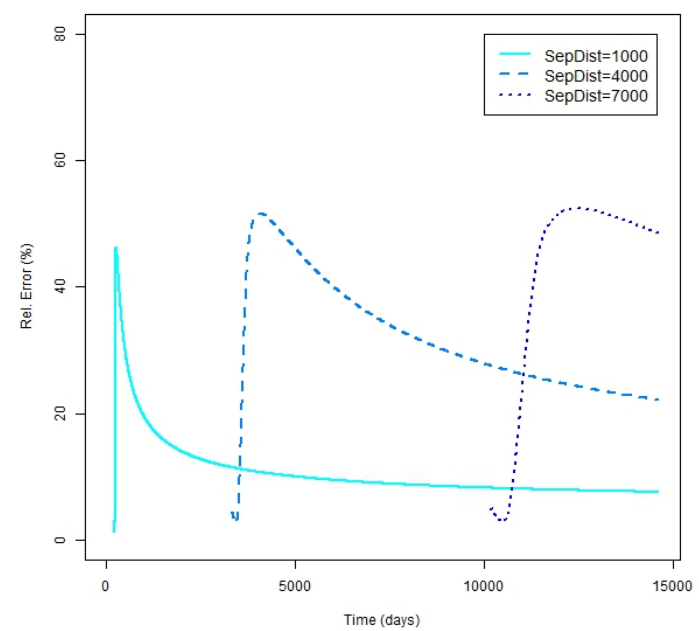

Figure 4-7. Relative error vs. time for scenarios having altered separation distance

Figure 4-8 and Figure 4-9 show dimensionless leakage and relative error versus time for the set of scenarios in which the passive well permeability was altered from the base case. While leakage began at approximately the same time large increases in both maximum and final relative error were observed for greater values of passive well permeability. Relative error dropped off slower for scenarios having higher passive well permeability.

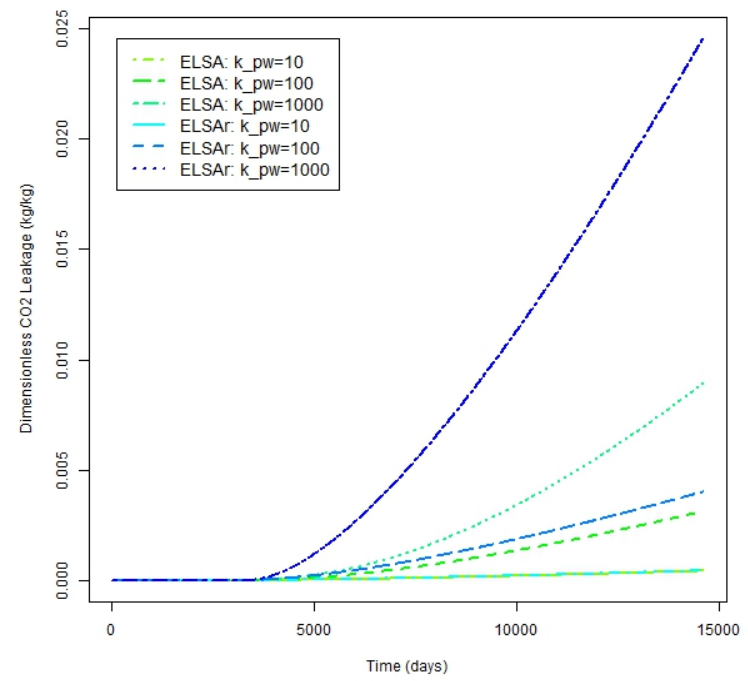

Figure 4-8. Dimensionless leakage vs. time for scenarios having altered passive well permeability 


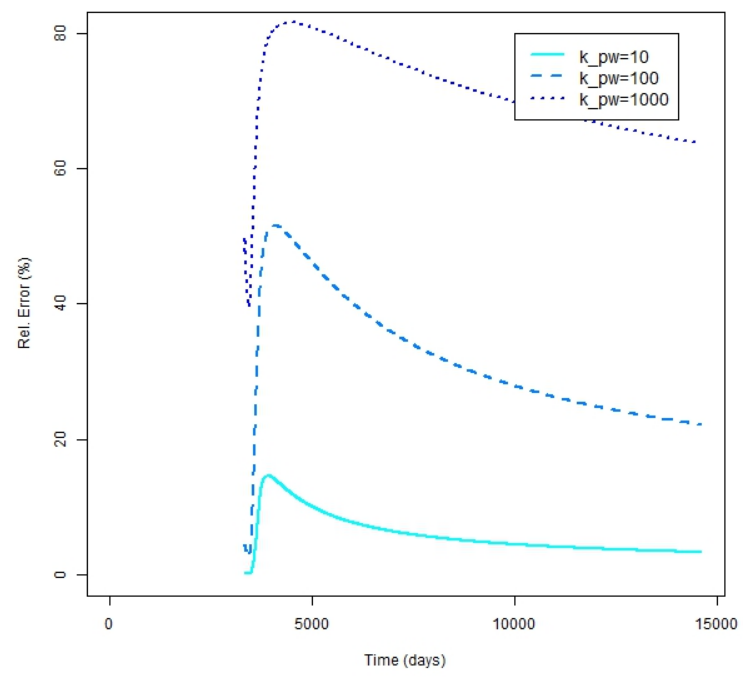

Figure 4-9. Relative error vs. time for scenarios having altered passive well permeability

The final set of scenarios involved altering the passive well radius from the base case. Figure 4-10 and Figure 4-11 show that increasing the passive well radius produces similar results to increasing passive well permeability, however relative error did not drop off slower for scenarios having higher passive well radii.

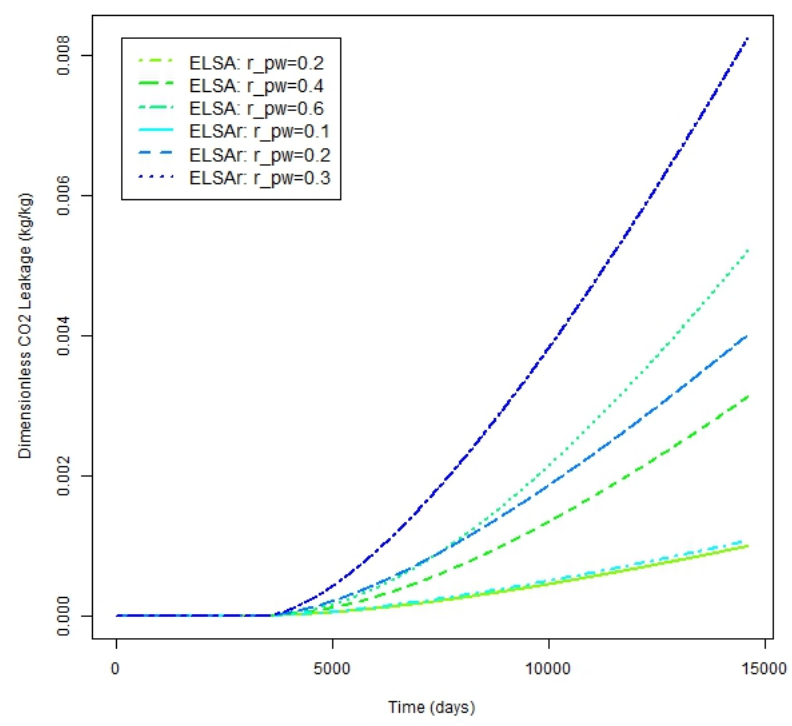

Figure 4-10. Dimensionless leakage vs. time for scenarios having altered passive well radius 


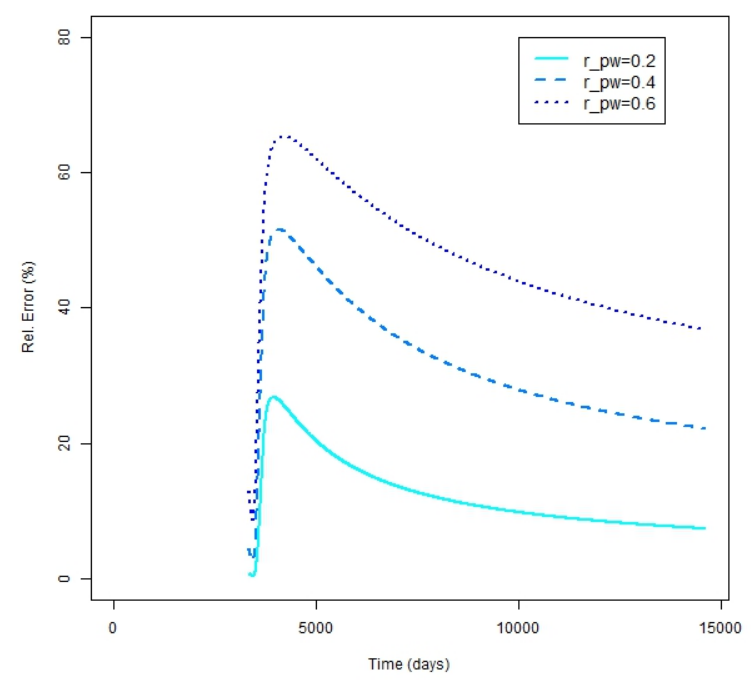

Figure 4-11. Relative error vs. time for scenarios having altered passive well radius

\subsection{Conclusions}

This work has led to an important modification of the semi-analytical algorithm presented by Nordbotten et al. (2009) and developed by Celia et al. (2011). An accuracy improvement involving the use of average (as opposed to instantaneous) caprock flux rates to estimate aquifer fluid pressure changes throughout the domain has been proposed, validated, and explored. Mathematical and graphical justification of the modification has been presented and cumulative $\mathrm{CO}_{2}$ leakage mass versus injection time estimated by the established and modified semi-analytical algorithms have been compared for scenarios having varied injection scheme and domain characteristics.

Relative error values between the existing and proposed semi-analytical algorithms ranged between 5 and $>80 \%$ and were found to be very high for most scenarios tested. Factors inducing the greatest error were passive well transmissivity and length of the passive well's initial dormant period. This modification is recommend for all applications of semi-analytical leakage estimation, however results show that it is highly important for simulations involving variable injection rates (e.g. brine cycling) and/or highly transmissible passive wells located relatively far from the injection location. It is 
important to note that this modification may also be applied to the singe-phase leakage algorithm proposed by Nordbotten et al. (2004).

\section{Multi-objective Optimization of $\mathrm{CO}_{2}$ Sequestration using Evolutionary Algorithms}

Conjunctive preliminary project planning involves the characterization, feasibility study, and risk assessment of several potential GCS sites. There are, however, several difficulties associated with these tasks. The first is that large-scale, multi-phase numerical modeling of several potential injection sites for the purpose of initial assessment is infeasible due to both the effort involved in model construction and calibration. Also, because of their propensity to be computationally expensive, the direct use of numerical methods would be unrealistic in simulating the high volume of realizations needed for risk assessment and optimization of large subsurface domains exhibiting multi-phase flow.

The high computational costs associated with numerical models may be overcome by use of a response surface, however, this work has chosen to use a semi-analytical multi-phase flow model presented by Nordbotten et al. (2009) and modified by Cody et al. (2013) for multi-phase subsurface flow simulation. The resulting framework will ultimately be used to optimize and compare large quantities of potential injection sites having vastly different domain characteristics. Creating and calibrating each potential injection site's numerical model, as well as training the resulting response surface requires user expertise and large investments of computational time. The semi-analytical leakage algorithm is very general and is able to be applied to simplified computational models of the vast majority of potential injection sites.

An additional difficulty associated with preliminary project planning is that potential GS sites typically exhibit a high degree of uncertainty associated with physical parameters. Celia et al. (2011) identified abandoned well permeabilities as being the most dominate uncertain parameter when estimating fluid leakage due to GCS. In North America, significant numbers of abandoned oil wells may perforate the caprock in formations attractive to GCS (Nogues et al., 2012). Most likely, very little inform exists 
on the sealing properties of these wells. Several efforts have been made to investigate and accommodate the uncertainties associated with abandoned wells. Watson and Bachu (2008; 2009) developed an abandoned well integrity scoring index based upon typically available information (e.g. completion date, regulatory requirements, etc.). Crow et al. (2009) physically sampled and analyzed segments of a $30 \mathrm{yr}$. old abandoned well that had been continuously exposed to $96 \% \mathrm{CO}_{2}$. Nogues et al. (2012) explored the effects of caprock permeability uncertainty on fluid leakage estimation. Similarly to Celia et al. (2011), this work applies a stochastic Monte Carlo approach to estimate leakage risk associated with caprock permeability uncertainty.

A stochastic optimization framework has been created to perform preliminary assessment of potential GS sites while accounting for uncertainties inherent in subsurface domains. A genetic algorithm (NSGA-II with $\varepsilon$-dominance) has been chosen as the optimization driver to create a tradeoff surface between three competing objectives. Mass of $\mathrm{CO}_{2}$ sequestered is maximized while project cost and risk of project cost exceedance are minimized by selecting optimal injection well locations and injection rates. This framework has been compiled into a computational tool (COSMOS: $\mathrm{CO}_{2}$ Sequestration Simulation and Multi-objective Optimization Software). COSMOS may be used to visually display domain characteristics, pressure pulse and $\mathrm{CO}_{2}$ plume propagation for injection schemes, and objective tradeoff information.

\subsection{Stochastic Optimization Framework}

The general procedure followed by this algorithm is presented below in Figure 5-1. Once input files are read, an initial population of injection scenarios is randomly generated. Each injection scenario represents a set of decision variable values and is encoded into a chromosome (i.e. a vector of numbers) with length equal to double the number of injection wells. The first half of the chromosome represents each injection well's injection location index while the second half represents injection rate. The optimization is constrained by the following: 
- $\quad$ Pressures at injection wells must not exceed the geological fracture pressure

- The number of injection wells must be less than or equal to the quantity specified

- $\quad$ Injection well flow rates must be within the specified range



Figure 5-1. Schematic of the stochastic optimization algorithm 
Objective values are calculated for each population member. Mass sequestered is simply the total mass of $\mathrm{CO}_{2}$ injected and is calculated by multiplying the sum of injection well flow rates by the injection duration.

$$
M_{S e q}=\sum_{w=1}^{n I W} Q_{w}^{c} * t_{i n j}
$$

In Equation (1), $w$ is the injection well index, $n I W S$ is the number of injection wells, $Q_{w}^{c}$ is the $\mathrm{CO}_{2}$ injection rate for well $w$, and $t_{i n j}$ is the injection duration. The project cost (Cost), consisting the summation of the capital $\left(\operatorname{Cap}_{w}\right)$, operational $\left(O P_{w}\right)$, surface maintenance $\left(\operatorname{SurM}_{w}\right)$, subsurface maintenance $\left(\operatorname{SubM}_{w}\right)$, variable $\left(V_{w}\right)$, and leakage $(L C)$ costs, is defined as

$$
\begin{gathered}
\text { Cost }=\sum_{w=1}^{n I W s}\left[\operatorname{Cap}_{w}+O P_{w}+\operatorname{SurM}_{w}+\operatorname{SubM}_{w}+\right. \\
\left.V_{w}\left(\text { Mseq }_{w}\right)\right]+L C
\end{gathered}
$$

The cost associated with leakage (LC) is estimated as

$$
L C=c_{L} \cdot \text { Mleak }^{r_{A}}
$$

where $c_{L}$ is the coefficient representing penalty cost per unit of $\mathrm{CO}_{2}$ leakage $(\$ / \mathrm{kg})$, Mleak is the mass of $\mathrm{CO}_{2}$ leakage $(\mathrm{kg})$, and $r_{A}$ is a risk adversity factor reflecting preferences of the decision maker. Project costs at each non-exceedance probability are calculated. The following list of input variables may be represented as stochastic using COSMOS:

- $\quad$ Aquifer thicknesses for each layer

- $\quad$ Aquitard thicknesses for each layer

- $\quad$ Aquifer porosity for each layer 
- $\quad$ Radial aquifer permeabilities for each layer

- Vertical aquifer permeabilities for each layer

- Total effective compressibility for each layer

- $\quad$ Aquifer specific storage for each layer

- $\quad$ The bottom depth of the lowest aquifer from the surface

- $\quad$ Leaky well radii for each horizontal location in each aquitard

- $\quad$ Leaky well permeabilities for each horizontal location in each aquitard

Each uncertain parameter is assigned a discrete probability distribution function (PDF). A random number between 0 and 1 is generated for each uncertain parameter in each Monte Carlo (MC) simulation. This random number is used to select the value of the uncertain parameter used in the simulation by determine the location along the PDF to sample. In this method, each Monte Carlo simulation has an equal probability of occurrence.

Leakage mass is then calculated for each Monte Carlo simulation using the semi-analytical multiphase flow model discussed above. Cumulative distribution functions (CDFs) are then compiled and used to define non-exceedance probability for each injection scenario cost. Finally injection scenarios are ranked based upon expected value of project cost.

\subsection{NSGA- specifics}

The NSGA-II (Deb et al., 2002) is among the best high-performance multi-objective optimization evolutionary algorithms (Cheng et al., 2009). The NSGA-II was further improved by using the concept of E-dominance (Laumanns et al., 2002; Deb et al., 2005) to improve shortcomings associated with solution deterioration and diversity.

This work uses an NSGA-II with $\varepsilon$-dominance to create a new population of injection scenarios by evaluating the performance of current population members using established methodology. First, population members are ranked $\left(i_{\text {rank }}\right)$ using the fast-nondominated sorting procedure (Deb, 2001) with the 
$\varepsilon$-dominance relaxation factor (Laumanns, 2002) then assigned a crowding distance $\left(i_{\text {distance }}\right)$ based upon their density in objective function space. Next, a partial order is established using crowding comparison operator, $\geq_{n}$, as

$$
i \geq_{n} j=\operatorname{IF}\left\{\left(i_{\text {rank }}<j_{\text {rank }}\right) \text { OR }\left(\left(i_{\text {rank }}=j_{\text {rank }}\right) \text { AND }\left(i_{\text {distance }}>j_{\text {distance }}\right)\right)\right\}
$$

An iterative tournament style selection process is used to choose parents for the next generation. A constant number of population members are selected randomly and the population member with higher partial order value is chosen as a parent. Once parents have been selected, crossover, a method of taking some of the traits of each parent, is used to finish creating the new generation of injection schemes. Finally, there is a small chance, quantified as the mutation rate, in which chromosome elements of this new population will be randomly altered. This process is repeated until the convergence criterion is met. Injection schemes providing the best combinations of expected project cost and sequestered mass are selected as optimal injection scenario. Risk values are calculated using each optimal injection scenario's cumulative distribution function (CDF) of leakage.

\subsection{Case Study: Hypothetical Optimization of $\mathrm{CO}_{2}$ sequestration at the Michigan Technological University Test Site}

Preliminary planning results for a hypothetical GCS project at the MTU test site were generated using the framework presented in Bau (2013a). Optimal injection rates and well locations are determined for a maximum of 3 injection wells assumed to operate at a constant rate over a 30-year injection duration. Injection well locations are chosen from 9 candidate locations uniformly distributed over a 1 $\mathrm{km}^{2}$ square grid. Figure 5-2 provides a view of the COSMOS interface showing both plan and elevation views of the domain. The plan view shows a map of the site with candidate injection well locations as 
black circles and existing passive well locations as blue pluses. The elevation view shows aquifer and caprock thicknesses and depths.

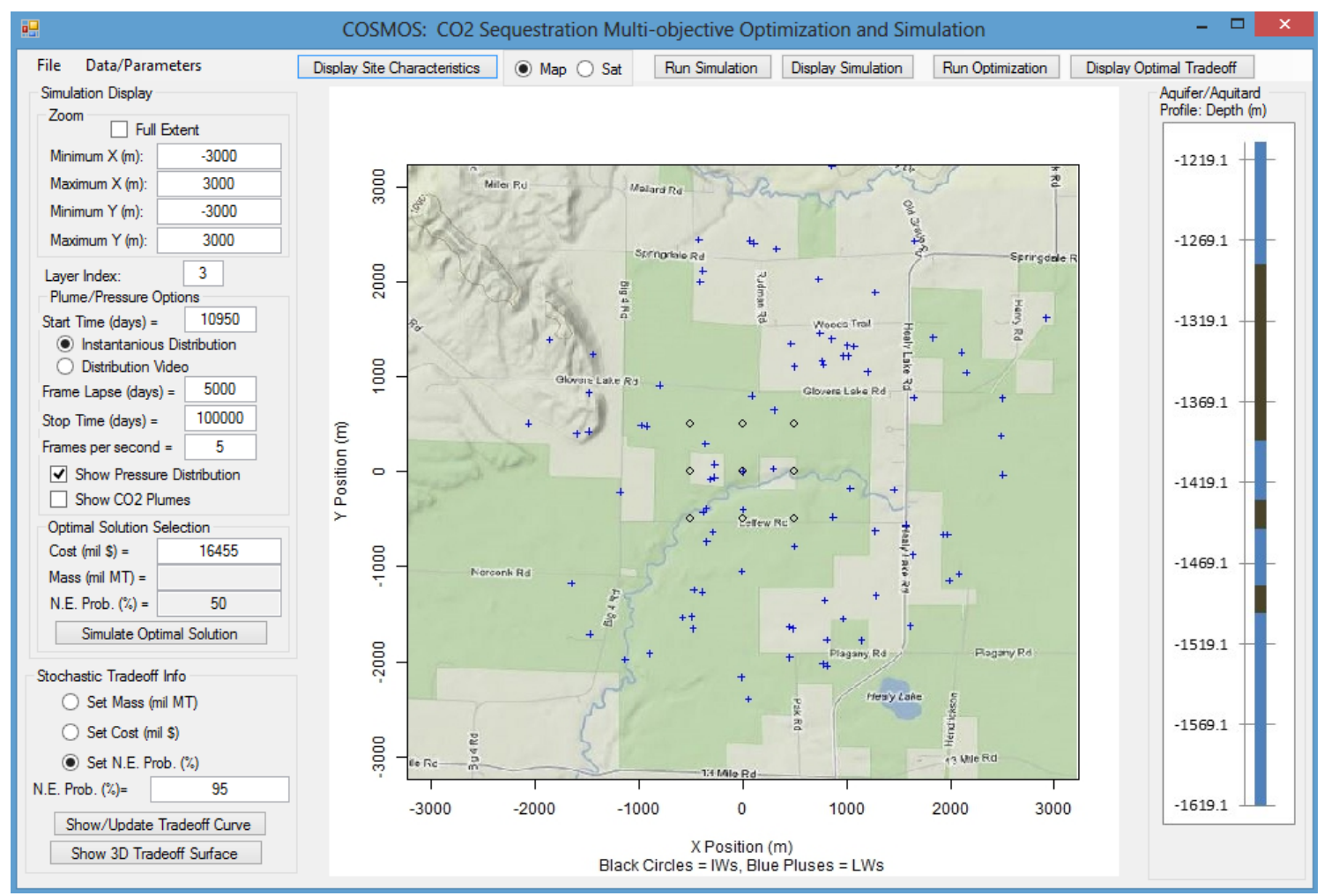

Figure 5-2. COSMOS interface showing the plan and elevation views of the MTU test site.

Leakage is defined as the cumulative mass of $\mathrm{CO}_{2}$ that has escaped into the top layer at the end of the project operation. Costs associated with leakage, operations, and maintenance were assigned using data from Lepinski (2012) and are shown in Table 5-1. Leakage cost parameters $c_{L}$ and $r_{A}$ were assigned values of 0.6 and 1.3, respectively. This analysis does not include costs involved with site characterization, permitting, lease/purchase of land/pore space, financing, insurance, monitoring, verification, EPA financial bond requirement, post-injection site care, and long-term liabilities though these may be significant in the final financial assessment (Lepinski, 2012). 
Table 5-1. Cost values used in this study.

\begin{tabular}{|c|c|c|c|c|}
\hline $\begin{array}{l}\text { Capital Cost } \\
(\$ / \text { well })\end{array}$ & $\begin{array}{c}\text { Fixed O\&M Costs } \\
(\$ / \text { day/well })\end{array}$ & $\begin{array}{c}\text { Surface } \\
\text { Maintenance } \\
\text { (\$/yr/well) }\end{array}$ & $\begin{array}{c}\text { Subsurface } \\
\text { Maintenance } \\
\text { (\$/yr/well) }\end{array}$ & $\begin{array}{l}\text { Variable Costs } \\
\left(\$ / \mathrm{kg} \text { of } \mathrm{CO}_{2}\right)\end{array}$ \\
\hline $3,537,104.04$ & $\begin{array}{c}\$ \\
11,566.00\end{array}$ & $120,608.00$ & $\begin{array}{c}\$ \\
37,611.69\end{array}$ & 0.010049 \\
\hline
\end{tabular}

\subsubsection{Convergence Testing}

Optimization algorithm parameters such as the tournament size, population size, and number of generations were selected by observing convergence trends in the deterministic optimization problem. Two optimization problems having different random number seeds were processed for each parameter value. The best convergence records for each parameter value were then compared. Tournament sizes of 2 and 3 and population sizes of 50,100, 150, and 200 are analyzed over 500 generations. The average project cost for the given set of solutions is used as the convergence measure. Figure 5-3 shows convergence performance for each combination of parameter values.

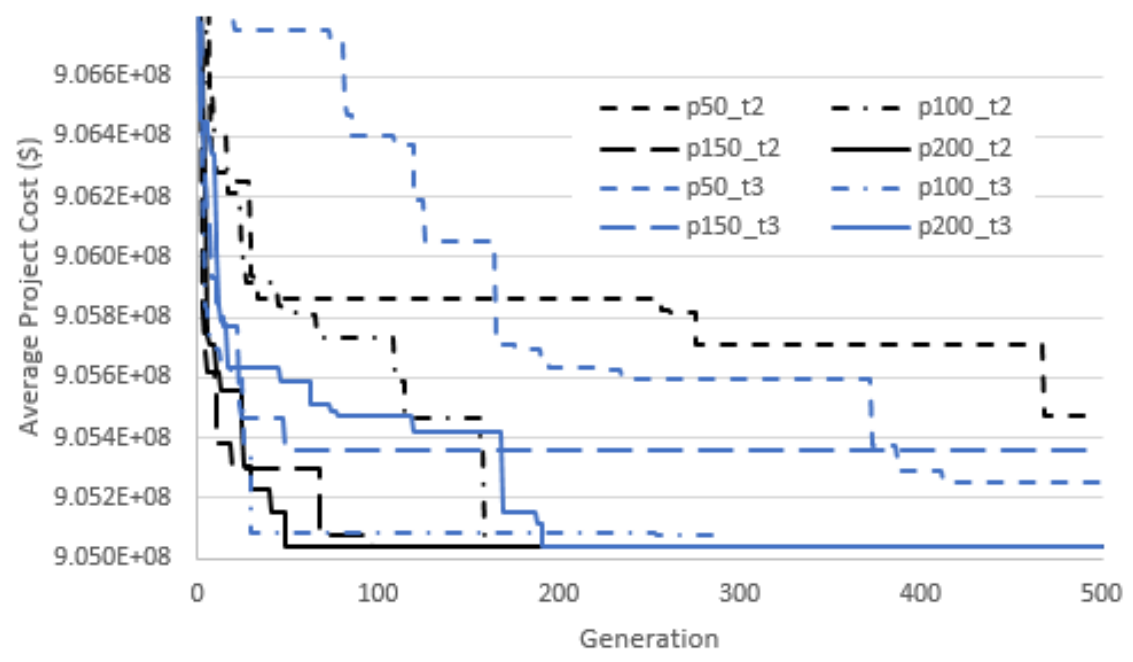

Figure 5-3. Convergence performance for combinations of population and tournament sizes

With the exception of cases having a population size of 50 (p50), the best convergence is achieved using a tournament size of 2 (t2). Convergence occurs in less than 100 generations for both 
population sizes 150 and 200 when the tournament size is set to 2. Parameter values for the stochastic optimization problem were selected using this convergence analysis (Table 5-2).

Table 5-2. Optimization parameter values used for stochastic optimization

\begin{tabular}{|c|c|c|}
\hline Tournament Size & Population Size & Number of Generations \\
\hline 2 & 150 & 150 \\
\hline
\end{tabular}

\subsubsection{Objective Tradeoff Analysis}

Stochastic optimization was then performed for the MTU Test Site. Figure 5-4 shows the resulting three-dimensional tradeoff surface between competing objectives. Project cost increases with both non-exceedance probability and mass of $\mathrm{CO}_{2}$ sequestered. Project cost sharply increases with increasing non-exceedance probability above $70 \%$. This demonstrates that the magnitude of uncertainty associated with passive well permeability results in a high degree of project cost uncertainty for this site. In addition, two plateaus are observed on the top of the surface showing regions where the mass of $\mathrm{CO}_{2}$ sequestered may be greatly increased for relatively small increases in project cost.

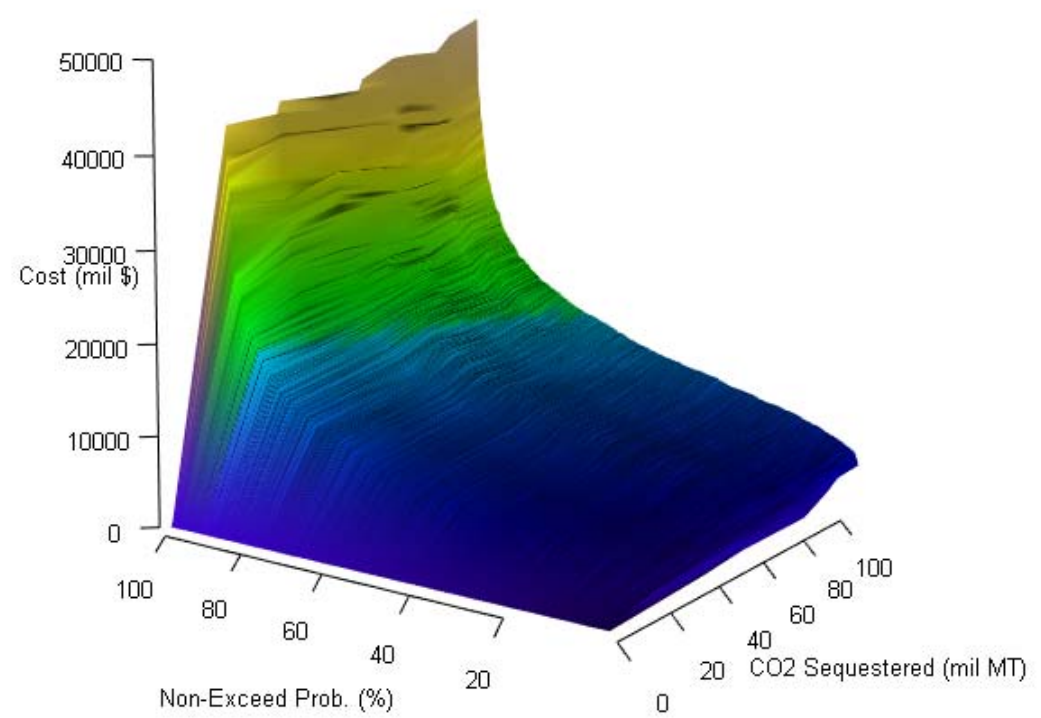

Figure 5-4. Optimal tradeoff surface between competing objectives 
Suppose a decision maker is willing to accept a $5 \%$ risk that the project cost predicted by this algorithm will be exceeded. A two-dimensional tradeoff curve may then be generated by bisecting tradeoff surface along a non-exceedance probability of 95\% (Figure 5-5). This plot shows the two tradeoff plateaus between points 3 to 4 and 5 to 6 .

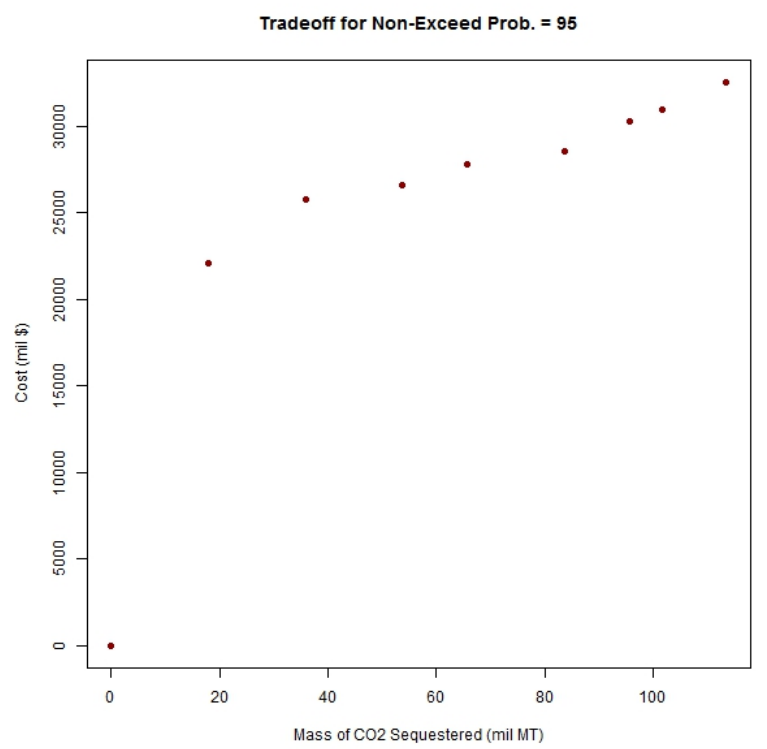

Figure 5-5. Pareto-optimal tradeoff curve between project cost and mass sequestered

COSMOS may also be used to display pressure pulse or $\mathrm{CO}_{2}$ plume propagation versus time for any optimal scenario using the expected values of uncertain variables. Figure 5-6 and Figure 5-7 show the fluid pressure distribution and the $\mathrm{CO}_{2}$ plume propagation, respectively, in the $2^{\text {nd }}$ aquifer at the end of 30 years of simulation for a mass of $\mathrm{CO}_{2}$ sequestered of 113.5 million metric tonnes (MT). Fluid pressures tend to build in regions having clusters of passive wells with the greatest magnitudes found near injection wells (Figure 5-6). As seen in Figure 5-7, larger $\mathrm{CO}_{2}$ plumes are typically transmitted through passive wells located closer to injection wells. 


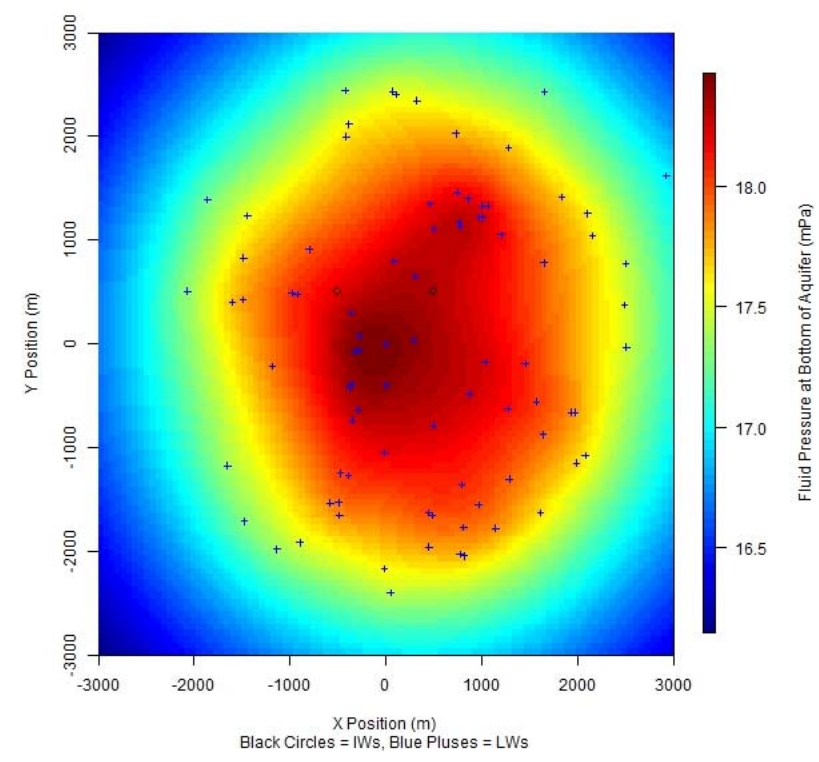

Figure 5-6. Fluid pressure distribution in the $2^{\text {nd }}$ aquifer at the end of 30 -yr simulation

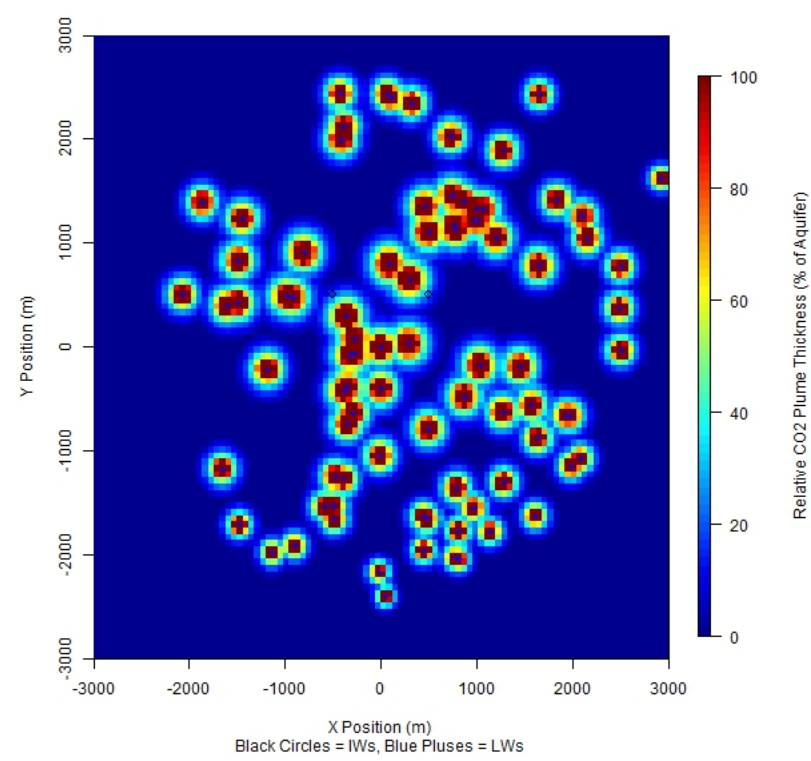

Figure 5-7. $\mathrm{CO}_{2}$ plume distribution in the $2^{\text {nd }}$ aquifer at the end of 30 -yr simulation

\section{Influence of Uncertain Parameters on the Leakage of $\mathrm{CO}_{2}$ to Overlying Formations}

Characteristics of the cap rock overlying the injected formations are decisive elements of a carbon capture and sequestration system. Permeability, spatial distribution of potential carbon escape pathways, 
and increase of pressure at the formation directly influence $\mathrm{CO}_{2}$ leakage. Also, addition leakage pathways may be created during the $\mathrm{CO}_{2}$ injection process due to fracturing of the caprock associated with increased pore pressure and the ensuing effective stress reduction.

Therefore, assessing the risk of leakage of $\mathrm{CO}_{2}$ given the uncertainty on the afore mentioned parameters is vital prior to the implementation of this technology. In this work, parameters studied were: porosity and permeability of injected aquifers, caprock permeability, and the location, size and permeability of $\mathrm{CO}_{2}$ leakage pathways through the sealing layers. A statistical probability distribution function was prescribed to each of these parameters representing typical ranges of variability. Several injection scenarios were investigated, which differ from one another depending on $\mathrm{CO}_{2}$ injection rates and time schedules.

A semi-analytical model was used to simulate the injection of $\mathrm{CO}_{2}$ into a hypothetical deep saline aquifer overlain by a series of aquitards and aquifers. A stochastic simulation was applied to model the influence of the uncertain parameters on the sensitivity of the: (i) mass of $\mathrm{CO}_{2}$ that migrates into overlying formations, in relation to the total mass of injected $\mathrm{CO}_{2}$; and (ii) maximum fluid overpressure produced by carbon injection. Results are presented in terms of sample cumulative distribution functions, which can be used to estimate the probability of leaked mass to be exceeding predefined threshold values and the probability of fracturing that may undermine the sealing properties of the caprock.

\subsection{Methodology}

The model used was composed of a hypothetical deep saline aquifer overlain by three aquifers and four aquitards (Figure 6-1). The enumeration of the aquifers starts at the deepest from L1 to L4. It is a radial axisymmetric model. There is only one injection well of supercritical $\mathrm{CO}_{2}$. The aquifer where injection of $\mathrm{CO}_{2}$ takes place has a thickness of $100 \mathrm{~m}$, meanwhile the other 3 overlying aquifers are of $350 \mathrm{~m}$. 


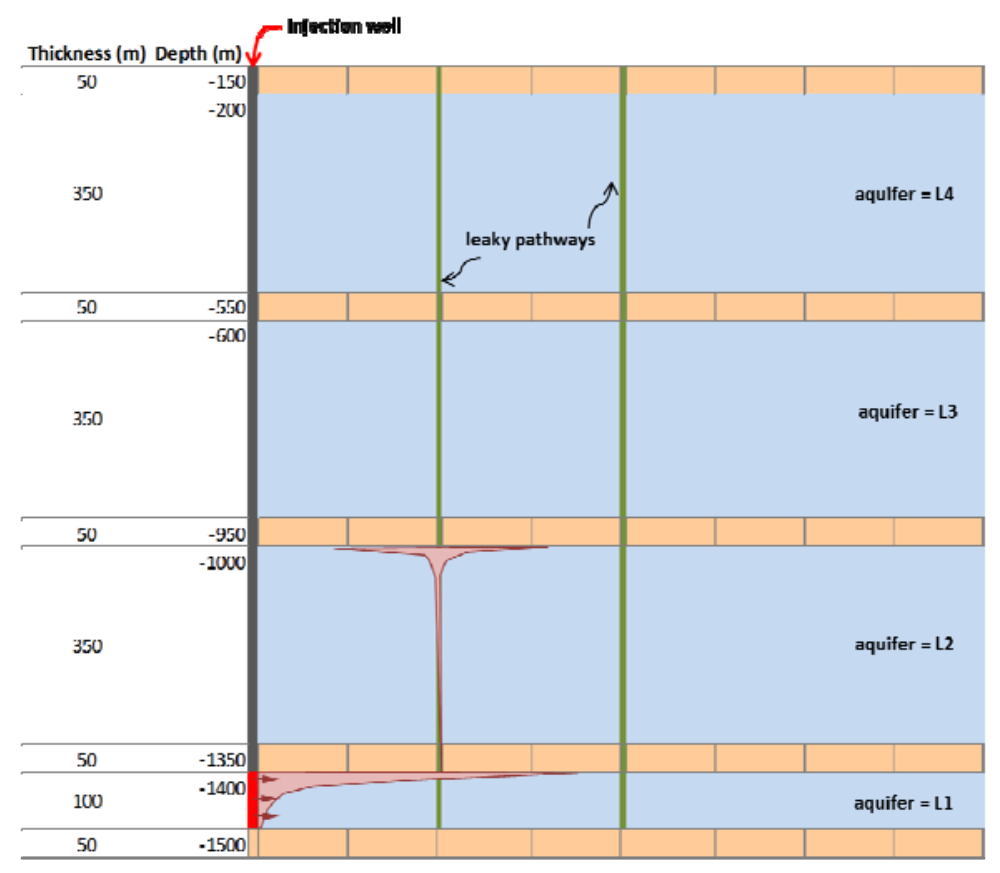

Figure 6-1.Geological settings of the model used.

The bottom of aquifer $\mathrm{L} 1$ is at $1500 \mathrm{~m}$. The aquifers are separated by $50 \mathrm{~m}$ of aquitard, which are assumed impermeable except where there is a pathway. When the plume of $\mathrm{CO}_{2}$ reaches a leaky pathway, the $\mathrm{CO}_{2}$ escapes to the upper aquifer. The distribution and permeability of the leaky pathways varied with simulation. The compressibility of the system was $4.6 \mathrm{E}-10 \mathrm{~m}^{2} / \mathrm{N}$. A residual brine saturation of 0.3 was considered in all simulations. Initially all formations were saturated with brine at hydrostatic pressure. Brine and $\mathrm{CO}_{2}$ densities were considered constant with values of 1000 and $600 \mathrm{~kg} / \mathrm{m}^{3}$, respectively, as well as viscosities of 4.6E-5 and 4.5E-4 Pa·s. Parameter values were chosen according to the geology of the Michigan Technological University test site.

Three main scenarios having differing $\mathrm{CO}_{2}$ injection rates and durations were simulated. The final injected mass of $\mathrm{CO}_{2}$ of each scenario was the same: 630,072,000 TN (Table 6-1).

The studied parameters were: (a) permeability and porosity of injected aquifers; (b) permeability pathways; and (c) caprock heterogeneity (location, size and permeability of pathways). Twenty four leaky 
pathways were assigned. The position of these pathways formed a square grid with the injection well positioned at its center. The distance between the N-S and E-W leaky pathways was $1 \mathrm{~km}$.

Table 6-1. Investigated injection scenarios.

\begin{tabular}{|c|c|c|}
\hline Scenario & $\begin{array}{c}\text { Time } \\
\text { (years) }\end{array}$ & $\begin{array}{c}\text { Injection flow } \\
\text { rate }(\mathrm{kg} / \mathrm{s})\end{array}$ \\
\hline 1 & 20 & 100 \\
\hline 2 & 40 & 50 \\
\hline 3 & 60 & 33.33 \\
\hline
\end{tabular}

A base case was defined with the parameters of Table 6-2. Parameters of this table remained unchanged unless the parameter of interest was being studied.

Table 6-2. Parameters of base case and parameter distribution.

\begin{tabular}{|c|c|c|}
\hline Parameter & Symbol & Value \\
\hline Aquifer permeability $\left(\mathrm{m}^{2}\right)$ & $k$ & $10^{-13}$ \\
\hline Aquifer porosity $(/)$ & $\phi$ & 0.15 \\
\hline Pathways permeability $\left(\mathrm{m}^{2}\right)$ & $k_{l p}$ & $10^{-13}$ \\
\hline Radius pathways (m) & $r$ & 0.20 \\
\hline Number of pathways (/) & $n_{l p}$ & 24 \\
\hline
\end{tabular}

First, simulations were run to obtain the overpressure in the aquifer for a wide range of injection rates and aquifer permeabilities. The maximum overpressure was considered to be at the injection well. Overpressure in the aquifer can create new leakage pathways during the $\mathrm{CO}_{2}$ injection process due to the increased pore pressure and the ensuing effective stress reduction. Hence, it is important to know the maximum pressure that the aquifer can bear. The maximum overpressure can be calculated as (Teatini et al., 2010):

$$
\Delta p_{\max }=\sigma^{\prime} \cdot \frac{v}{1-v}
$$

Where: $v$ is Poisson ratio and $\sigma^{\prime}$ is the average effective vertical stress in the aquifer. This value is calculated as the increase in pore pressure that completely offsets the horizontal (i.e., minimum) effective stress in a normally pressurized and consolidated basin. This horizontal stress is here estimated 
as the product between the vertical effective stress and the so-called confinement factor, $\frac{v}{1-v}$, which, for example is equal to $1 / 3$ if a value of 0.25 is assumed for $v$. This value is deemed to be safe enough to avoid the generation of a tensile state of stress that might fracture the porous medium, and hence to prevent the caprock that confines the injected aquifer from fissuring.

A summary of the distributions of the uncertain parameters is shown in Table 6-3.

Table 6-3. Summary of the distributions used for the study of uncertain parameters.

\begin{tabular}{|c|c|c|c|c|c|c|}
\hline Parameter & Distribution & $\begin{array}{c}\text { Expected } \\
\text { value }\end{array}$ & $\begin{array}{c}\text { Standard } \\
\text { deviation }\end{array}$ & $\begin{array}{c}\text { Minimum } \\
\text { value }\end{array}$ & $\begin{array}{c}\text { Maximum } \\
\text { value }\end{array}$ & Realizations \\
\hline Aquifer permeability $\left(\mathrm{m}^{2}\right)$ & Log-normal & $10^{-13}$ & 0.5 & - & - & 1000 \\
\hline Aquifer porosity $(/)$ & Uniform & - & - & 0.05 & 0.35 & 1000 \\
\hline $\begin{array}{c}\text { Pathways permeability } \\
\left(\mathrm{m}^{2}\right)\end{array}$ & $\begin{array}{c}\text { Case 1: Log- } \\
\text { normal }\end{array}$ & $10^{-13}$ & 1 & - & - & 1000 \\
& Case 2: Bimodal & $10^{-13}$ & - & $10^{-15}$ & $10^{-11}$ & 1000 \\
& Case 3: Bimodal & $10^{-13}$ & - & $10^{-16}$ & $10^{-10}$ & 1000 \\
\hline Pathway continuity & Log-normal & $10^{-13}$ & 1 & - & - & 1000 \\
\hline
\end{tabular}

The heterogeneity of the caprock was studied by applying 100 leaky pathways $\left(k_{l p}=10^{-13} \mathrm{~m}^{2}\right)$ with differing radii in order to obtain different $\%$ of leakage areas (Table 6-4). The positions of the leaky areas are assigned randomly.

Table 6-4. Area of leakage (\%) depending on the caprock heterogeneity.

\begin{tabular}{|c|c|c|c|}
\hline Leaky pathways & Radius pathways (m) & Area of leakage (\%) & Realizations \\
\hline 100 & 1.0 & 0.0003 & 500 \\
\hline 100 & 4.0 & 0.005 & 500 \\
\hline 100 & 5.6 & 0.01 & 500 \\
\hline
\end{tabular}

\subsection{Results}

Results are presented in terms of sample cumulative distribution functions (CDF), which can be used to estimate: (i) the probability of fracturing that may undermine the sealing properties of the caprock; (ii) the probability of leaked mass to be exceeding predefined threshold values. Percentage of 
leaked $\mathrm{CO}_{2}$ leakage is defined as the mass of $\mathrm{CO}_{2}$ that escapes from aquifer $\mathrm{L} 1$ to overlying aquifers with respect to the final amount of $\mathrm{CO}_{2}$ that is introduced in the system $(630,072,000 \mathrm{TN})$.

\subsubsection{Permeability of the aquifer}

The permeability of the aquifer significantly influenced the maximum overpressure obtained. Its range varied between 8 bar and 400 bar for scenario with $Q=100 \mathrm{~kg} / \mathrm{s}$ (left Figure 6-2). From this same scenario, only $65 \%$ of the realizations did not exceed the maximum overpressure. For scenario $\mathrm{Q}=33.33$ $\mathrm{kg} / \mathrm{s}$, only around the $10 \%$ of the cases overcome the maximum overpressure (left Figure 6-2).

For the majority of the cases (around 94\%), less leakage of $\mathrm{CO}_{2}$ occurred with lower injection rates, although it seems to reverse when $\%$ of leakage was greater than $0.1 \%$ (right Figure $6-2$ ). This also can be seen in Figure 6-4: when $\log k$ was greater than -13.75 more leakage was produced with greater injection rates, but for $\log k$ lower than -13.75 the situation was inverted.

Lower $k$ as well as greater injection rates produced bigger overpressures (Figure 6-3). For $\log k$ greater than -12.5 overpressure was less than 25 bar and the leakage less than $0.005 \%$.
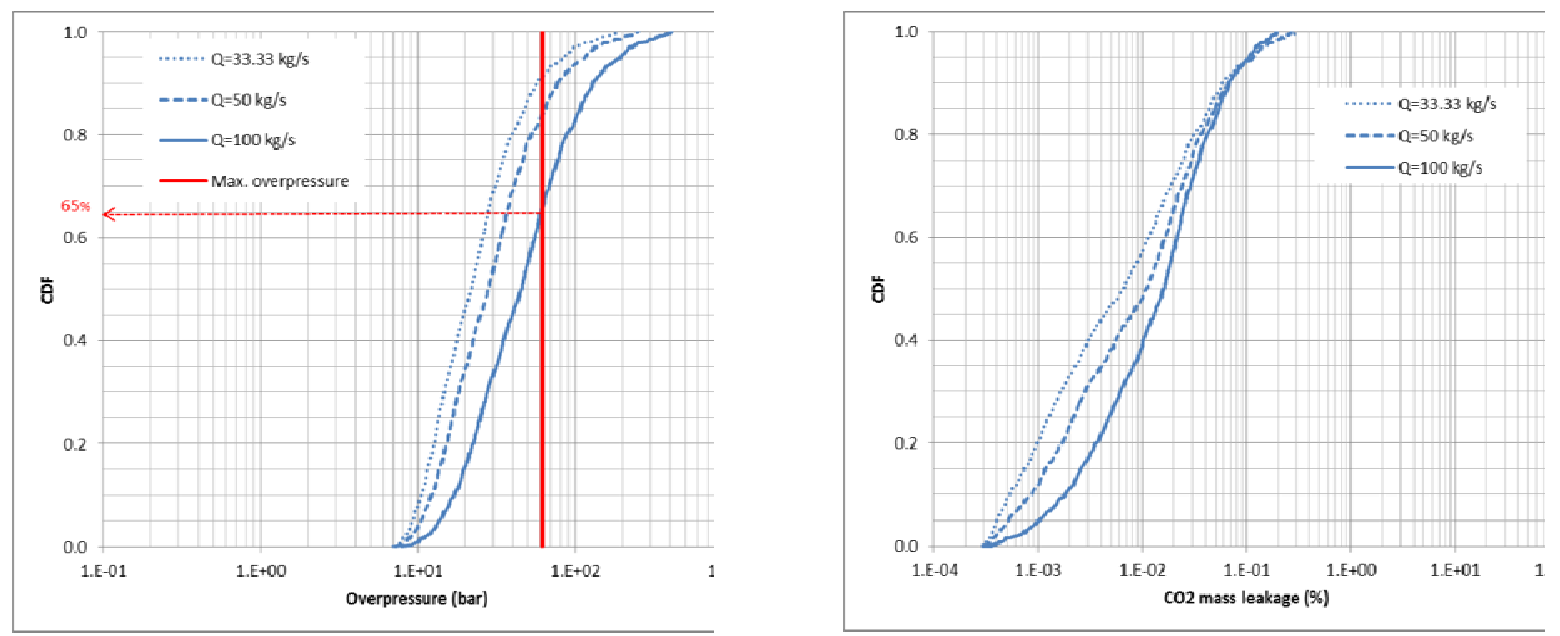

Figure 6-2. Cumulative Distribution Function of the overpressure (left) and $\mathrm{CO}_{2}$ mass leakage (\%) (right) for the uncertainty coming from aquifer permeability. 


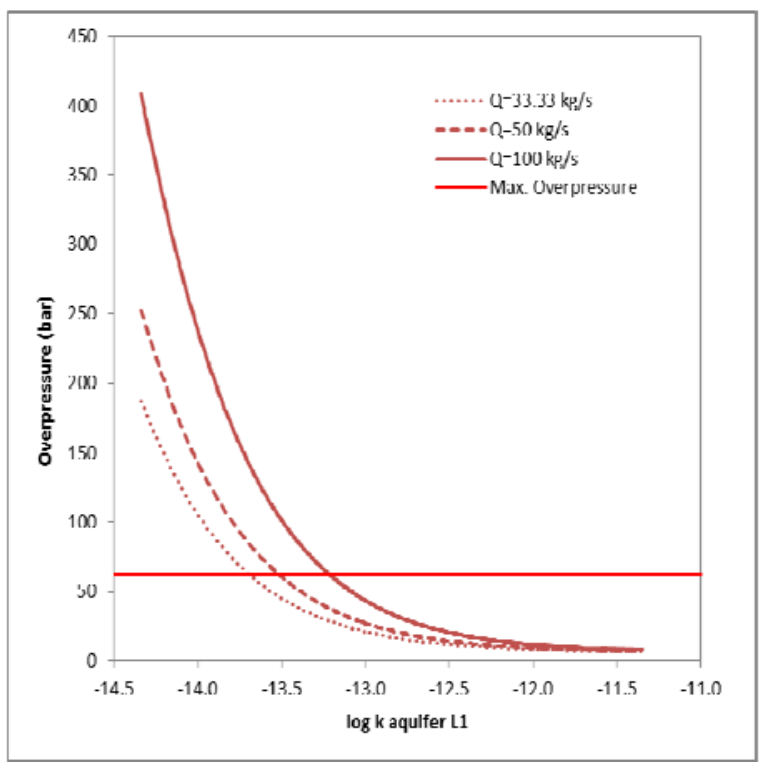

Figure 6-3. Overpressure at the injection well as a function of aquifer permeability.

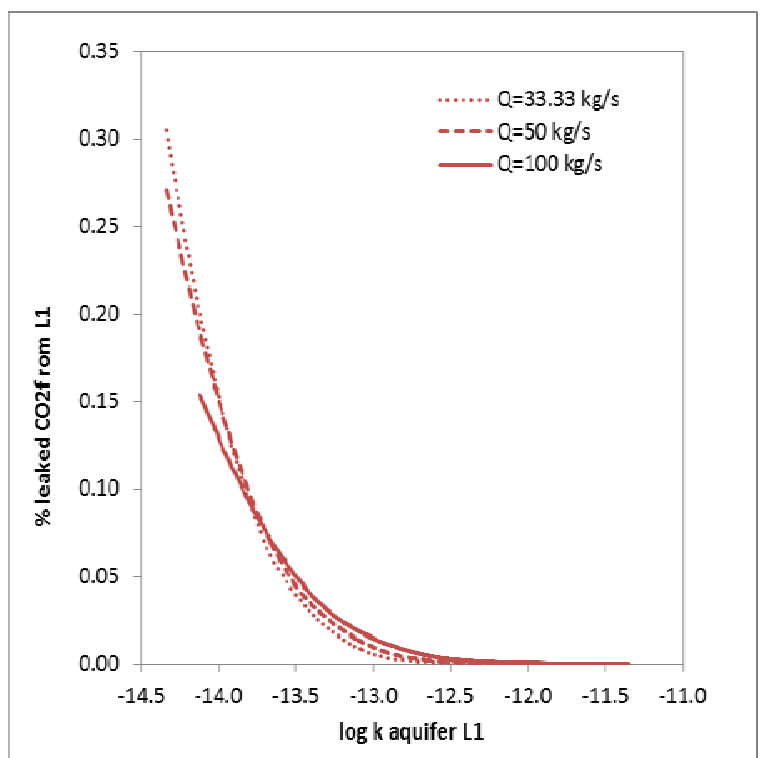

Figure 6-4. Percentage of leaked mass of $\mathrm{CO}_{2}$ as a function of aquifer permeability.

\subsubsection{Porosity of the aquifer}

The porosity of the aquifer slightly influenced the maximum overpressure obtained. The greatest change in overpressure was found with scenario $\mathrm{Q}=100 \mathrm{~kg} / \mathrm{s}$. This resulted in a minimum value of 38 bar and a maximum value of 48 bar (left Figure 6-5). This can be seen in Figure 6-6, where similar overpressures are produced for scenarios $\mathrm{Q}=50 \mathrm{~kg} / \mathrm{s}$ and $\mathrm{Q}=33.33 \mathrm{~kg} / \mathrm{s}$. Greater porosities resulted in greater values of overpressure. This is because the same amount of $\mathrm{CO}_{2}$ for a greater porosity occupies less volume in the aquifer, hence retarding the spread of the pressure pulse.

The range of variability of $\mathrm{CO}_{2}$ mass leakage was also decreased with decreasing porosity uncertainty (Figure 6-5). Lower leakages were obtained with lower injection rates as well as with greater porosities (Figure 6-7). The shape of the plume depends on porosity. Lower porosity results in faster plume propagation and a higher likelihood of encountering leaky pathways. 

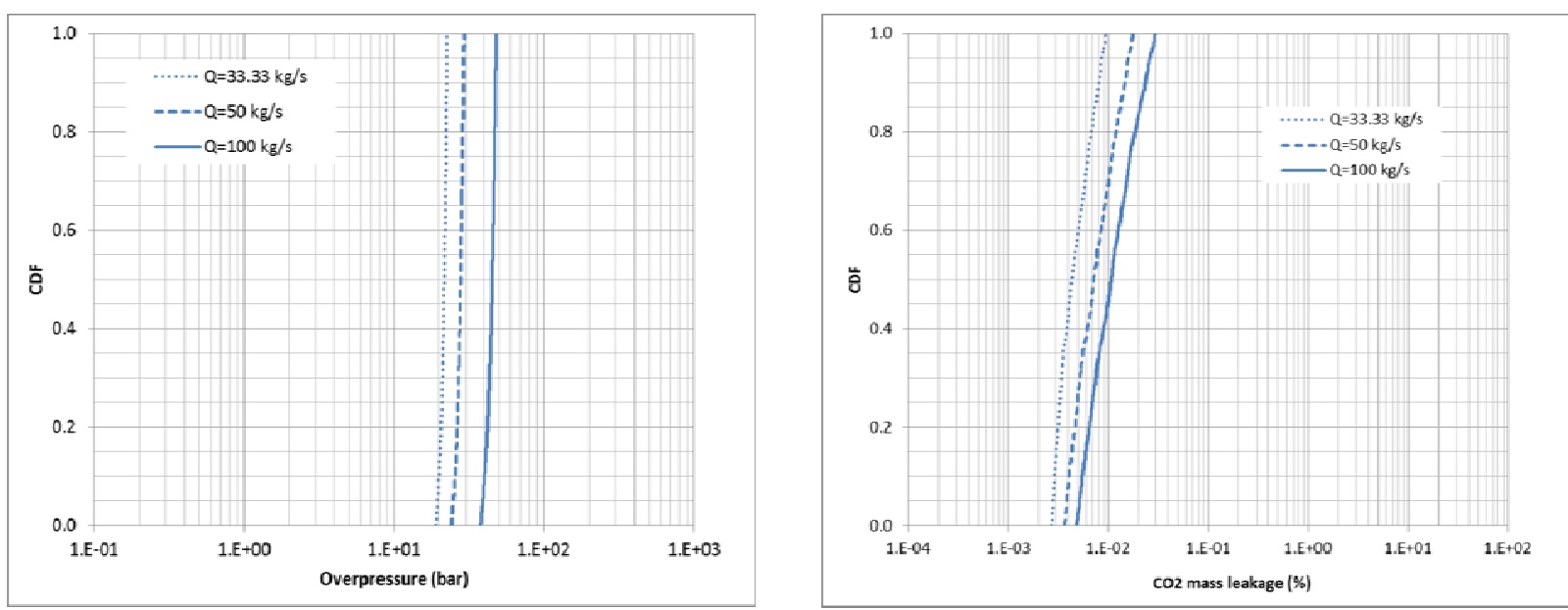

Figure 6-5. Cumulative Distribution Function of the overpressure (left) and $\mathrm{CO}_{2}$ mass leakage (\%) (right) for the uncertainty coming from aquifer porosity.

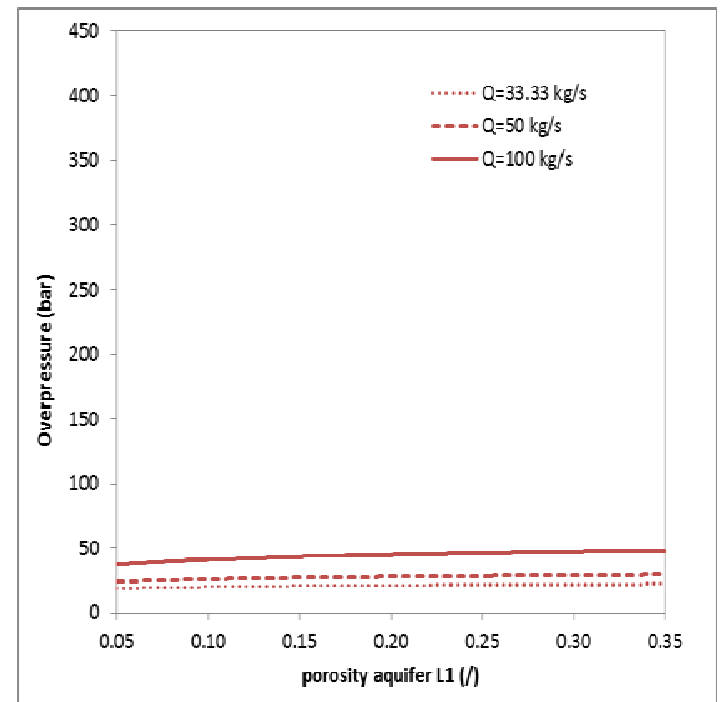

Figure 6-6. Overpressure at the injection well as a function of aquifer porosity.

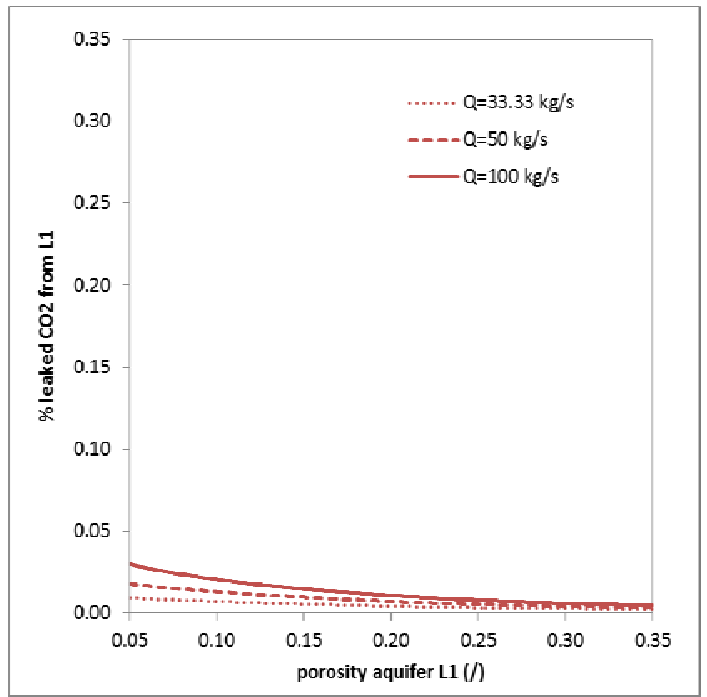

Figure 6-7. Percentage of leaked mass of $\mathrm{CO}_{2}$ as a function of aquifer porosity. 


\subsubsection{Pathway permeability}

Overpressure seemed to be fairly insensitive to pathway permeability (left Figure 6-8). Cases 1 and 2 almost overlap, while case 3 obtained smaller overpressure, although slightly. Again, greater injection rates obtained greater overpressure.

The amount of $\mathrm{CO}_{2}$ leakage was different from one case to another, although all of them agree that lower injection rates obtained lower leakage (right Figure 6-8). Case 1 obtained less leakage due to the diversity of pathway permeability, meanwhile Case 2 and Case 3 only have two options (leaky or not leaky). The maximum pathway permeability influenced the leakage obtained: greater permeability at the pathway results in greater amount of leaked $\mathrm{CO}_{2}$ (right Figure 6-8).
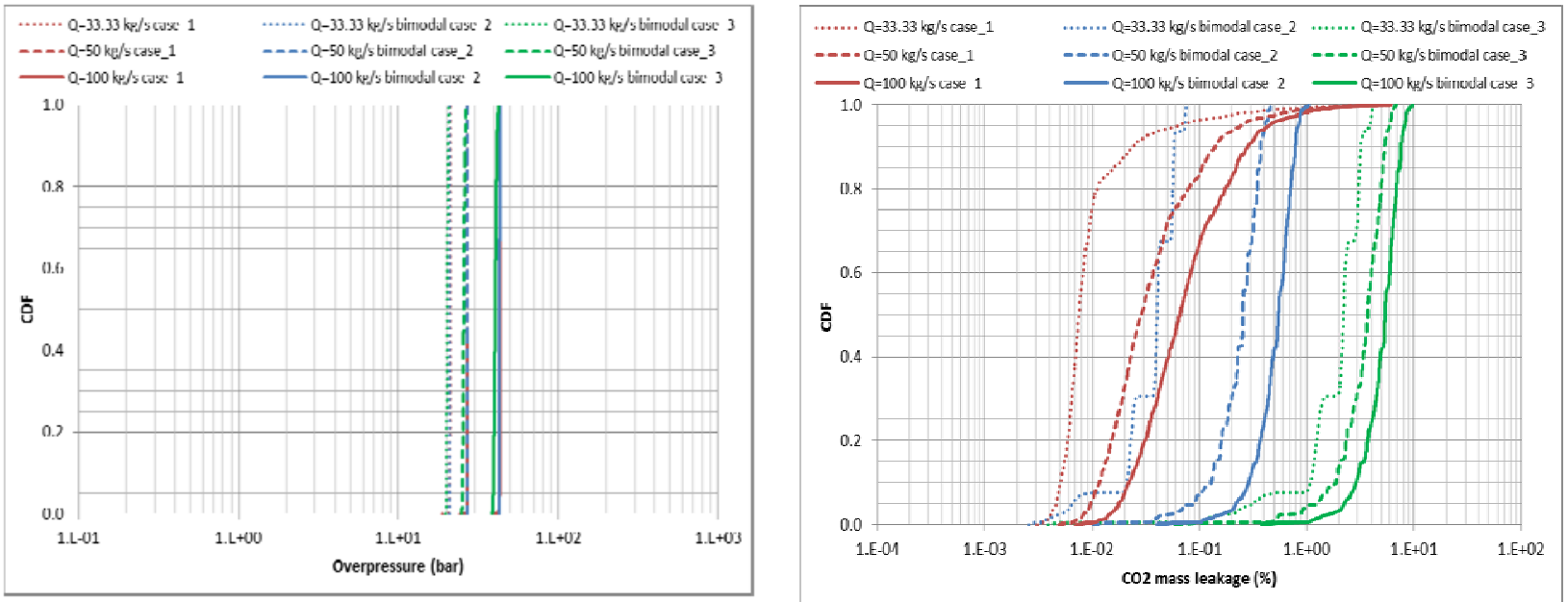

Figure 6-8. Cumulative Distribution Function of the overpressure (left) and $\mathrm{CO}_{2}$ mass leakage (\%) (right) for the uncertainty coming from pathway permeability.

\subsubsection{Pathway continuity}

The overpressure obtained for continuous and non-continuous pathways overlap and its range was found to be fairly constant for all realizations of each scenario (left Figure 6-9). Lower injection rates obtained lower overpressure, which is consistent with previous simulations.

The distribution of $\mathrm{CO}_{2}$ leakage was different between continuous and non-continuous pathways. For both cases, lower injection rates obtained lower leakage (right Figure 6-9). Non-continuous pathways 
obtained less leakage of $\mathrm{CO}_{2}$. This is because continuous pathways facilitate the escape of $\mathrm{CO}_{2}$ to overlying aquifers while the travel of the plume is more tortuous for non-continuous pathways.

\subsubsection{Heterogeneity of the caprock}

Overpressure varied with the caprock heterogeneity. Overpressure decreased with increasing permeable aquitard area. As expected, greater injection rates also obtained greater overpressure (left Figure 6-10).
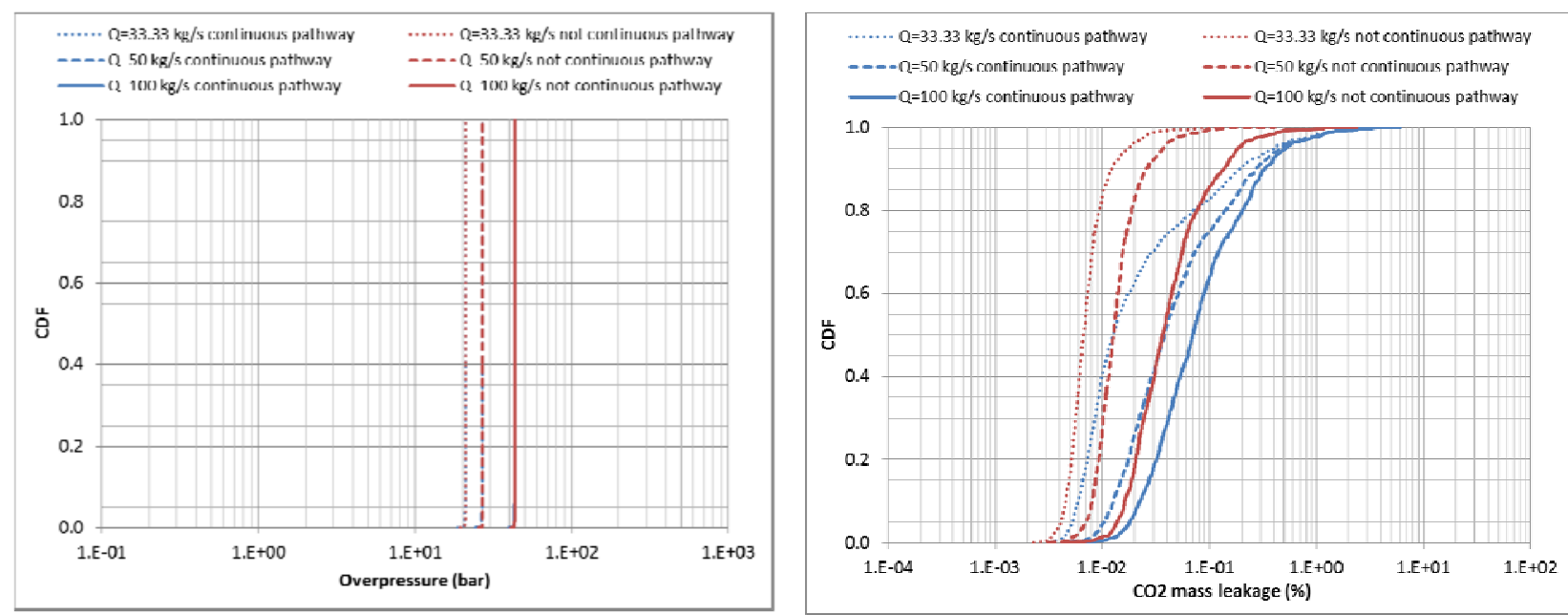

Figure 6-9. Cumulative Distribution Function of the overpressure (left) and $\mathrm{CO}_{2}$ mass leakage (\%) (right) for the uncertainty coming from pathway continuity.
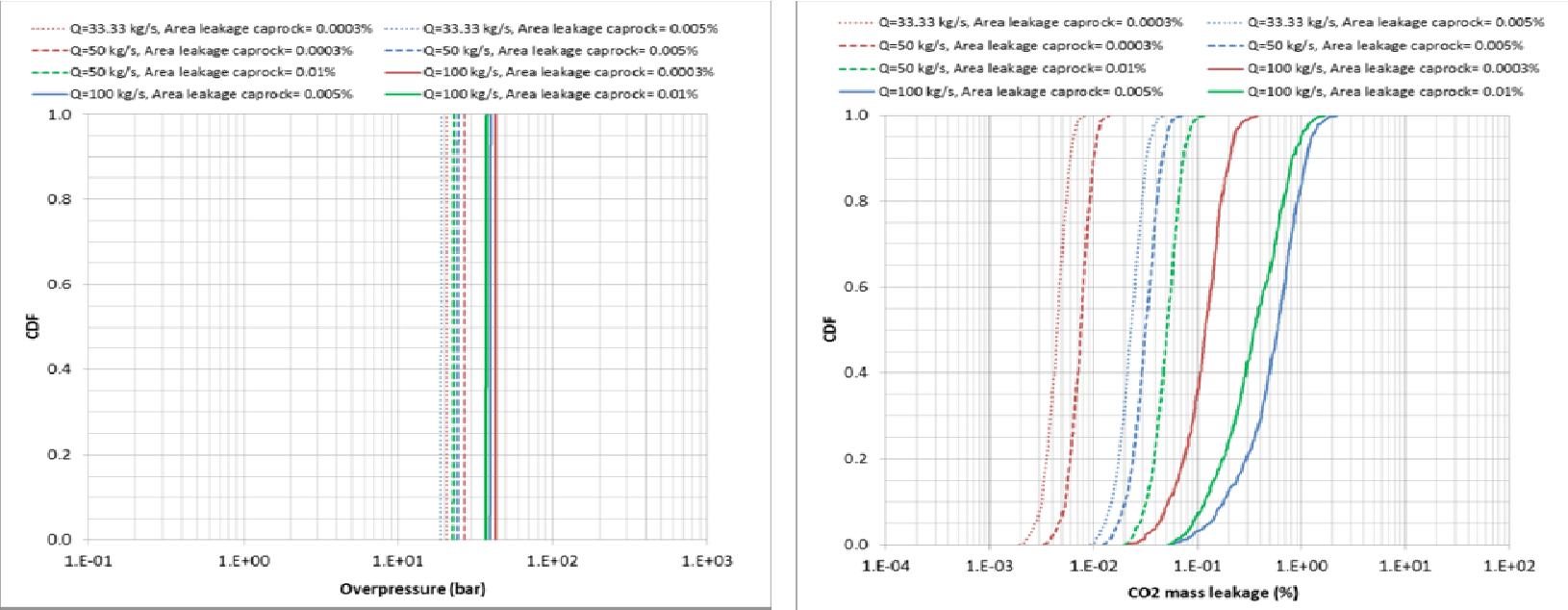

Figure 6-10. Cumulative Distribution Function of the overpressure (left) and $\mathrm{CO}_{2}$ mass leakage (\%) (right) for the uncertainty coming from caprock heterogeneity. 


\subsection{Conclusions}

The influence of the following parameters have been studied: permeability and porosity of injected aquifers; permeability pathways; and caprock heterogeneity: location, size and permeability of pathways. Greater injection rates create greater overpressure in the aquifer. Larger overpressures result in greater leakage flux to overlying aquifers. Lower aquifer permeability as well as greater injection rates produce greater overpressures. The porosity of the aquifer slightly influences the maximum overpressure obtained. Greater porosities obtained greater values of overpressure. Lower leakages are obtained with greater porosities. Overpressure created in the aquifer seems not to be influenced by the pathway permeability, however the amount of $\mathrm{CO}_{2}$ leakage differs between cases. The overpressure results for continuous and non-continuous pathways overlapped and its range was almost the same for all realizations of each scenario. Non-continuous pathways obtained less leakage of $\mathrm{CO}_{2}$. Smaller overpressure and greater leakage of $\mathrm{CO}_{2}$ were obtained with increased area of permeability of the caprock.

\section{Uncertainty Analysis of Continuity of Geological Confining Units using Categorical Indicator Kriging (CIK)}

The aim of this report is to estimate the sealing properties of the Gray Niagaran formation at the MTU-site (Michigan) for geological carbon storage. A Categorical Indicator Kriging (CIK) technique is used to study the uncertainty on the continuity of the geological unit overlying the Gray Niagaran. The CIK creates binary fields of caprock (low permeability) and inclusions (high permeability). Inclusions are areas where $\mathrm{CO}_{2}$ could leak. Inclusions having relatively similar spatial locations are grouped and considered as a cluster to reduce the number of leaky points used by the semi-analytical multiphase flow model CO2FLOW, thus improving computational efficiency. Simulations of the MTU-site are also carried out with a numerical code to understand the limitations of the semi-analytical model. 


\subsection{Methodology}

\subsubsection{Categorical Indicator Kriging applied to MTU-site}

The thickness of the caprock is relatively small when compared to the horizontal extension of this formation (e.g. $30.5 \mathrm{~m}$ thickness of sealing layer vs. $7000 \mathrm{~m}$ of estimated grid extension). For this reason the permeability is assumed to be constant in the vertical direction (z), whereas in the horizontal direction ( $\mathrm{x}$ and $\mathrm{y}$ ) the permeability is assumed heterogeneous. Assuming the caprock (facies 1 with low permeability) comprises uncertain inclusions of high permeability where $\mathrm{CO}_{2}$ could leak (facies 2 with high permeability), the permeability in the horizontal direction can be considered as a binary field. The horizontal permeability of the confining formation will be low relative to values for inclusions. The inclusions represent randomly distributed zones of high permeability in the caprock.

If only two categories are possible (low permeability and high permeability), the distribution will be bimodal.

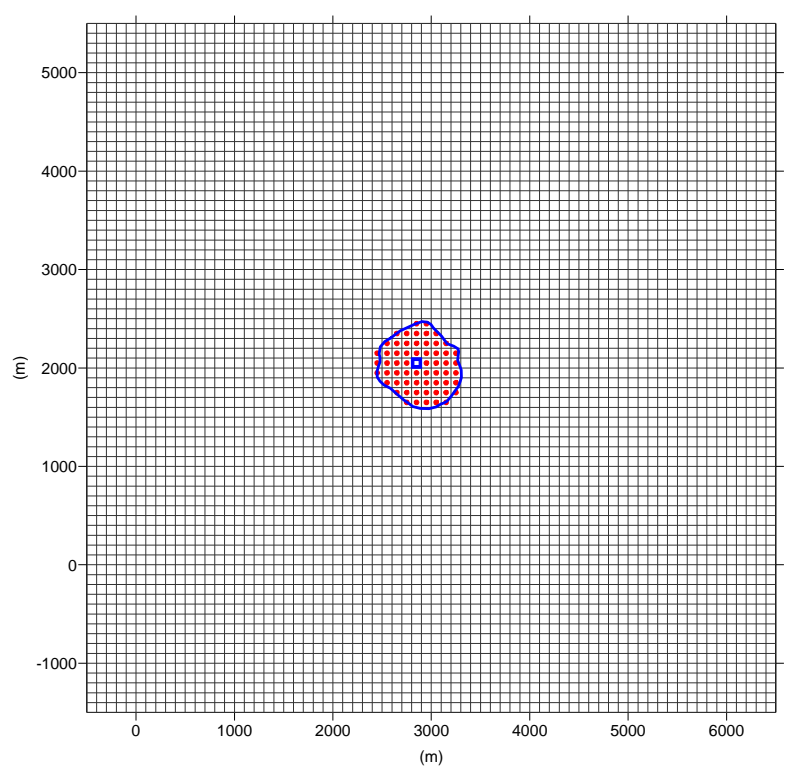

Figure 7-1. Gridblock of $7 \mathrm{~km} \times \mathbf{~} \mathbf{~ k m}$ used by Simple Indicator Kriging. Each gridblock is $100 \mathrm{~m} \mathrm{x} 100 \mathrm{~m}$. Limit of the reservoir is shown by the blue line. Red spots correspond to the sealing caprock (conditional locations of facies 1). Stech well appears as the blue square in the center of the reservoir. 
Simple Indicator Kriging is applied to the overlying formation of the Gray Niagara to simulate the uncertainties of the sealing caprock where data is not available. A grid of $7 \mathrm{~km} \mathrm{x} 7 \mathrm{~km}$ is built with the MTU reservoir placed in its center (Figure 7-1). The lateral boundary of the reservoir is shown by the blue line. Red spots correspond to the sealing caprock (conditional locations of facies 1). The blue square represents the location of the Stech well.

Each block is $100 \mathrm{~m} \times 100 \mathrm{~m}$, therefore a total of 4900 blocks $(70 \times 70)$ compose the grid. The depleted reservoir is already known to be covered by a sealing formation. Hence the blocks in the reservoir are assumed to be the known sealing formation (facies 1: low permeability), whereas the formation of the others blocks (unsampled locations) are unknown and need to be simulated stochastically. Different fields are simulated for this grid following the properties of Table 7-1. For each simulation 500 fields are generated.

If the concentration of inclusion gridblocks is high enough (two or more), these will be considered as a cluster instead of an individual inclusion. The size and distribution of these clusters depends on the parameters assigned for their generation. A cluster is considered when two (or more) inclusion-blocks are in contact, that is the distance between the centers of their gridblocks is $\leq \sqrt{2 \Delta x^{2}}$, for our grid this distance is $141.42 \mathrm{~m}$. The position of the circular area is calculated as the average $\mathrm{x}$ and $\mathrm{y}$ of the gridblock centers that constitute this cluster.

The method that groups these clusters is applied to the generated fields. Each cluster is modeled as a single circular area of leakage with the equivalent area of the cluster. Grouping the inclusions by clusters decreases the number of leaky areas enhancing the performance of the semi-analytical model.

One example after grouping the clusters are shown in Figure 7-2. This simulation has 84 gridblocks that are inclusions, after grouping this number is represented by only 16 clusters. Each of these groups is used as a leaky point in the semi-analytical model CO2FLOW. Decreasing the number of leaky points enhances computational efficiency. 
Table 7-1. Parameters used for the simulation of different fields. All cases considered here are assumed to have a correlation scale in $\mathrm{X}$ and $\mathrm{Y}$ direction of $1000 \mathrm{~m}$ for facies 1.

\begin{tabular}{|c|c|c|c|c|c|c|}
\hline $\begin{array}{c}\text { Simulation } \\
\#\end{array}$ & Variogram Model & $\begin{array}{l}\text { Ensemble } \\
\text { Size }\end{array}$ & Facies* & Probability** & $\begin{array}{l}\text { X Correlation } \\
\text { Scale } \\
(\mathrm{m})\end{array}$ & $\begin{array}{c}\text { Y Correlation } \\
\text { Scale } \\
(\mathrm{m})\end{array}$ \\
\hline 1.1 & \multirow{7}{*}{ Exponential } & \multirow{7}{*}{500} & \multirow{7}{*}{2} & \multirow{7}{*}{0.0005} & 100 & 100 \\
\hline 1.2 & & & & & 200 & 200 \\
\hline 1.3 & & & & & 400 & 400 \\
\hline 1.4 & & & & & 600 & 600 \\
\hline 1.5 & & & & & 1000 & 1000 \\
\hline 1.6 & & & & & 1500 & 1500 \\
\hline 1.7 & & & & & 2000 & 2000 \\
\hline 2.1 & \multirow{7}{*}{ Exponential } & \multirow{7}{*}{500} & \multirow{7}{*}{2} & \multirow{7}{*}{0.001} & 100 & 100 \\
\hline 2.2 & & & & & 200 & 200 \\
\hline 2.3 & & & & & 400 & 400 \\
\hline 2.4 & & & & & 600 & 600 \\
\hline 2.5 & & & & & 1000 & 1000 \\
\hline 2.6 & & & & & 1500 & 1500 \\
\hline 2.7 & & & & & 2000 & 2000 \\
\hline 3.1 & \multirow{7}{*}{ Exponential } & \multirow{7}{*}{500} & \multirow{7}{*}{2} & \multirow{7}{*}{0.005} & 100 & 100 \\
\hline 3.2 & & & & & 200 & 200 \\
\hline 3.3 & & & & & 400 & 400 \\
\hline 3.4 & & & & & 600 & 600 \\
\hline 3.5 & & & & & 1000 & 1000 \\
\hline 3.6 & & & & & 1500 & 1500 \\
\hline 3.7 & & & & & 2000 & 2000 \\
\hline 4.1 & \multirow{7}{*}{ Exponential } & \multirow{7}{*}{500} & \multirow{7}{*}{2} & \multirow{7}{*}{0.01} & 100 & 100 \\
\hline 4.2 & & & & & 200 & 200 \\
\hline 4.3 & & & & & 400 & 400 \\
\hline 4.4 & & & & & 600 & 600 \\
\hline 4.5 & & & & & 1000 & 1000 \\
\hline 4.6 & & & & & 1500 & 1500 \\
\hline 4.7 & & & & & 2000 & 2000 \\
\hline 5.1 & \multirow{7}{*}{ Exponential } & \multirow{7}{*}{500} & \multirow{7}{*}{2} & \multirow{7}{*}{0.02} & 100 & 100 \\
\hline 5.2 & & & & & 200 & 200 \\
\hline 5.3 & & & & & 400 & 400 \\
\hline 5.4 & & & & & 600 & 600 \\
\hline 5.5 & & & & & 1000 & 1000 \\
\hline 5.6 & & & & & 1500 & 1500 \\
\hline 5.7 & & & & & 2000 & 2000 \\
\hline
\end{tabular}

$*$ Where facies $=2$ corresponds to inclusions. $* *$ Probability of facies $1, \mathrm{p} 1$, will be: $\mathrm{p} 1=1-\mathrm{p} 2$. 


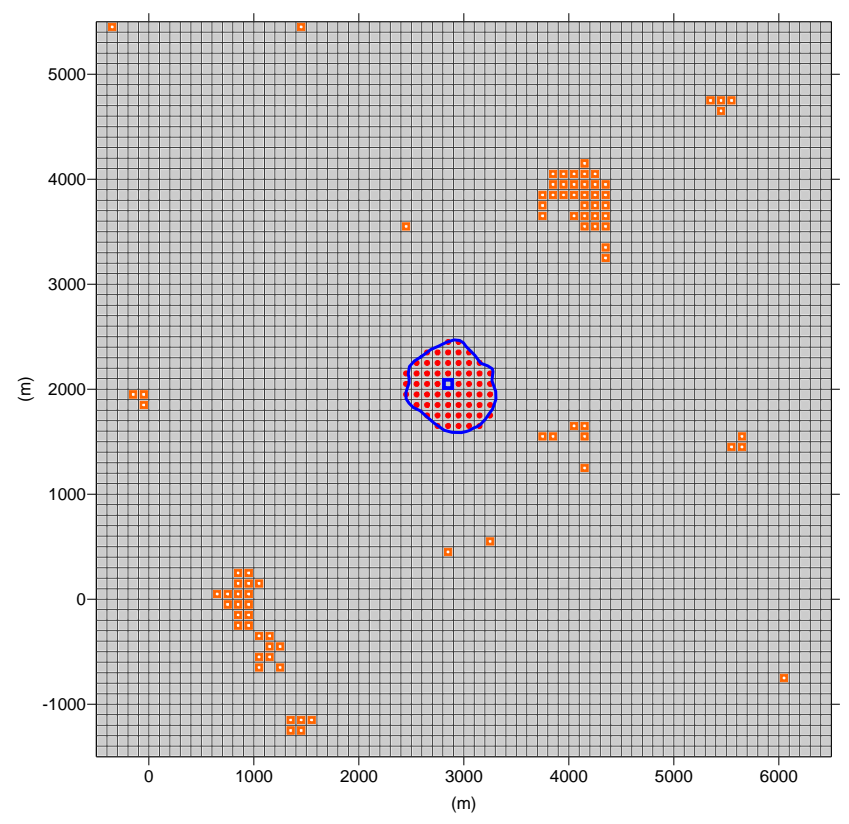

a) Simulation \#1, field \#2: 84 blocks are inclusion

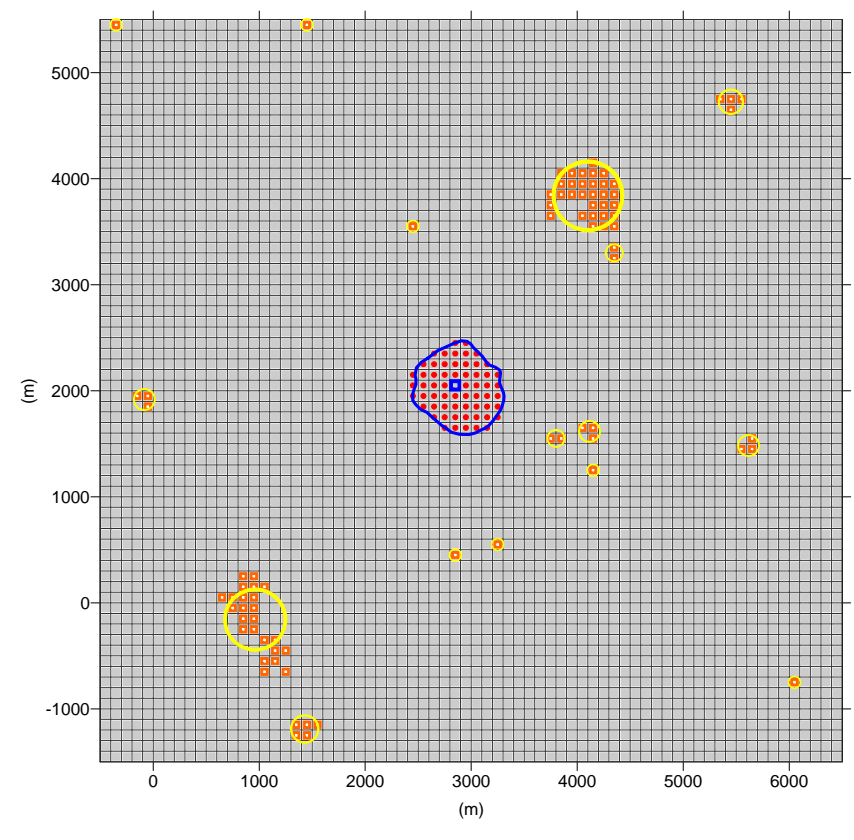

b) Simulation \#1, field \#2

Sealing formation (facies 1)

Inclusions (facies 2)

Figure 7-2. Representation of the circular equivalent area of the clusters for Simulation 1.

\subsubsection{Geological setting}

The analysis is applied to MTU-site system consisting of a deep saline aquifer (Gray Niagaran formation) overlain by one aquitard and one aquifer. Supercritical $\mathrm{CO}_{2}$ is injected within the deepest aquifer from a single well. We have considered a thickness for the Gray Niagaran formation and its overlying aquifer to be $109 \mathrm{~m}$ and $100 \mathrm{~m}$, respectively, with the bottom of the Gray Niagaran formation $1609 \mathrm{~m}$ deep. The aquitard is $30 \mathrm{~m}$ thick.

The aquitard is assumed impermeable except where there are inclusions. Initially all formations are saturated with brine under hydrostatic pressure conditions. The injection rate is $10 \mathrm{~kg} / \mathrm{s}$ and remains constant during the 10 years of simulation. ECLIPSE (Schlumberger, 2010) is used to model immiscible fluids and assumes capillary pressure to be negligible. Van Genuchten model (van Genuchten, 1980) is used to calculate relative permeability of $\mathrm{CO}_{2}$ and brine. The parameters used for this model are from 
Zhou et al. (2009), where the fitting parameter and residual saturation of brine is

The brine phase is assumed as water to exclude the impact of salt on results allowing for comparable with CO2FLOW. Representations of the relative permeability curves are shown in Figure 7-3. For simplification, since no data from the overlying aquifer is available, both aquifers and leakage areas have been assigned the same set of properties. The hydro-geomechanical parameters are provided inTable 7-2.

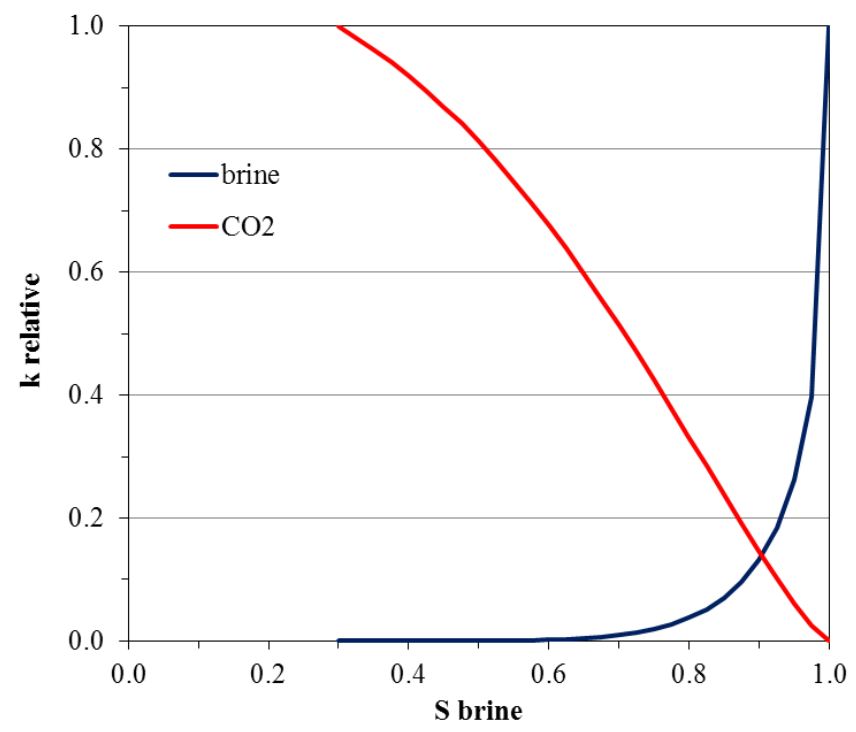

Figure 7-3. Relative permeability curves of $\mathrm{CO}_{2}$ (red) and brine (blue).

Table 7-2. Hydro-geomechanical parameters.

\begin{tabular}{ccc}
\hline Parameter & Symbol & Value \\
\hline Aquifer permeability $\left(\mathrm{m}^{2}\right)$ & $\mathrm{k}$ & $6 \mathrm{E}-15$ \\
Aquifer porosity $(/)$ & $\phi$ & 0.035 \\
Pathways permeability* $\left(\mathrm{m}^{2}\right)$ & $\mathrm{k}_{\mathrm{lp}}$ & $6 \mathrm{E}-15$ \\
Brine density $\left(\mathrm{kg} / \mathrm{m}^{3}\right)$ & $\rho_{\mathrm{b}}$ & 990 \\
$\mathrm{CO}_{2}$ density $\left(\mathrm{kg} / \mathrm{m}^{3}\right)$ & $\rho_{\mathrm{c}}$ & 573 \\
$\mathrm{Brine}$ viscosity $(\mathrm{Pa} \cdot \mathrm{s})$ & $\mu_{\mathrm{b}}$ & $4.6 \mathrm{E}-4$ \\
$\mathrm{CO}_{2}$ viscosity $(\mathrm{Pa} \cdot \mathrm{s})$ & $\mu_{\mathrm{c}}$ & $4.3 \mathrm{E}-5$ \\
Brine residual saturation $(/)$ & $\mathrm{s}_{\mathrm{r}, \mathrm{b}}$ & 0.3 \\
System compressibility $\left(\mathrm{m}^{2} / \mathrm{N}\right)$ & $\mathrm{C}$ & $4.6 \mathrm{E}-10$ \\
\hline
\end{tabular}




\subsection{Results}

Results are presented in terms of sample cumulative distribution functions (CDF's). In these results, overpressure is defined as the difference between the final and initial pore pressures in proximity of the injection well. The percentage of leaked $\mathrm{CO}_{2}$ leakage is defined as the ratio between the mass of $\mathrm{CO}_{2}$ that escapes from aquifer $L 1$ into overlying aquifers and the total amount of injected $\mathrm{CO}_{2}$ :

$$
\% \text { CO2 mass leakage }=\frac{\text { leaked mass } C O 2 \text { from } L 1}{\text { total mass } C O 2 \text { injected }} \cdot 100
$$

First, relationships between (i) correlation scale and distance from the center of the cluster to the injection well, and (ii) correlation scale and number of leaky wells ratio are presented. These relationships will help to understand CDF results.

We define $\mathrm{D}$, the distance between the cluster center and injection well, as:

$$
D=\frac{1}{N M C} \cdot \sum_{j=1}^{N M C} \frac{\sum_{i=1}^{N c l} A_{i} \cdot d_{i}}{\sum_{i=1}^{N c l} A_{i}}
$$

Where $N M C$ is the total number of realizations, $\mathrm{Ncl}$ is the total number of clusters of one realization, $A$ is the area of one cluster, and $d$ is the distance between cluster center and injection well.

Figure 7-4 shows the relationship between correlation scale and the distance from the center of the cluster to the injection well for probabilities $\mathrm{p}=0.0005, \mathrm{p}=0.005$ and $\mathrm{p}=0.01$. The distance from the center of the cluster to the injection well decreases when correlation scale increases until reaching a minimum for $\mathrm{p}=0.0005$. This distance then increases with increasing correlation scale until seems it stabilize.

The ratio of leaky cell, ratio $\# l c$, is defined as the ratio between leaky cells average of one simulation and the expect number of leaky cells of one simulation:

$$
\text { ratio \#lc }=\frac{\frac{\sum_{i=1}^{N M C} l c_{i}}{N M C}}{p \cdot \# \text { cells }}
$$


Where $p$ is the probability, \#cells is the total number of grid cells, and $l c$ is the number of leaky cells (cells with facies 2). In our case, the total number of grid cells is 4900 . Hence if the probability is $\mathrm{p}=0.01$, the expected number of leaky cells for one simulation is 49 .
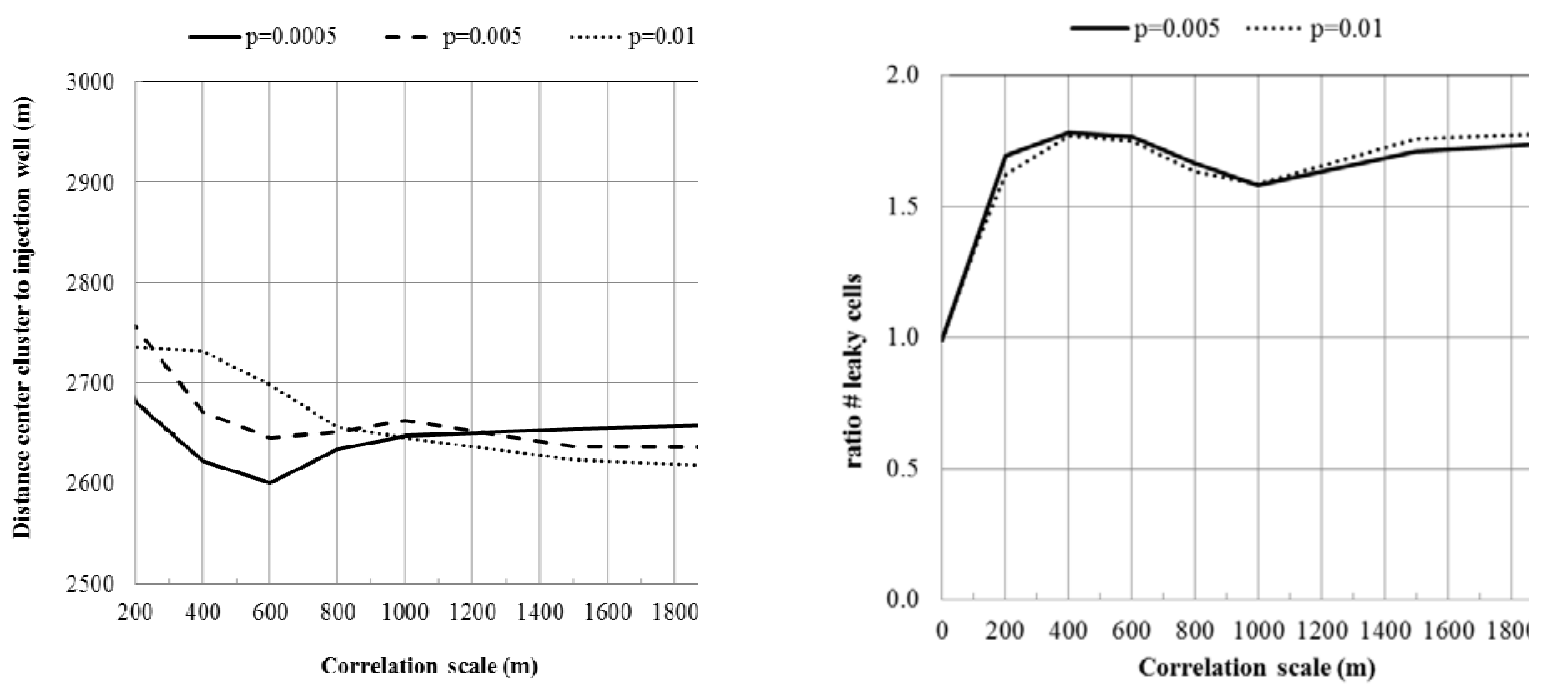

Figure 7-4. Relationship between correlation scale Figure 7-5. Relationship between correlation scale and the distance from center cluster to injection well. and the ratio of leaky wells.

Figure 5 shows that the average of leaky cells of one simulation is equal to the expected leaky cells only when the correlation scale $=0.1 \mathrm{~m}$. The ratio of leaky cells increases with correlation scale. This means that the correlation scale affects the number of leaky cells of one simulation. This correlation does not seem to exist for greater correlation scales (e.g. $1=1500 \mathrm{~m}, 1=2000 \mathrm{~m}$ ).

When keeping the correlation scale constant (1) and increasing the probability (p) the $\%$ of $\mathrm{CO}_{2}$ mass leaked and the mass of leaked brine increase, but the overpressure at the proximity of the injection well decreases.

Figure 7-6a shows results of simulations with same correlation scale $1=200 \mathrm{~m}$ and different probabilities. Mass leaked of $\mathrm{CO}_{2}$ is much greater for a simulation with $\mathrm{p}=0.02$ than in a simulation with $\mathrm{p}=0.0001$. In $81 \%$ of cases with $\mathrm{p}=0.0005$ and $\mathrm{l}=200 \mathrm{~m}, \mathrm{CO}_{2}$ mass leakage is lower or equal to $1 \mathrm{E}-03 \%$. Figure 7-6b shows the same tendency seen in Figure 7-6a when the correlation scale is increased to $1=400$ 
m. When comparing the amount of leaked $\mathrm{CO}_{2}$ for the two correlation scales, we see that $\mathrm{CO}_{2}$ leakage is greater for correlation scale $1=400 \mathrm{~m}$. This agrees with two facts: 1 ) the distance from the center cluster to the injection well is lower for correlation scale $1=400 \mathrm{~m}$ (see Figure 7-4), and 2) the ratio of leaky cells is greater for $1=400 \mathrm{~m}$ (see Figure 7-5). Therefore, in the case of $1=400 \mathrm{~m}$, there are more leaky cells in one simulation and the distance that the plume of $\mathrm{CO}_{2}$ must travels until reaches the center of the cluster is smaller, favoring the $\mathrm{CO}_{2}$ leakage.

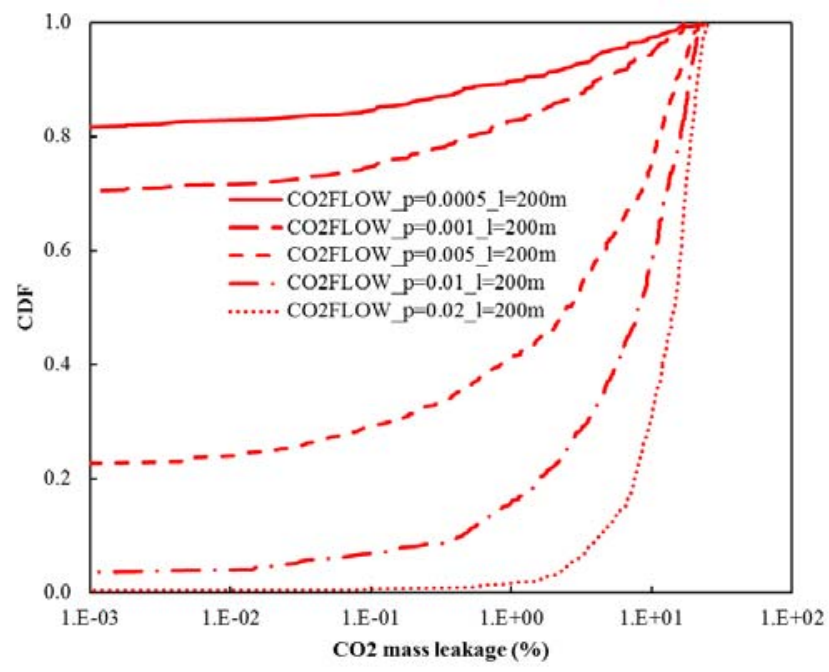

a) Correlation scale $1=200 \mathrm{~m}$

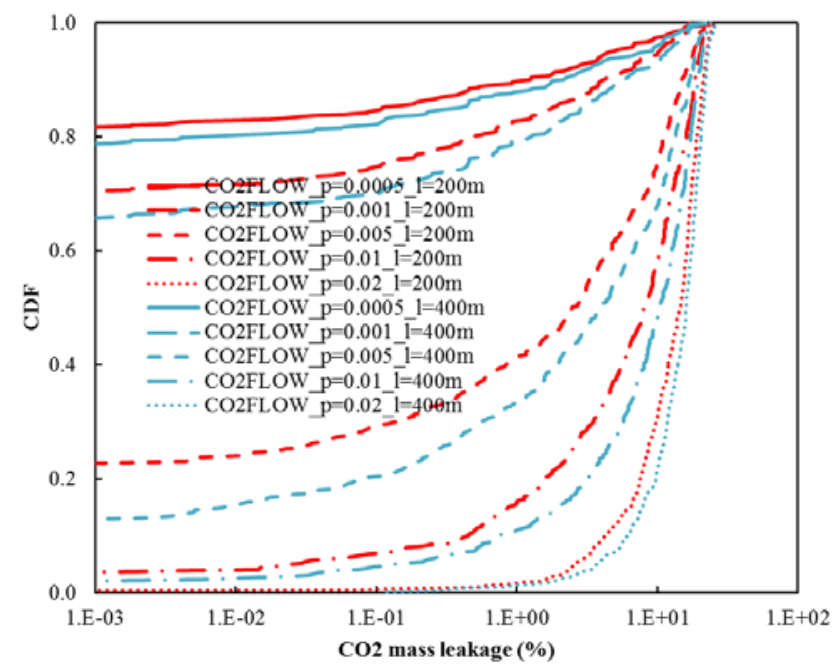

b) Correlation scale $\mathrm{l}=200 \mathrm{~m}$ in red and $\mathrm{l}=400 \mathrm{~m}$ in blue

Figure 7-6. $\mathrm{CO} 2 \mathrm{FLOW} \mathrm{CO}_{2}$ mass leakage results of simulations with correlation scale $\mathrm{l}=200 \mathrm{~m}$ and correlation scale $\mathrm{l}=\mathbf{4 0 0} \mathrm{m}$.

Figure 7-7 shows the leakage of brine for different probabilities when correlation scale is $1=200 \mathrm{~m}$ (in red) and $\mathrm{l}=400 \mathrm{~m}$ (in blue). Brine and $\mathrm{CO}_{2}$ leakage in Figure 7-6a increase with probability. When correlation scale is $1=400 \mathrm{~m}$ brine leakage is superior. However, this difference is diminished for greater values of probabilities $(\mathrm{p}=0.01$ and $\mathrm{p}=0.02)$ where curves are overlapped.

Overpressure in the proximity of the injection well decreases when the probability of finding a leaky cell is greater (see curves of $\mathrm{p}=0.02$ in Figure 7-8). Increasing the number of leaky cells (or probability) will facilitate the leakage of $\mathrm{CO}_{2}$ and brine to overlying formations, relieving pressure in the 
injected aquifer, therefore overpressure results with correlation scale $1=400 \mathrm{~m}$ are slightly lower than results with $1=200 \mathrm{~m}$.

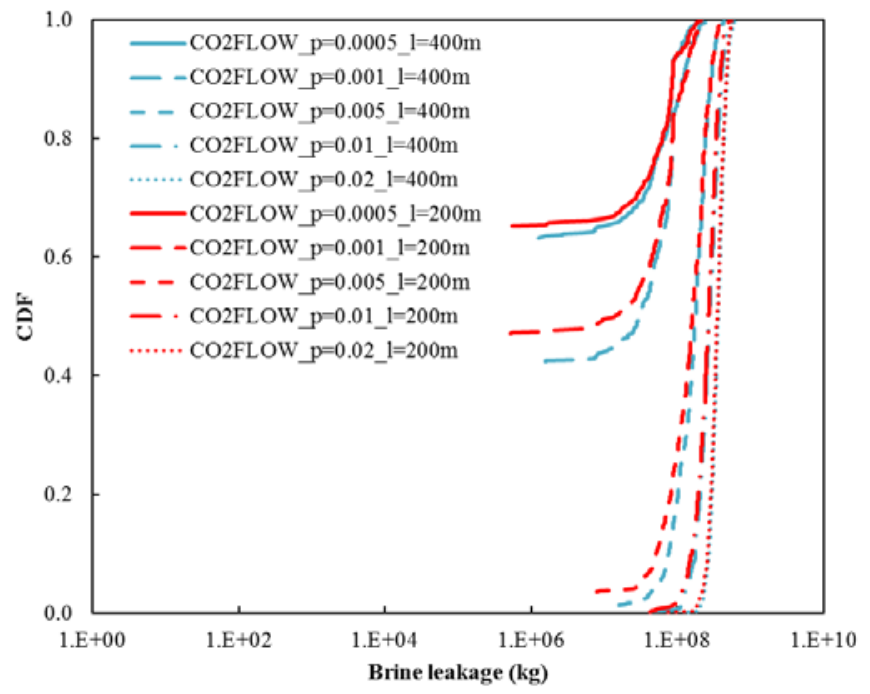

Figure 7-7. CO2FLOW brine leakage results of simulations with correlation scale $l=200 \mathrm{~m}$ and $\mathrm{l}=\mathbf{4 0 0 \mathrm { m }}$.

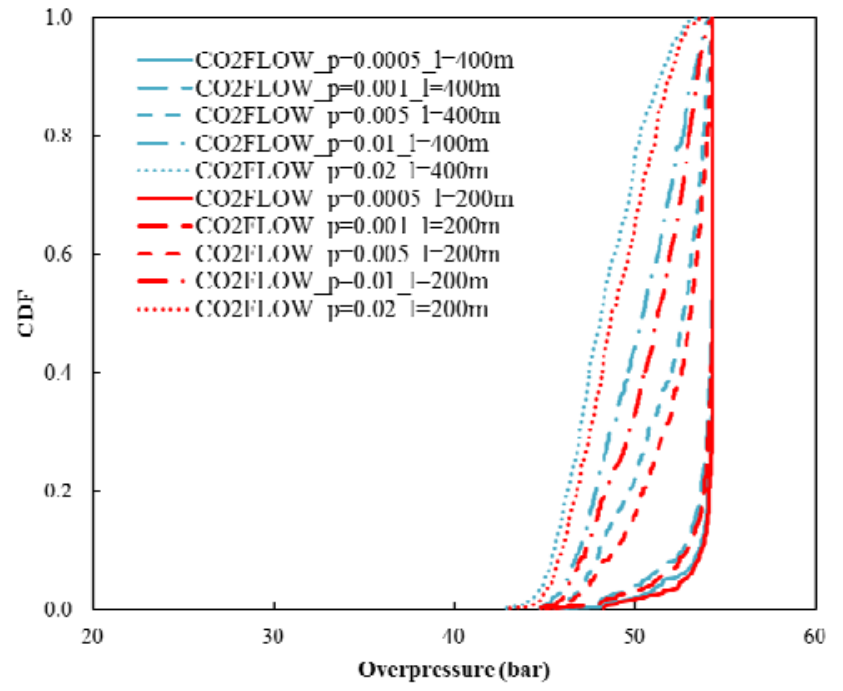

Figure 7-8. CO2FLOW overpressure results of simulations with correlation scale $\mathrm{l}=\mathbf{2 0 0} \mathrm{m}$ and $\mathrm{l}=\mathbf{4 0 0 \mathrm { m }}$.

When comparing results with the same probability of finding a leaky cell (Figure 7-9), we see that: $\mathrm{CO}_{2}$ leakage and brine leakage increases with correlation scale; and a decrease in overpressure. Figure 7-9a shows a decrease in $\mathrm{CO}_{2}$ leakage when decreasing the probability from $\mathrm{p}=0.01$ (in blue) to $\mathrm{p}=0.005$ (in red). Figure 7-9b presents the same tendency seen in Figure 7-9a for brine leakage. Overpressure, in Figure 7-9c, decreases when increasing the correlation scale and when increasing the probability of finding a leaky cell: greatest overpressure is for $\mathrm{p}=0.005$ and $\mathrm{l}=200$ (in red) $\mathrm{m}$ and lowest overpressure is for $\mathrm{p}=0.01$ and $\mathrm{l}=1500 \mathrm{~m}$ (in blue).

Results of the comparison between both codes (CO2FLOW and ECLIPSE) are presented in Figure 7-10. $\mathrm{CO}_{2}$ mass leakage results of ECLIPSE are similar to CO2FLOW results. Figure 7-10a shows results of both codes are close. Main differences are found for probabilities of $p=0.005$ and $p=0.01$. On the other hand, brine leakage results of ECLIPSE differ from results of CO2FLOW. In Figure 7-10b, for all probabilities the brine leakage is greater when simulation is carried out with ECLIPSE. However, the shape of these CDF curves are similar. The overpressure obtained with CO2FLOW is slightly greater than 
with ECLIPSE. The greatest difference is around 4 bar for a probability of $p=0.02$. This pressure difference in Figure 7-10c could be reduced by increasing the distance between the observation and injection locations.

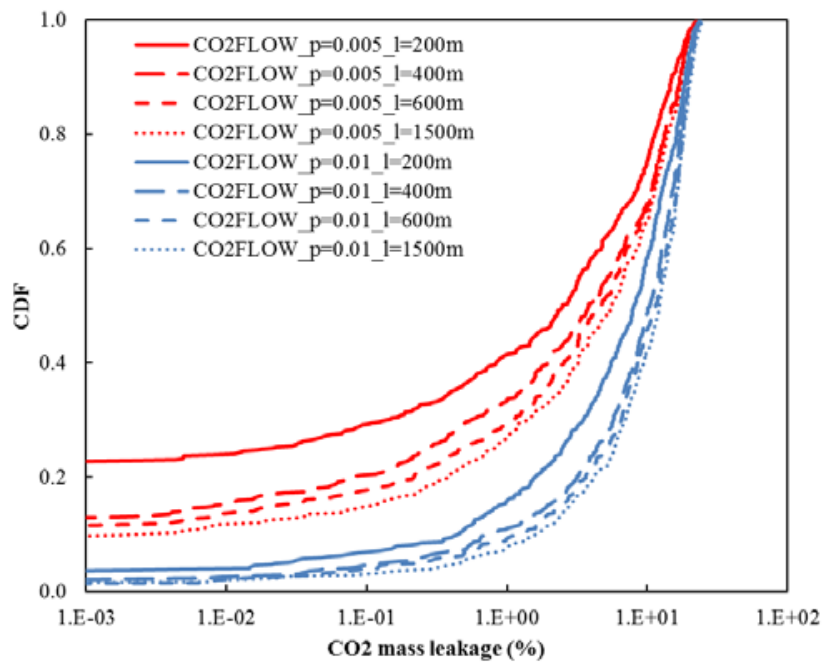

a) $\mathrm{CO} 2 \mathrm{FLOW} \mathrm{CO}_{2}$ mass leakage results of simulations with probability $\mathrm{p}=0.005$ and $\mathrm{p}=0.01$.

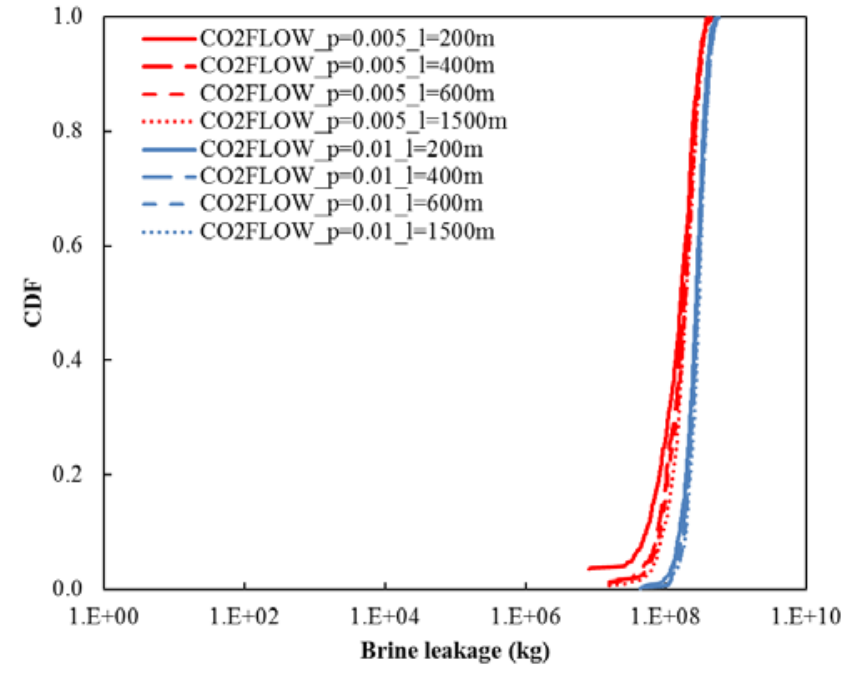

b) CO2FLOW brine leakage results of simulations with probability $\mathrm{p}=0.005$ and $\mathrm{p}=0.01$.

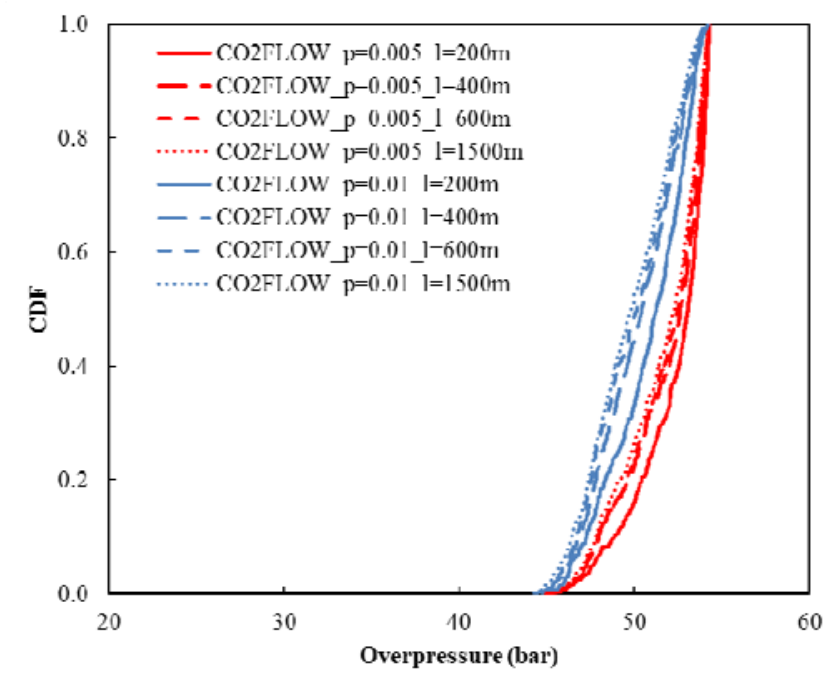

c) CO2FLOW overpressure results of simulations with probability $p=0.005$ and $p=0.01$.

Figure 7-9. CO2FLOW results of simulations with probability $p=0.005$ (in red) and $p=0.01$ (in blue). 


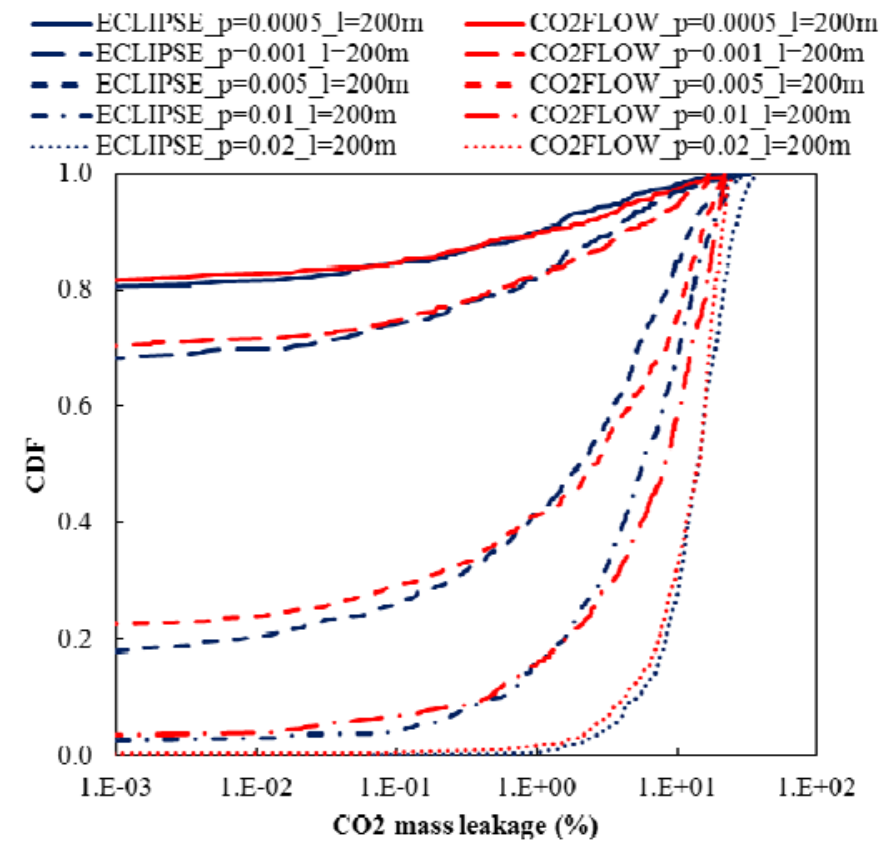

a) $\mathrm{CO}_{2}$ mass leakage

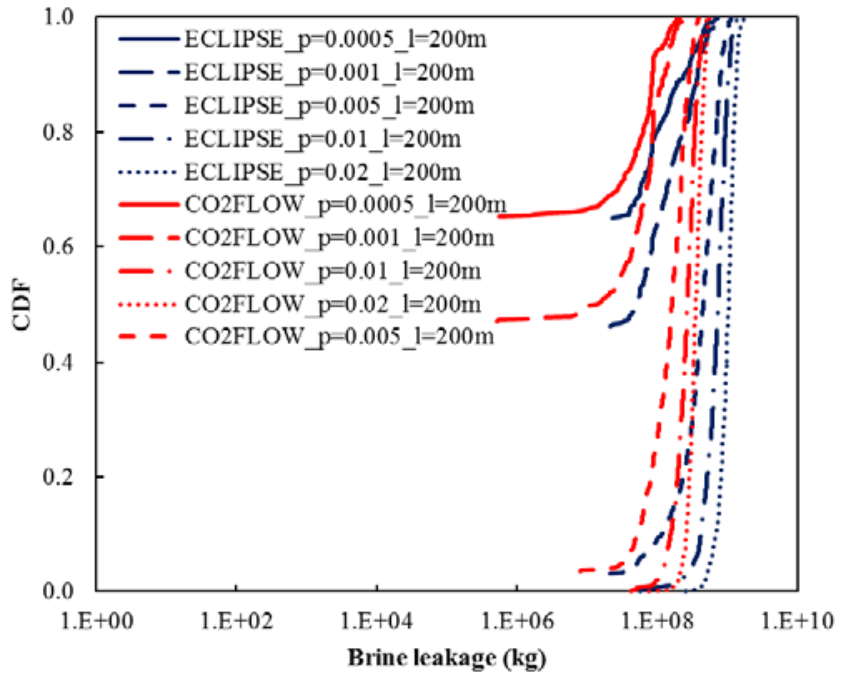

b) Brine leakage

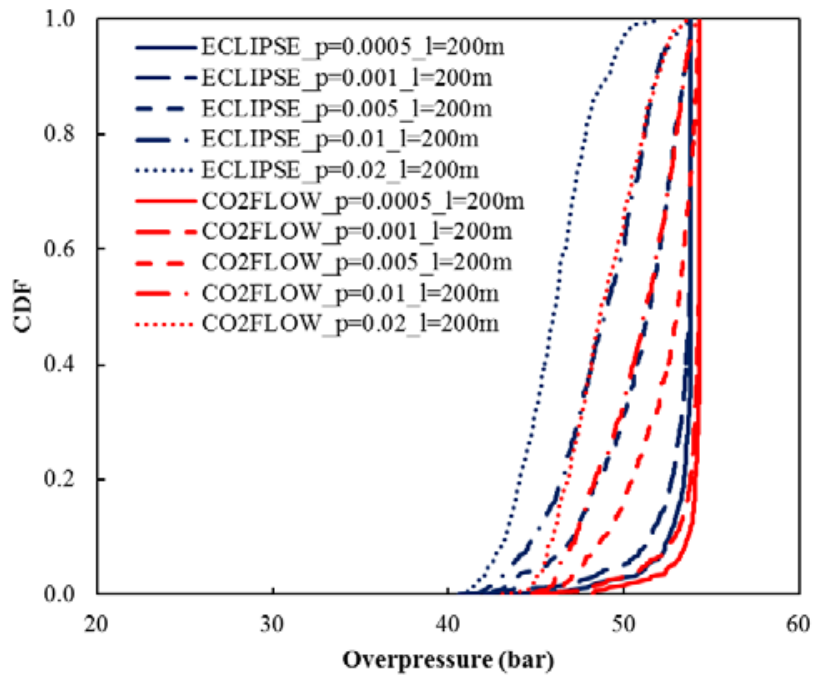

c) Overpressure

Figure 7-10. Comparison CO2FLOW (in red) with ECLIPSE (navy blue), simulations with correlation scale l=200 $\mathbf{~ m}$.

\subsection{Conclusions}

A total of 35 simulations are carried out to study the sealing properties of the caprock overlying the Gray Niagaran formation. From their results we conclude: (i) When keeping the correlation scale constant and increasing the probability of finding a leaky cell the mass of $\mathrm{CO}_{2}$ and brine leakage increase, whereas the overpressure near the injection well decreases; (ii) Increasing the correlation scale has the 
same effect as increasing the probability of finding a leaky cell (i.e. $\mathrm{CO}_{2}$ and brine leakage increases and overpressure decreases); and (iii) $\mathrm{CO}_{2}$ mass leakage results are very similar in both codes, brine leakage results are greater in ECLIPSE, and overpressure results are very close in both codes.

\section{Characterization of geophysical properties and lithology of MTU test site}

The test site operated by MTU is located near the town of Thompsonville, MI. The hypothetical formation proposed for CCS is embedded in the northern reef trend of the Michigan Basin and about 1,000 feet above the reef (Figure 8-1). Figure 8-1 shows the typical geometry of the subsurface configuration of the so-called Niagaran reef of the Michigan basin. These reefs are evaporate-encased and, up until a few decades ago, significantly contributed to the production of hydrocarbons in Michigan. Most of these formations are associated with reef buildups of Middle Silurian age.

The MTU test site is an example of Niagaran reef. For this site, a large ensemble of seismic imaging methods has been tested. Over the 27 year history of the site, a large suite of images of a small volume of earth has been obtained. A first 3-D seismic image of that region was shot in 1983, during the early portion of its history. Figure 3 shows the spread of 576 surface geophones distributed over an area of about two square miles, which were used in the 1983 3D seismic survey. Those data will be available for this study, although their quality is lower than current standards. However, MTU's data library also provides higher resolution 2-D cross-well seismic reflection surveys (Quan and Harris, 1997), which have been obtained from the two outside boreholes shown in Figure 8-2. The zone between and around these boreholes will constitute the test volume of this study.

Figure 8-3 shows a cross section of the MTU site delineated using data collected from the boreholes of Figure 8-2. Figure 8-3 shows also the location of these boreholes, denotes as Burch 1-20B and Stech 1-21A, as well as the location of the only production well, Merit 1-20A, originally drilled by the Shell Oil Company. The MTU site is located between depths of approximately 4660 and 5000 feet 
(1420-1520 meters) and contains a nearly depleted hydrocarbon reservoir overlain by multiple saline aquifer intervals (see, for example, the Upper Bois Blanc Dolomite).

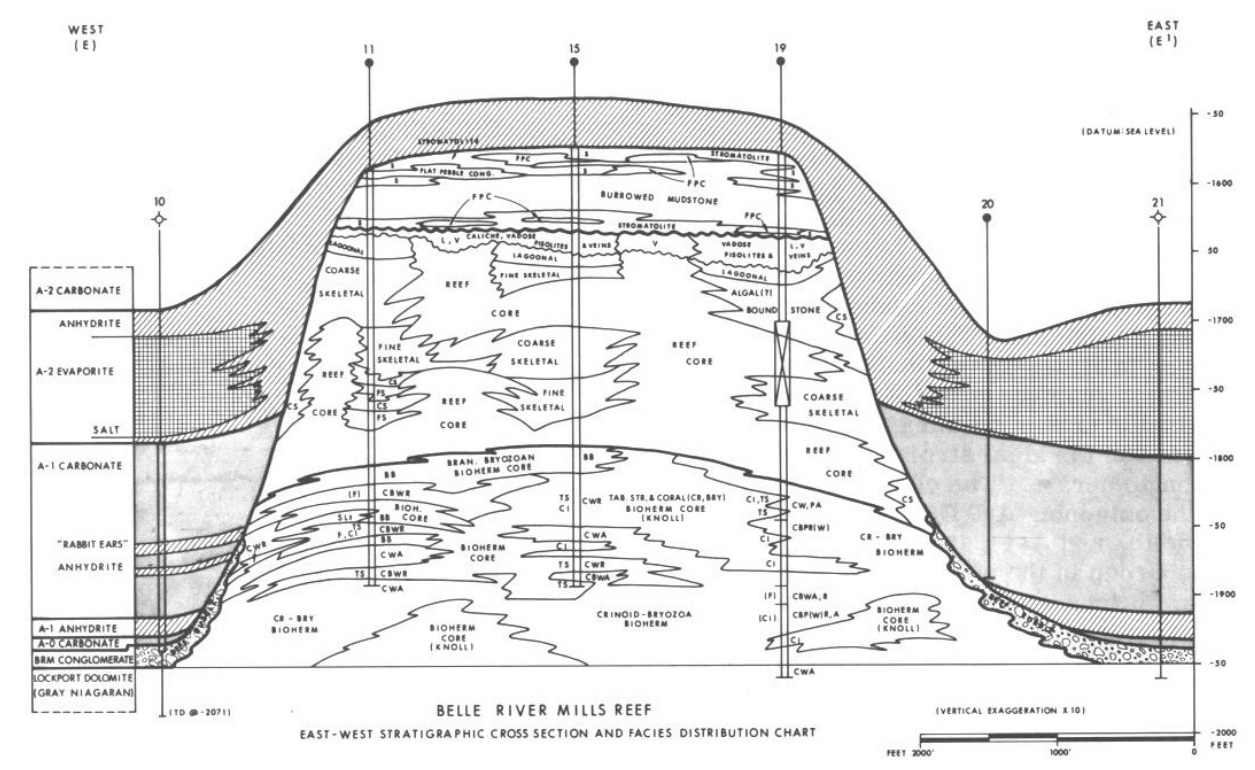

Figure 8-1. Vertical cross section of a typical reef formation situated in the Michigan geological basin along with reef facies distribution chart (adapted from [Gill, 1977]).

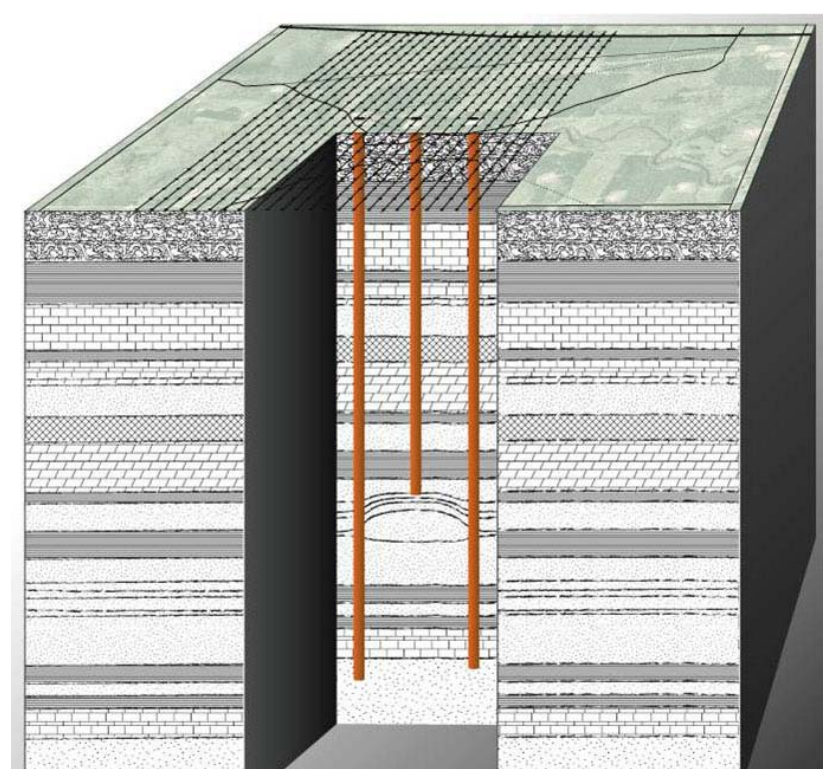

Figure 8-2. Schematic illustration of the Michigan Technological University's Test Site in the northern reef trend of Michigan. 


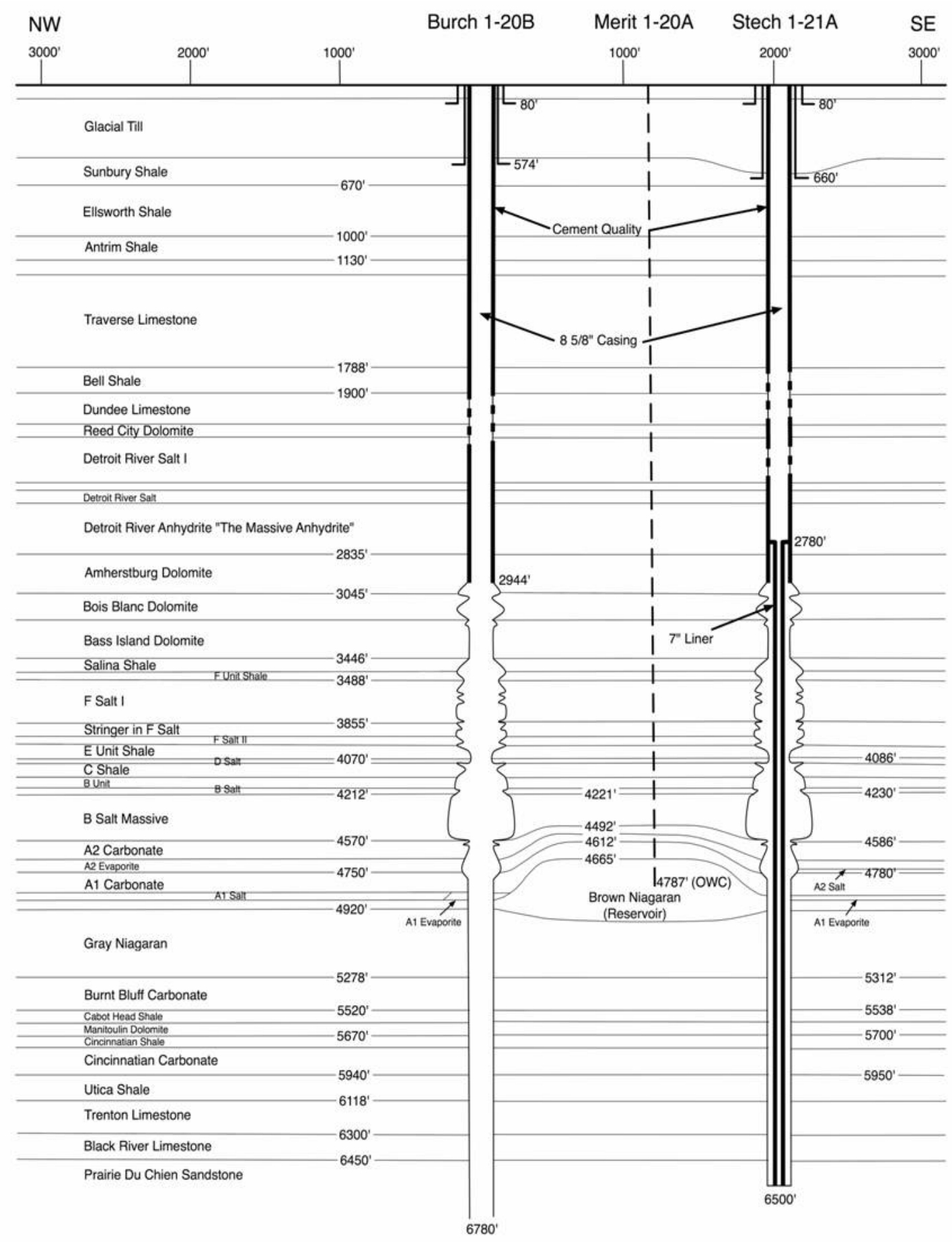

Figure 8-3. Cross-section of MTU's Test Site. The formation being considered for carbon injection is the Brown Niagaran Reservoir located in the depth interval 4665-5140 ft. 
(a)

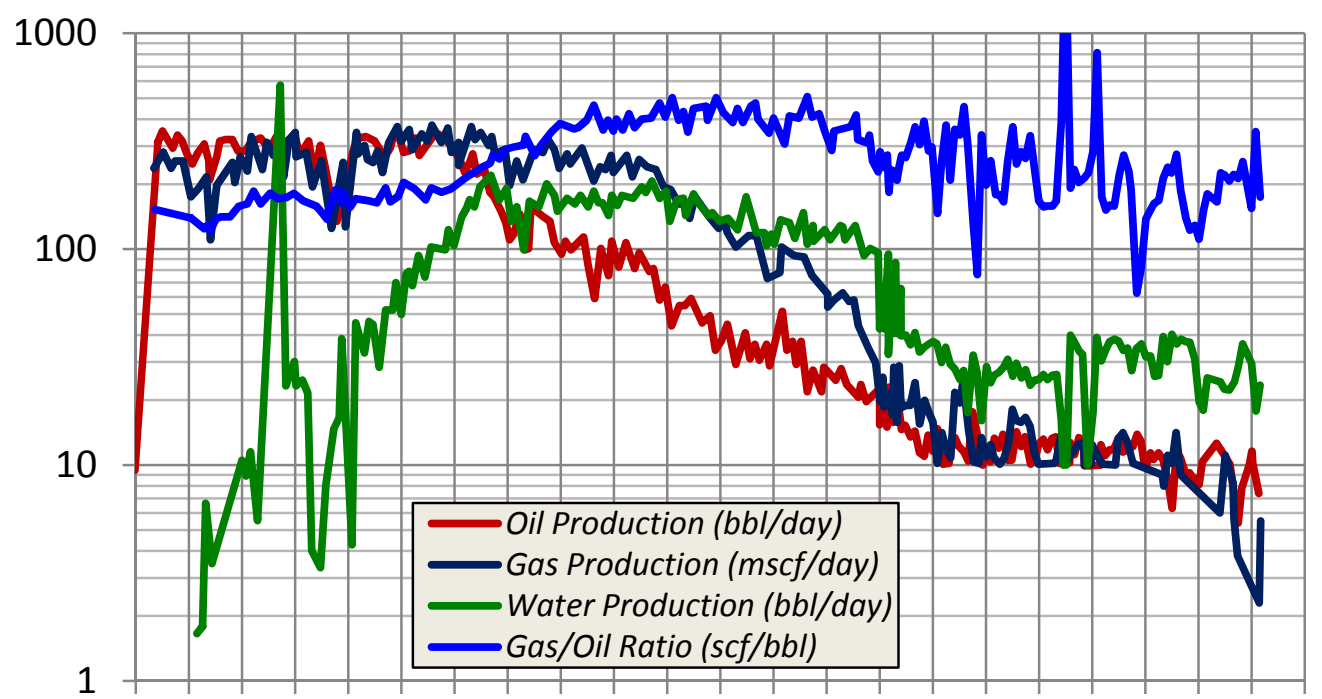

๙

Time (year)

(b)

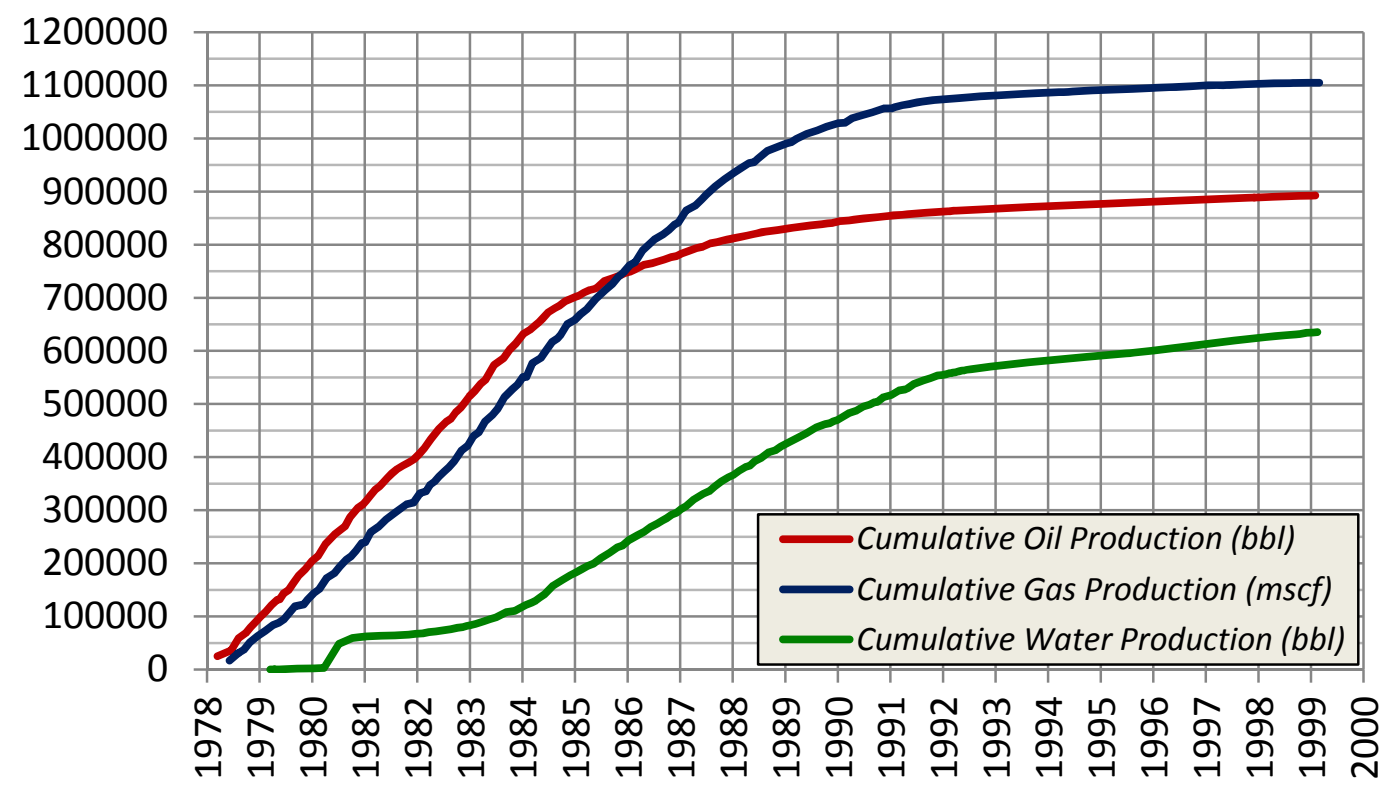

Time (year)

Figure 8-4. (a) Time series for oil, gas, and water production from the Niagaran reservoir from 1978 to 1999. (b) Cumulative oil, gas, and water production 1978-1999.

Figure 8-4a shows the profiles of oil, gas, and water production from the inception of the field development, in 1978, until 1999, when the reservoir was operated by the Shell Oil Company. These profiles show that as of 1999 the percentage of water mass produced largely exceeded the percentages for 
gas and oil, which constitutes a clear sign that the reservoir is nearing depletion. Figure 5b displays the profiles of the cumulative production of oil, gas, and water as obtained from the integration of the time series given in the in Figure 8-4a. As of today, the reservoir is still being produced by Merit Energy, with daily oil yield of the order of 10 bbl/day or less, similar to those observed in 1999 (see Figure 8-4a).

Figure 6 depicts the horizontal projection of the Niagaran reservoir. Shaded in dark green is the top of the reef, whereas the light green region indicates the bottom of the formation. The figure also indicates the location of production well installed by Shell in 1978, as well three boreholes currently used by MTU for seismic imaging research.

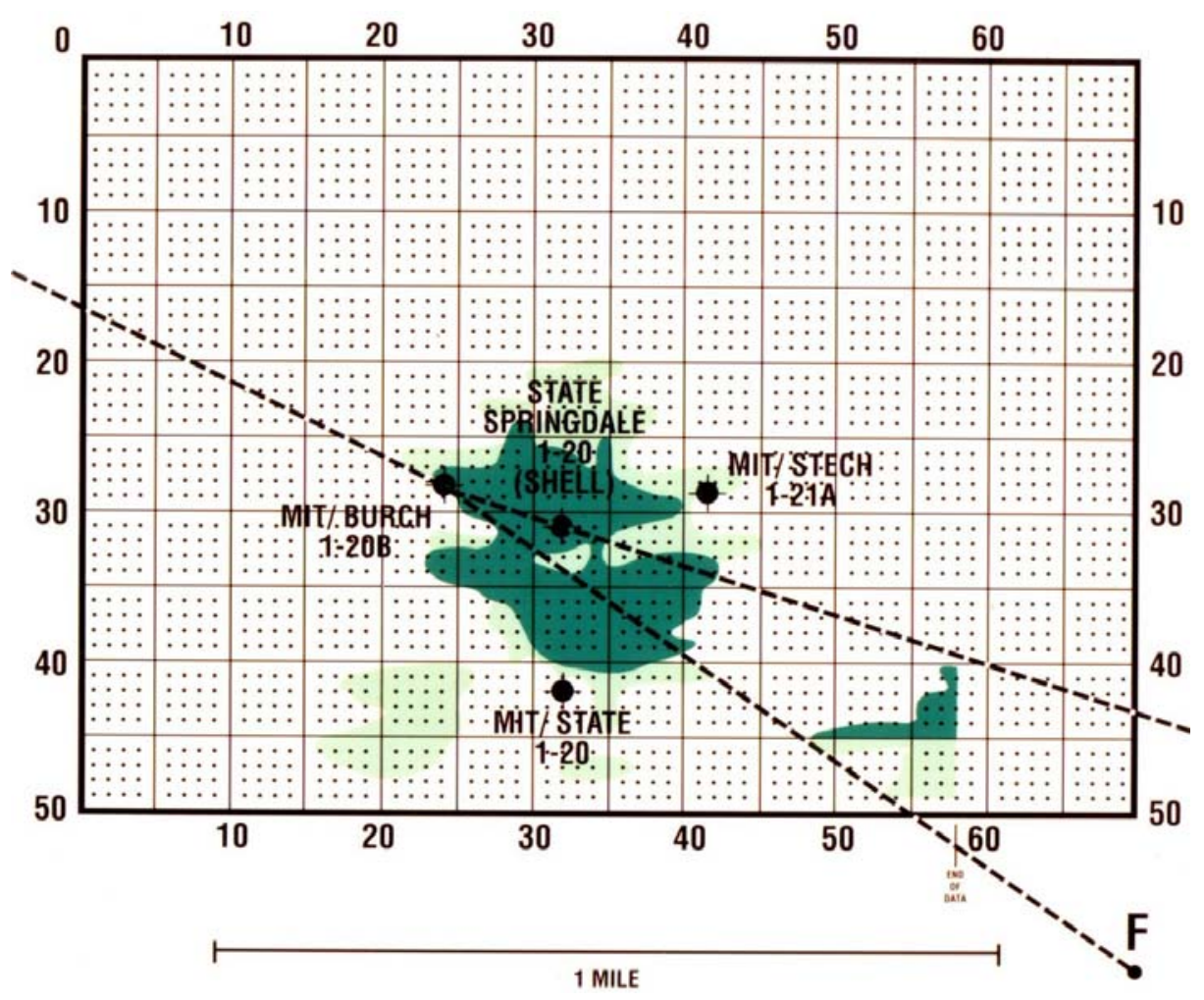

Figure 8-5. Plan view representation of the Niagaran reservoir. The dark green area represents the top of the reef, whereas the light green region indicates the bottom of the formation. The figure indicates the location of the "State Springdale" production well as well three boreholes currently used by MTU for seismic imaging research. 
Over the years, these boreholes have provided a wide variety of high resolution well logs that may be used to characterize properties such as density, porosity, electrical resistivity, compressional and shear wave velocities.

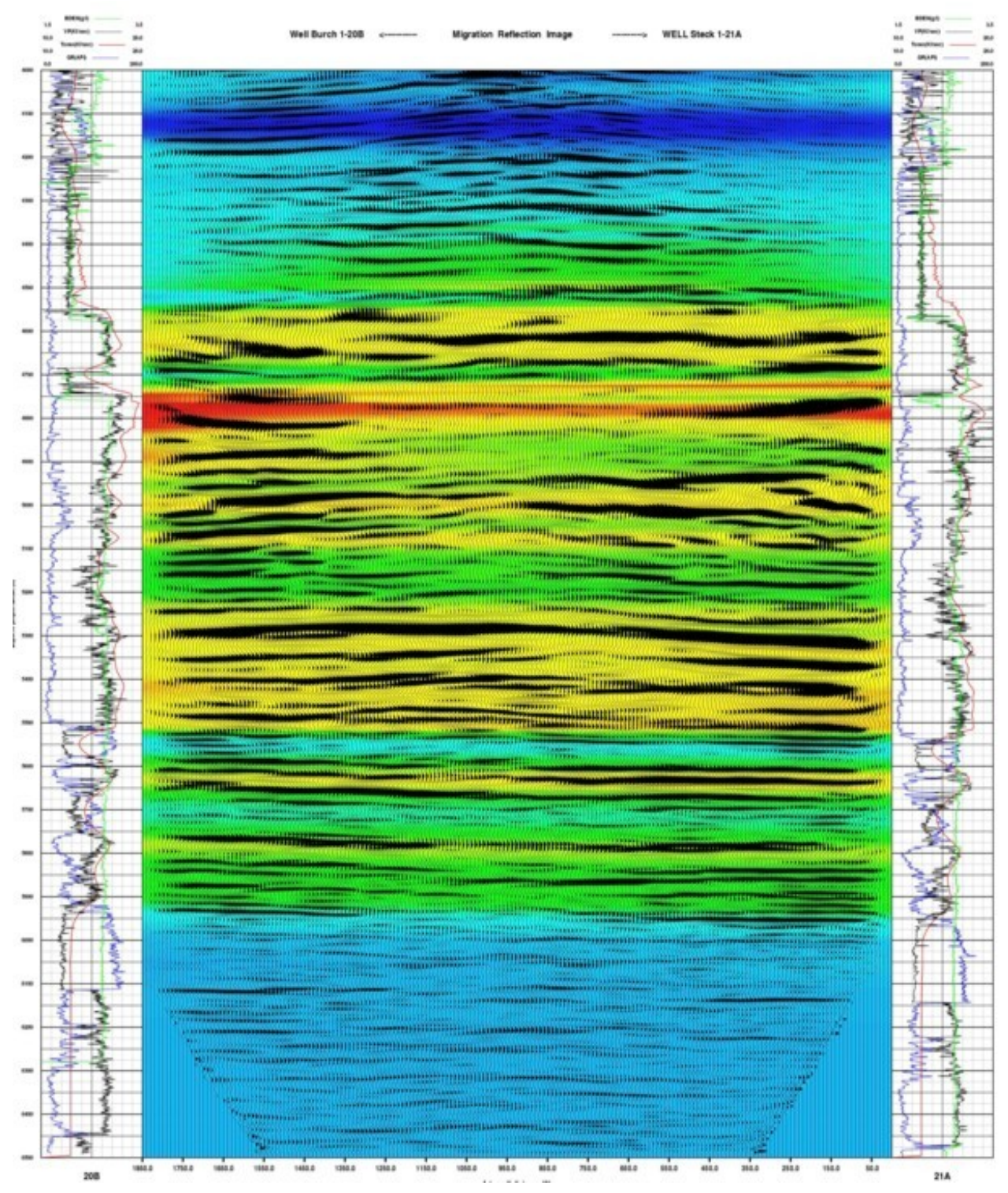

Figure 8-6. Cross-well seismic reflection image from the Niaragan reef Reservoir. Color background represents velocity model (kft/s) determined by cross-well transmission tomography. Wiggle traces are the migrated stacked seismic data from cross-well reflection imaging. Well logs are displayed along the edges. The vertical axis indicates depth,which from 4000 to $6500 \mathrm{ft}(1210-1970 \mathrm{~m})$. Warmer colors (red, yellow) indicate high velocity values. 
An example of the data collected from these boreholes is provided in Figure 8-6. The figure shows a cross-well seismic, reflection image from the Niaragan Reef Reservoir, combined with well logs recorded at the locations of the Burch (left) and Stech (right) boreholes (see Figure 8-3 and Figure 8-5).

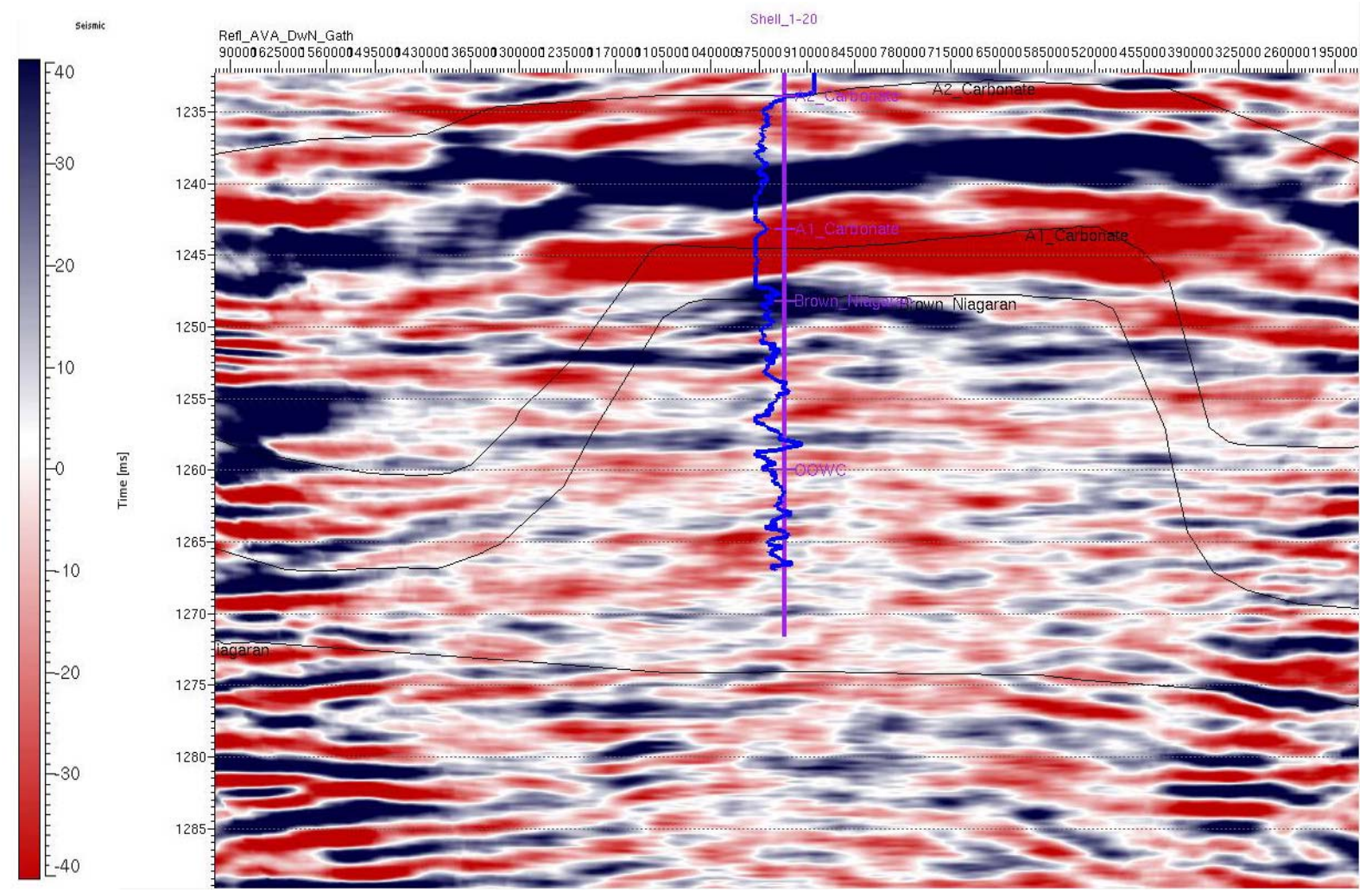

Figure 8-7. Stacked image of cross-well data obtained from the Niagaran reef reservoir (adapted from [Ibrahim et al., 2010]) . Solid lines represent the seismic horizons. The vertical blue line in the middle shows the location of the only producing well in this reef.

A clear description of the internal structure of Niagaran reef has been recently given by Ibrahim et al (2010), who obtained acoustic and impedance images using the results from a deterministic simultaneous inversion of a high-resolution cross-well seismic survey. Figure 8-8 shows the output of the cross-well seismic survey conducted using the two monitoring wells external to the reef "Burch" and "Stech" (Figure 8-3 and Figure 8-5). These wells extend over depths greater than the reef's, and imaging was conducted using reflections both from above and from beneath the reef, resulting in the best seismic images of any Niagaran pinnacle reef obtained to date. In Figure 8-8, the reef is visible as the lowamplitude region at depths of about 4700 to $5000 \mathrm{ft}$. near the center of the image. 


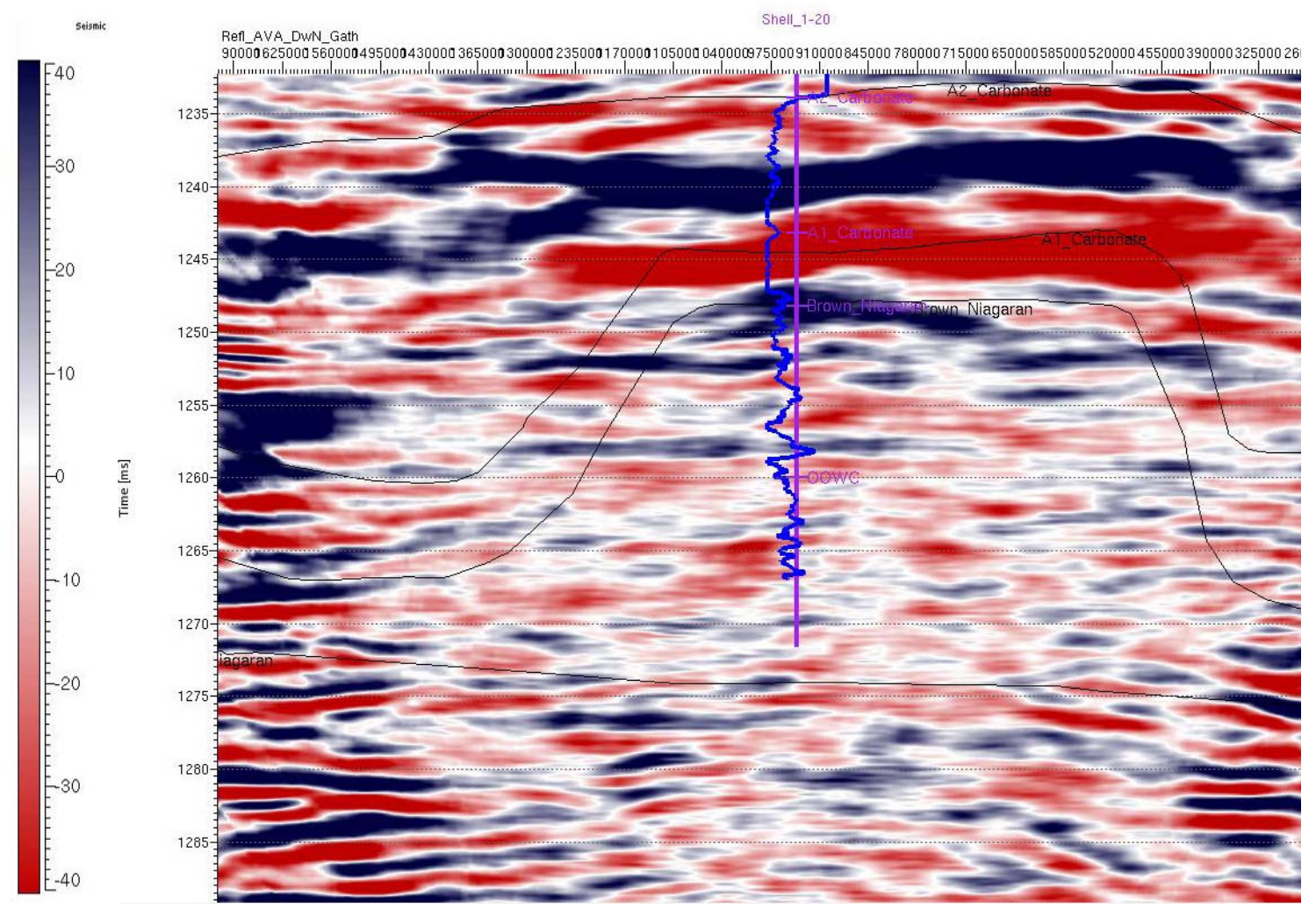

Figure 8-8. Stacked image of cross-well data obtained from the Niagaran reef reservoir (adapted from [Ibrahim et al., 2010]) . Solid lines represent the seismic horizons. The vertical blue line in the middle shows the location of the only producing well in this reef.

Figure 8-9 shows the elastic inversion results for compressional impedance obtained from the cross-well data given in Figure 8-8. This image displays a distribution of internal layers that is reasonable for this carbonate reef (see also Figure 8-1). It is believed that the impedance results are particularly significant in such a carbonate environment and indicate zones of higher porosity (low impedance) and lower porosity (higher impedance). Areas of lower impedance (yellows to reds) suggest higher porosity, while areas of higher impedance (greens to blues) suggest lower porosity, with some layers probably having all porosity occluded by anhydrite plugging (Ibrahim et al., 2010). In Figure 8-9, the top of the reservoir can be clearly distinguished, as well as its lateral extent or dipping edges. Reflection events internal to the reef are evident; some of them are fairly continuous across the reef and others are discontinuous. 


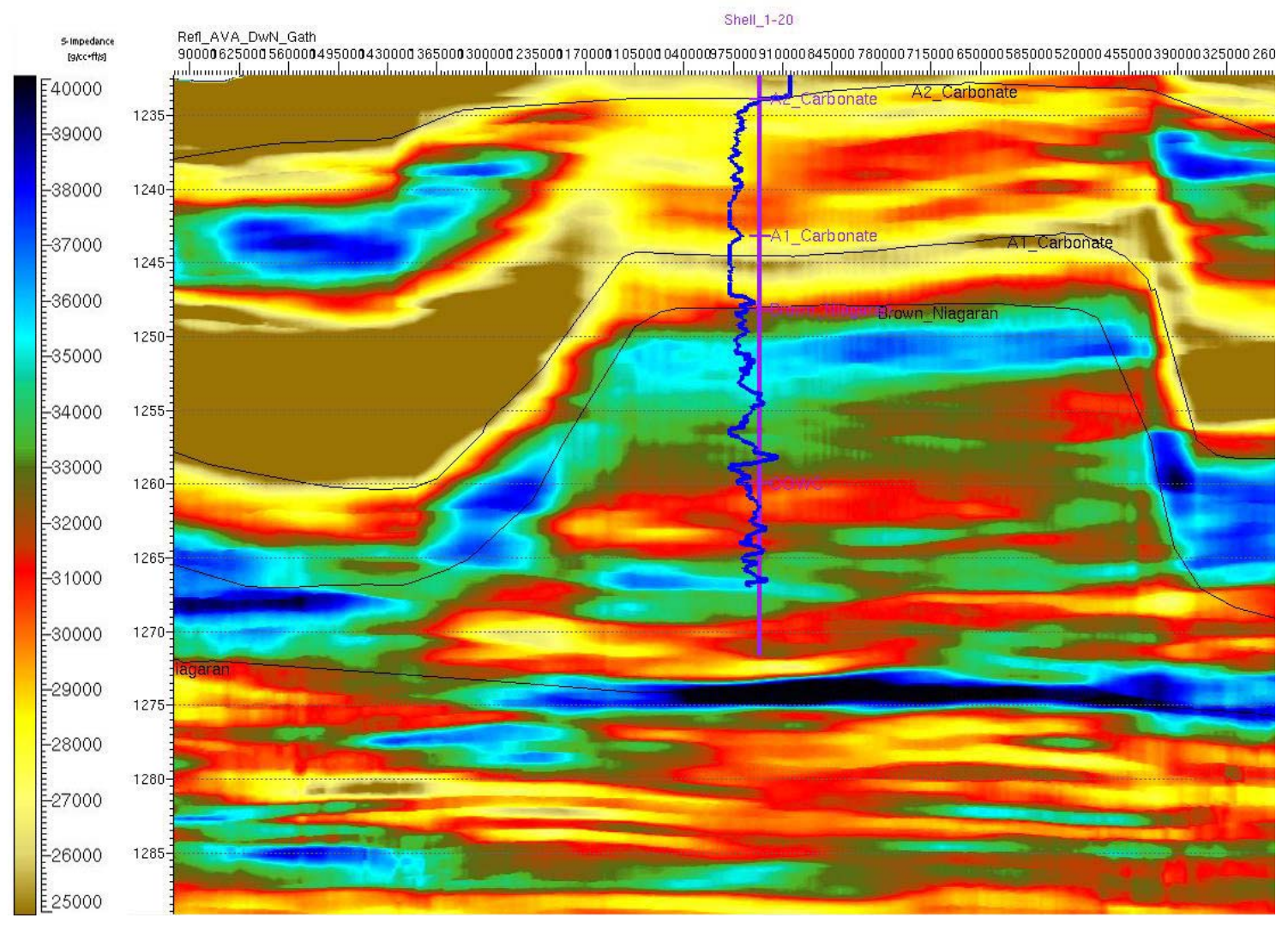

Figure 8-9. Results of elastic inversion expressed in terms of compressional impedance (adapted from [Ibrahim et al., 2010]) . The solid lines represent the seismic horizons. The vertical blue line in the middle shows the location of the only producing well in this reef.

Figure 8-10 shows a 3D representation of the reef geometry and the surrounding formations. It can be observed that the maximum thickness at the reservoir is around 340 feet at its central part and the thickness decreases abruptly at the boundaries of the reservoir.

Study of growth and dolomitization has been performed on Silurian Reefs at St. Clair County (near the area of the site of interest). It showed that A-1 and A-2 carbonate are nearly completely dolomitized (Mg/Ca ratio above 0.60) (Jodry, 1969). The dolomite in these layers has very little porosity preserved because the porosity increase during dolomitization has been destroyed by subsequent final compaction and lithification of the carbonate mud (values of porosity less than 0.002 ). The Niagaran carbonates have considerable, but variable, bioclastic content (Jodry, 1969). Porosity has developed in Niagaran rocks, and dolomite crystal size varies over a wide range. The porosity has been preserved 
because of a strong reef framework which resisted compaction. Porosity increases are negligible where dolomitization has reached less than approximately $70 \%$ of the carbonate content. This increases significantly to a maximum when dolomitization is the order of $75-80 \%$, and it decreases with increased the dolomitization. The increase in porosity is relative since porosity can increase to $2 \%$ or to $20 \%$ depending on the rock type.

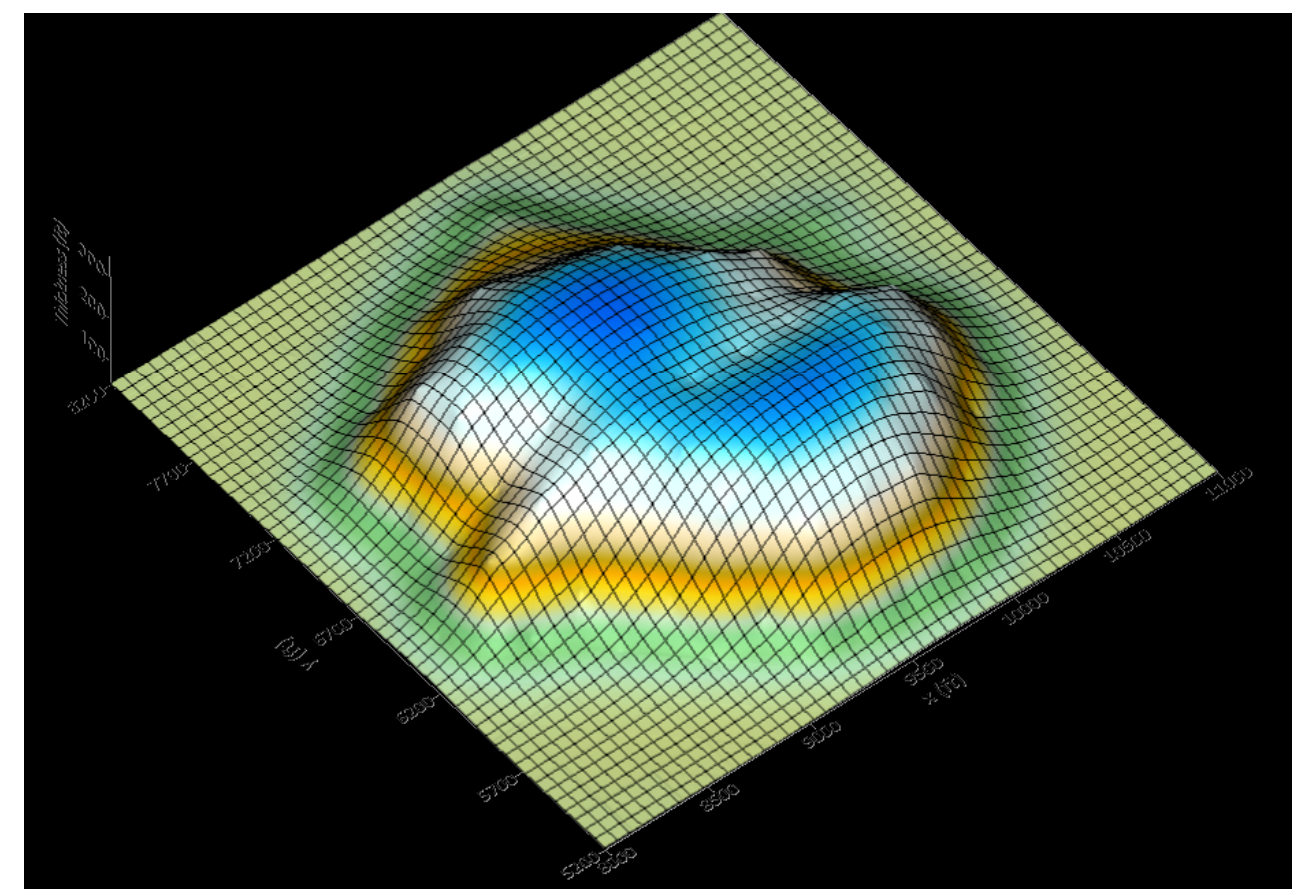

Figure 8-10. Three-dimension representation of the reef geometry and the surrounding formations.

Table 8-1 shows porosity values of major rock types found in the Niagaran. All have the same degree of dolomitization $(\mathrm{Mg} / \mathrm{Ca}$ ratios of 0.60 or $80 \%$ dolomite) (Jodry, 1969). It also shows the correspondent permeability and residual water saturation. The two first rock types present around $40 \%$ of the total porosity as ineffective, while the last two present $88 \%$ and $95 \%$ of the porosity effective.

Different logs of 1977 data are available. The representation of the log-porosity measured by neutron porosity hydrogen index is shown in Figure 8-11. The values of porosity at the caprock (between the two red lines) are between $2.5 \%$ and $6 \%$. The porosity increases at the Brown Niagaran formation having a minimum value of $4 \%$ and reaching a maximum value of $16 \%$ at a depth of $4800 \mathrm{ft}$. 
Table 8-1. Porosity, permeability and residual water saturation for different rock types found in the Niagaran reefs (Jodry, 1969).

\begin{tabular}{|c|c|c|}
\hline $\begin{array}{c}\text { Porosity } \\
(/)\end{array}$ & $\begin{array}{c}\text { Permeability } \\
(\mathrm{mD})\end{array}$ & $\begin{array}{c}\text { Residual water } \\
\text { saturation }(/)\end{array}$ \\
\hline 0.048 & 0.21 & 0.35 \\
\hline 0.085 & 0.08 & 0.40 \\
\hline 0.125 & 2.05 & 0.12 \\
\hline 0.123 & 30 & 0.05 \\
\hline
\end{tabular}

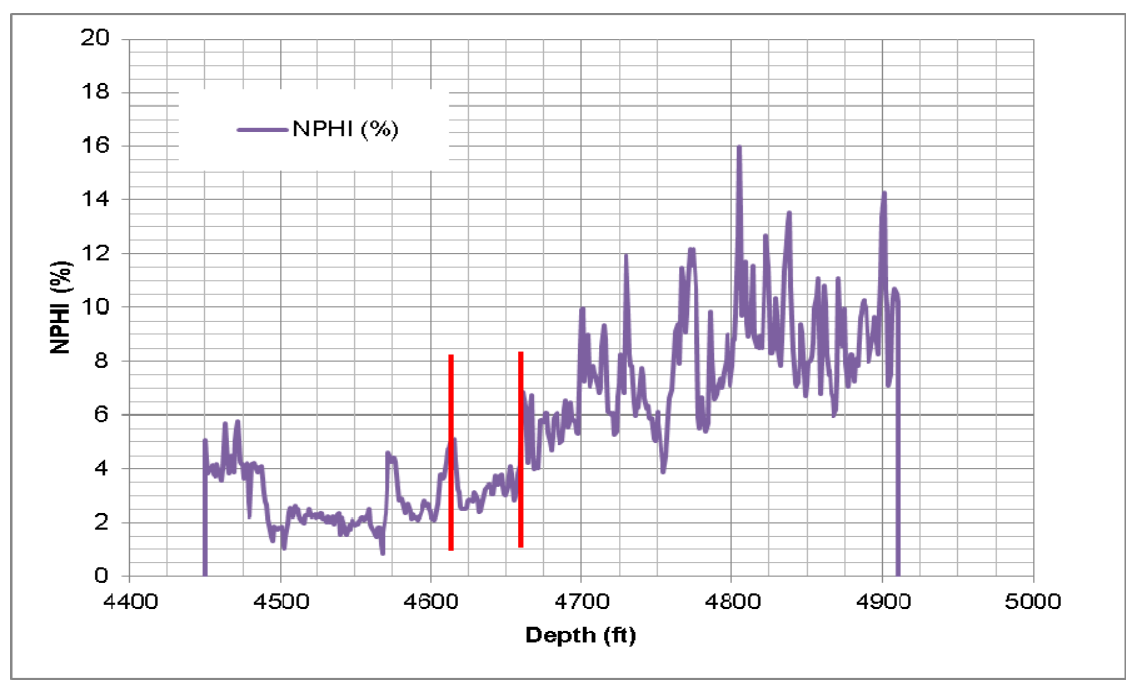

Figure 8-11. Neutron Porosity Hydrogen Index (NPHI in \%) measures at the Springdale 1-20 Shell well (1977). Left red line points out the caprock, and right red line the top of the reservoir.

Permeability at the reservoir, $k$ in $\mathrm{mD}$, can be calculated as (Trebin, 1945):

$$
\begin{aligned}
& k=2 \cdot e^{0.316 \cdot P} \quad \text { if } \mathrm{P}<12 \% \\
& k=4.94 \cdot P^{2}-763 \quad \text { if } \mathrm{P}>12 \%
\end{aligned}
$$

The reservoir having values of porosity between $4 \%$ and $16 \%$ would have a permeability of the range 7 and $500 \mathrm{mD}$ from the above equations. Permeability at the caprock must be much lower than in the reservoir. 


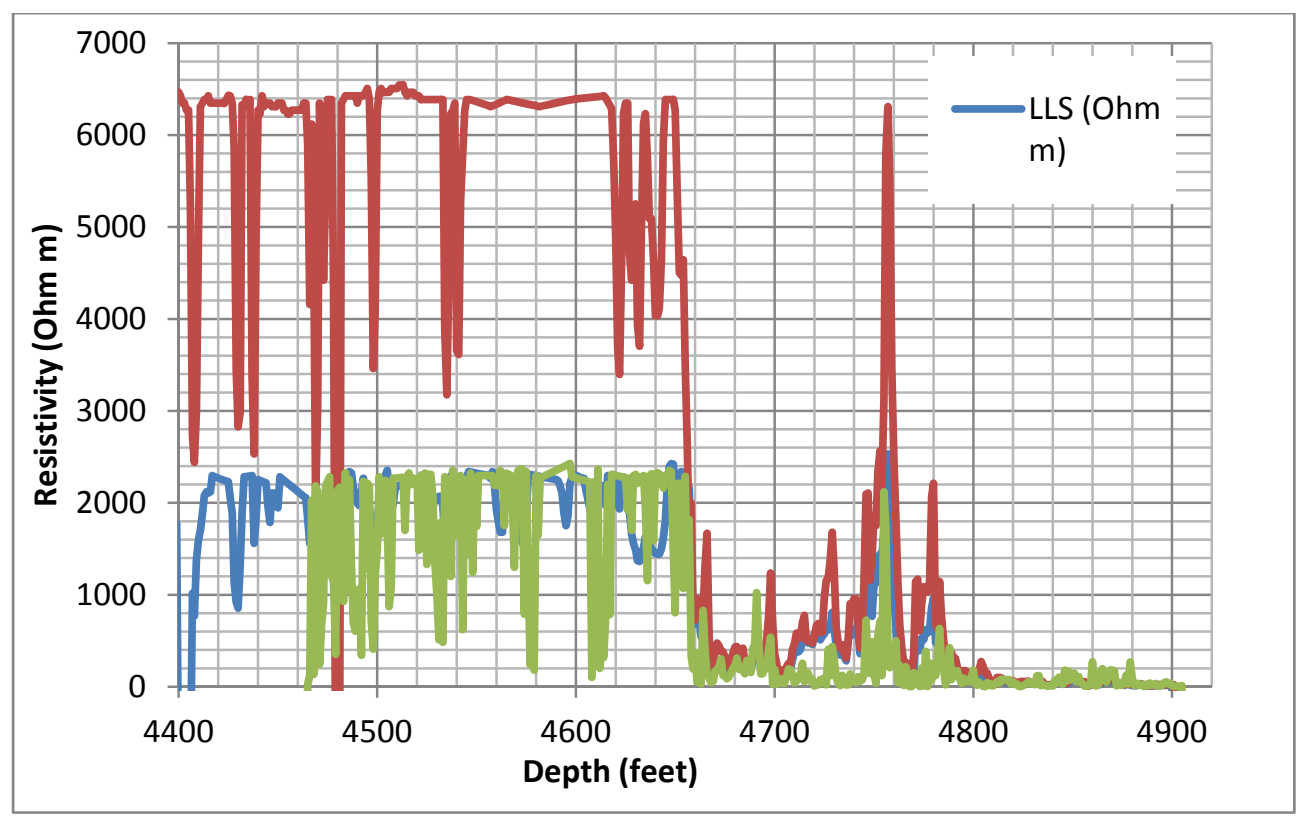

Figure 8-12. Measures of resistivity between $4400 \mathrm{ft}$ and $4920 \mathrm{ft}$ depth at the Springdale 1-20 Shell well (1977).

At this same log measures of resistivity starting at a depth of $4380 \mathrm{ft}$. The resistivity measures the degree of resistance to the flow of electrical current. The resistivity of a formation depends on its matrix and the percentage and nature of its fluids. The solids that form the matrix are highly resistive except by rock formations that contain certain conductive minerals (metal sulfides, native metals), salt water or clay. Rocks containing fluids such as oil or gas have high resistivity. There are Latero-log shallow resistivity (LLS, $\Omega \mathrm{m})$, Deep Induction Standard processed resistivity (ILD, $\Omega \mathrm{m})$, and Mll resistivity $(\Omega \mathrm{m})$. A sudden change is observed around $4650 \mathrm{ft}$; a low resistivity is detected, that coincides with the increase of porosity in the formation (Figure 8-11 and Figure 8-12). Around a depth of $4760 \mathrm{ft}$ an abrupt augmentation of the resistivity is observed, which could be an indicator of the presence of gas or oil. 


\section{Injection of $\mathrm{CO}_{2}$ at the MTU test site}

\subsection{Methodology}

\subsubsection{Description of the numerical model}

Several advancements have been made toward modeling the MTU test site. Figure 9-1 gives a detailed contour representation of the top and the bottom of this formation (subpanels (a) and (b), respectively).

Figure 9-1a and Figure 9-1b were obtained by displaying MTU site raw data using the commercial software SURFER (Golden Software, 2010), a contouring and surface modeling package that may be used for bathymetric modeling and contour mapping of three-dimensional surfaces.

Grid. The maps reported in Figure 9-1were the starting point for building a finite difference grid of the MTU test site in Petrel (Schlumberger, 2010a). Petrel is a commercial software for reservoir engineering workflows, that provides a fully featured reservoir simulation pre- and postprocessing environment for Eclipse (Schlumberger, 2010b). Figure 9-2a shows the grid created with Petrel for the top and bottom layers and Figure 9-2b is transversal profile of the grid. Grid is divided in 11 layers that follow the bottom surface. The grid has a total of 75735 cells $(85 \times 81 \times 11)$ and inside the reservoir area 33670. The extension of the grid is $850 \mathrm{~m} \times 810 \mathrm{~m} \times 108.26 \mathrm{~m}$. Size of the cells are around $10 \mathrm{~m} \times 10 \mathrm{~m} \times$ $11 \mathrm{~m}$. A local grid refinement is applied in cell $(38,42)$ along its vertical to allow the location of the well. This cell is divided in $3 \times 3$ subdivisions, with a proportion of 2:1:2, being the well the center cell with a size of $1 \mathrm{~m} \times 1 \mathrm{~m}$. 
(a)
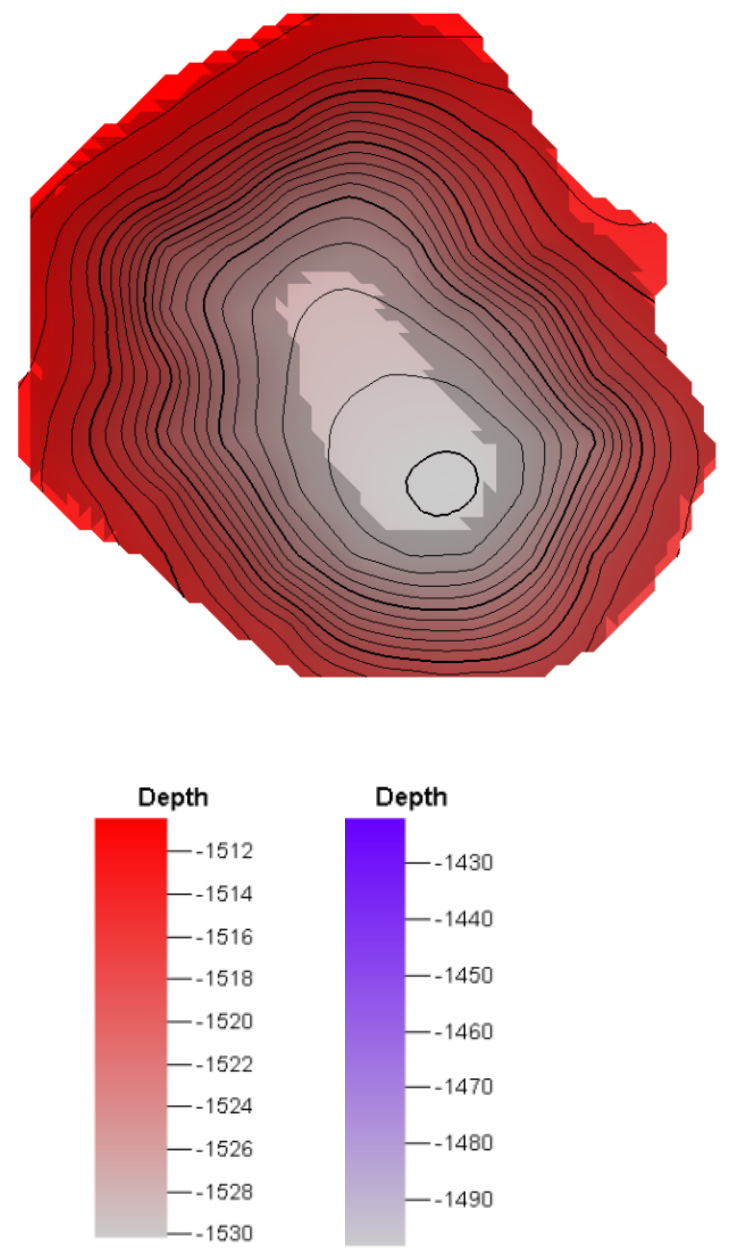

(a)

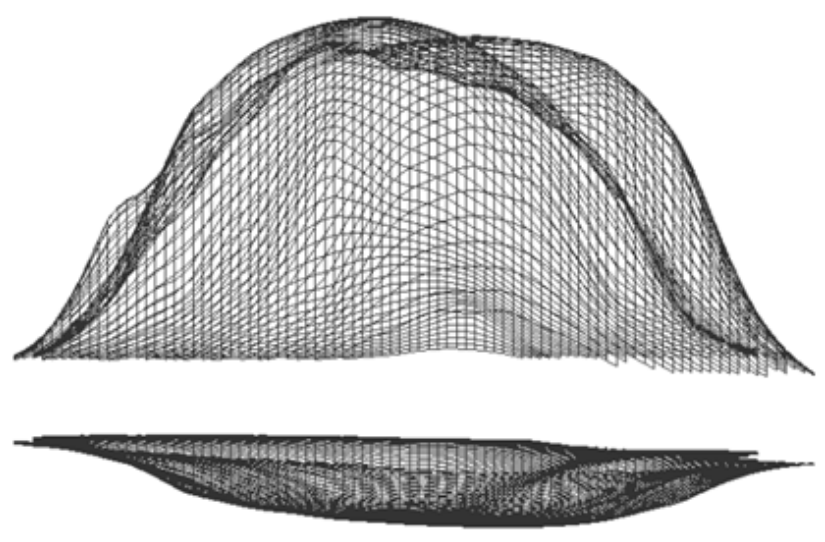

(b)

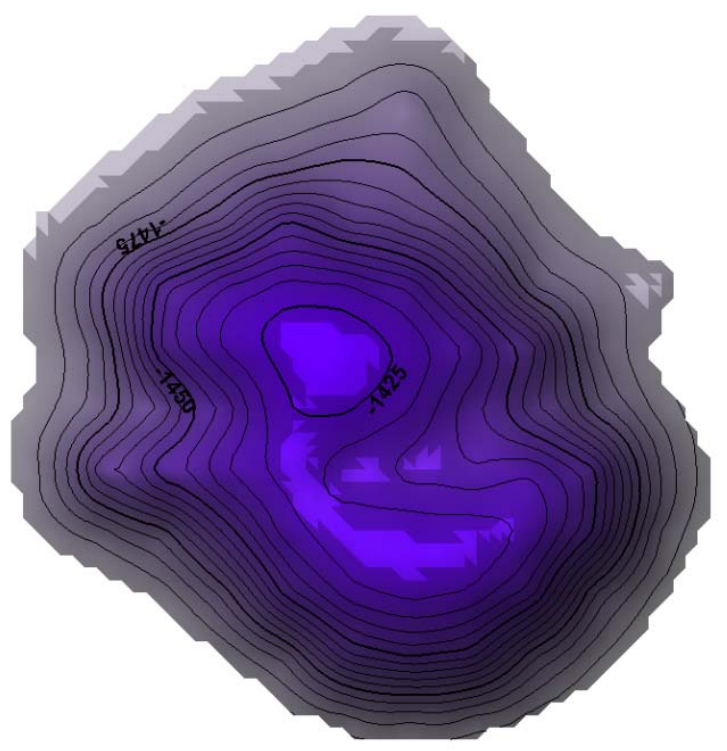

Figure 9-1. MTU test site: contour representation of the bathymetry (in meters) of (a) the top and (b) the bottom layers.

(b)

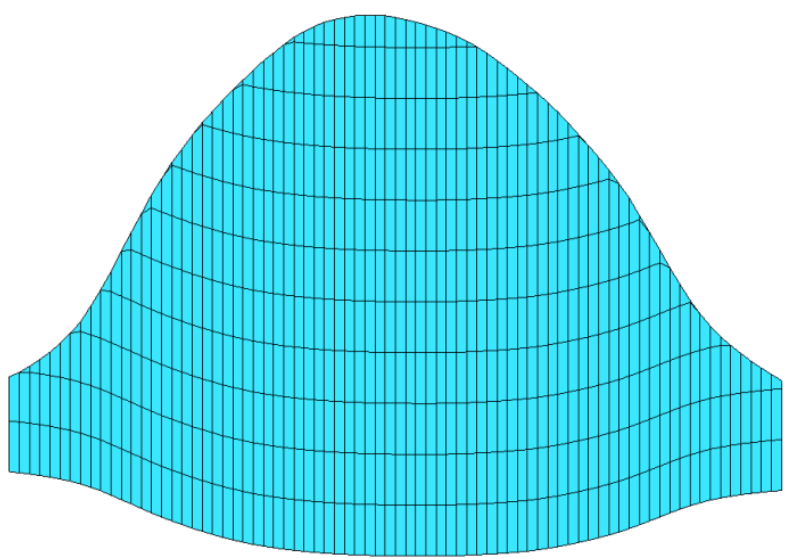

Figure 9-2. MTU test site: (a) Grid of finite differences for the top and bottom layer. (b) Cross-section profile of the grid. 
The construction of the three-dimensional grid constituted the first important step towards the development of a multiphase flow model of the MTU test site. In addition to that, the model requires exploring and prescribing plausible values for initial conditions, boundary conditions, and geological parameters distributions.

Initial conditions. The MTU site contains a nearly depleted hydrocarbon reservoir overlain by multiple saline aquifer intervals. The oil reservoir was initially developed by Shell in 1978 and is currently operated by Merit Energy. Oil production peaked $300 \mathrm{bbl} /$ day in the early 80 's but progressively decreased afterwards, and is currently less than 10 bbl/day (Baú, 2011b). Originally (before development), the reservoir was considered in hydrostatic equilibrium (Turpening, 2011). Under this assumption, an average hydrostatic pressure around 156 bar would be expected given the average depth of the reservoir (1476m). Currently, the pressure inside the reservoir is at 1.7 bar (Turpening, 2011) showing that a large depressurization of the reservoir has taken place during the time of development. Given the currently low yield and fluid pressure conditions, it is believed that the reservoir contains a mixture of brine (salt water) and gas originally dissolved in the brine that has been released out the solution following the strong pressure reduction (Turpening, 2011). Several scenarios reproducing the development of oil in the site are conducted in Eclipse (Schlumberger, 2010b) to reach closer initial conditions to real state of the MTU test site. To follow approximately the depletion of the reservoir from 1978 until 1999 (Figure 5a in Bau (2011a)) the production of oil shown in Figure 9-3 is imposed. At the same time a target of a minimum borehole pressure of 1.7 bar is applied not to go under the actual pressure of the reservoir (no more data of pressure are available). 


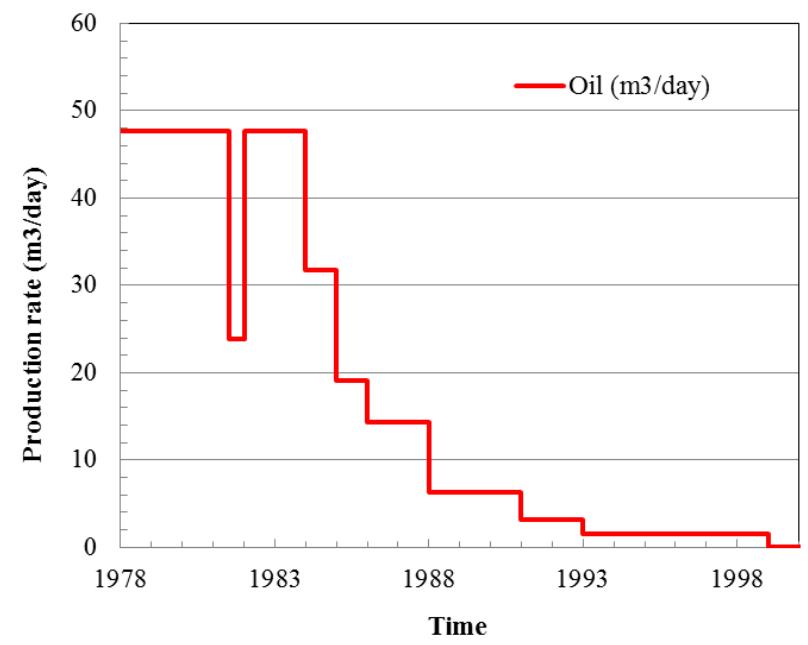

Figure 9-3. Time series for oil from 1978 to 1999 imposed to the scenarios.

The contact between oil and water (OWC) is considered at $1459 \mathrm{~m}$ of depth (Figure 4 in Bau (2011a)). There are no data available about the composition of the oil; therefore data from literature are used to determine a typical composition of a reservoir fluid (Danesh, 1998) (Table 9-1).

Table 9-1. Typical composition of a reservoir and simplified composition used in the model.

\begin{tabular}{cccc}
\hline Component $(\%$ mole $)$ & Black oil reservoir & Component $(\%$ mole $)$ & Simplified model \\
\hline $\mathrm{N} 2$ & 0.16 & $\mathrm{~N} 2$ & 0 \\
\hline $\mathrm{CO} 2$ & 0.91 & $\mathrm{CO} 2$ & 36 \\
\hline $\mathrm{C} 1$ & 36.47 & $\mathrm{C} 1$ & 10 \\
\hline $\mathrm{C} 2$ & 9.67 & $\mathrm{C} 2$ & 7 \\
\hline $\mathrm{C} 3$ & 6.95 & $\mathrm{C} 4$ & 6 \\
\hline $\mathrm{iC} 4$ & 1.44 & & 3 \\
$\mathrm{nC} 4$ & 3.93 & $\mathrm{C} 5$ & 4 \\
\hline $\mathrm{iC} 5$ & 1.44 & $\mathrm{C} 6$ & 17 \\
$\mathrm{nC5}$ & 1.41 & $\mathrm{C} 12$ & 17 \\
\hline $\mathrm{C} 6$ & 4.33 & $\mathrm{C} 20$ & \\
\hline $\mathrm{C} 7+$ & 33.29 & & \\
\hline & & & \\
\hline
\end{tabular}


Boundary conditions. The reservoir is considered isolated, therefore it does not have connection with others aquifers, which agrees with the fact that during its development the pressure decreased to the actual value of 1.7 bar.

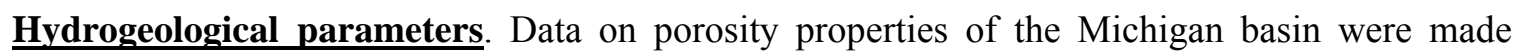
available within the MTU test-site dataset. Typical porosity values range between $4 \%$ and 16\% (Baú, 2011a). The MTU dataset does include permeability data. However, for the Michigan basin, the literature indicates that typical ranges of variability for permeability span between 5 and $500 \mathrm{mD}$. These values are obtained by applying the empirical formula presented by Trebin (1945) (Equation (8-1Error! Reference source not found.)). In Equation (8-1), $k$ is the permeability, while represents porosity. A porosity value of 0.15 is chosen whereas three values of permeability are considered in different scenarios. These three scenarios present permeabilities that could be possible in the reservoir. Table 9-2 shows these scenarios.

Hydrogeological parameters are provided in Table 9-3. The multiphase model also requires the prescription of laws describing the dependency of the capillary pressure, $p_{c}$, and the relative permeabilities, $k_{r w}, \mathrm{krg}$, and kro. In a three-phase system (gas, oil, and water) (Ahmed and Meehan, 2011), the water relative permeability depends only on water saturation. Similarly, the gas relative permeability depends only on gas saturation. The oil relative permeability depends on gas and water saturation. No experimental data of the three-phase relative permeability properties are available, neither for two-phases. Figure 9-4 shows data used for this study.

Table 9-2. Scenarios conducted to reach initial conditions after reservoir depletion.

\begin{tabular}{cc}
\hline Scenario & Permeability $(\mathrm{mD})$ \\
\hline 1 & 20 \\
2 & 100 \\
3 & 500 \\
\hline
\end{tabular}


Table 9-3. Hydrogeological parameters.

\begin{tabular}{cc}
\hline Parameter & Value \\
\hline Aquifer porosity $(/)$ & 0.15 \\
Salinity molality $(\mathrm{mol} / \mathrm{kg})$ & 0.0624 \\
$\mathrm{CO}_{2}$ density $\left(\mathrm{kg} / \mathrm{m}^{3}\right)$ & 600 \\
System compressibility $\left(\mathrm{m}^{2} / \mathrm{N}\right)$ & $4.6 \mathrm{E}-10$ \\
\hline
\end{tabular}

\subsubsection{Simulations}

Three main scenarios having differing $\mathrm{CO}_{2}$ injection rates are simulated after depleting the reservoir from 1978 to 1999 based on the different permeabilities of the reservoir. We have considered that $\mathrm{CO}_{2}$ injection starts at $1 / 01 / 2014$ and have a duration of 5 years. These scenarios are summarized in Table 9-4. The permeability of the aquifer and the injection rate is expected to have a significant influence on the fluid overpressure, with low permeability values and high injection rates producing large overpressures. The maximum admissible overpressure, $\Delta p_{\max }$, around the injection well is calculated as Equation (6-1) Error! Reference source not found. Assuming a Poisson ratio of $0.25, \Delta p_{\max }$ is equal to 58 bars. This value is considered as the overpressure threshold beyond which the caprock is likely to fissure. A maximum pressure of 214 bar ( $156 \mathrm{bar}+58 \mathrm{bar})$ is allowed to reach during the injection. When this value is reached the injection is stopped.

Table 9-4. Scenarios of $\mathrm{CO}_{2}$ injection after reservoir depletion.

\begin{tabular}{ccc}
\hline Scenario & Injection rate $(\mathrm{kg} / \mathrm{s})$ & $\mathrm{K}(\mathrm{mD})$ \\
\hline Q1 & 5 & 20,100, and 500 \\
Q2 & 10 & 20,100 , and 500 \\
\hline
\end{tabular}


(a)

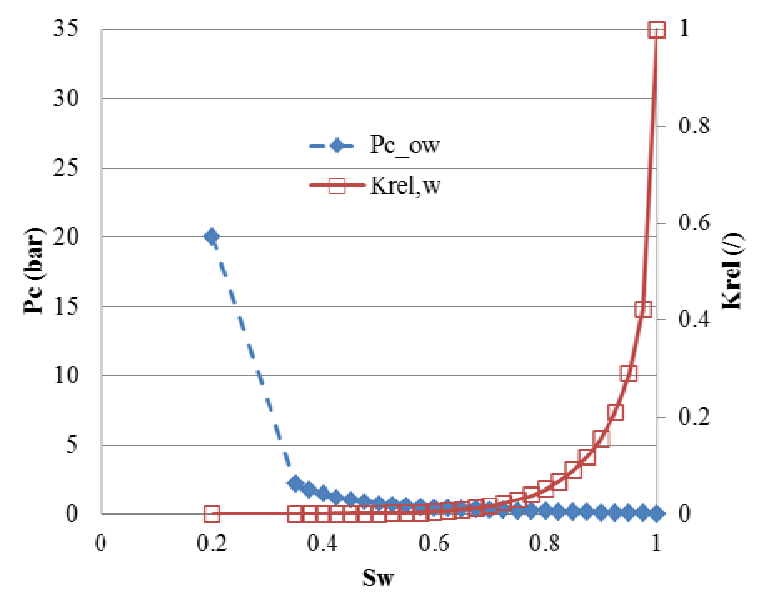

(c)

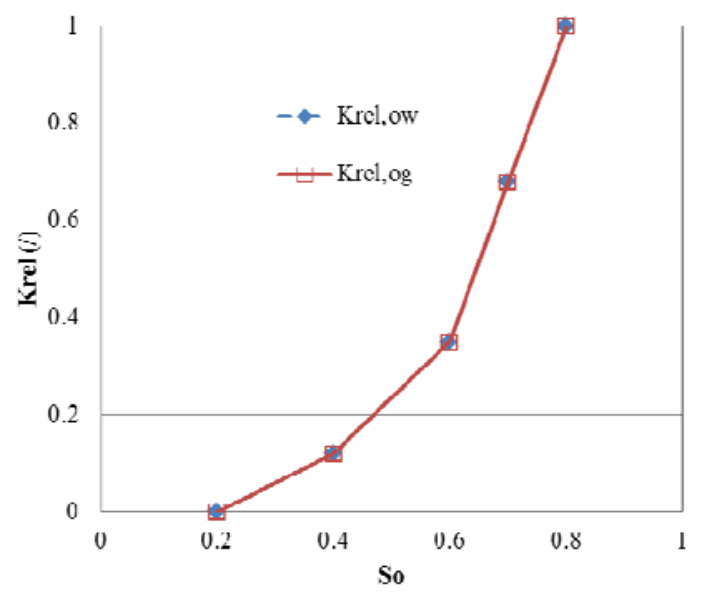

(b)

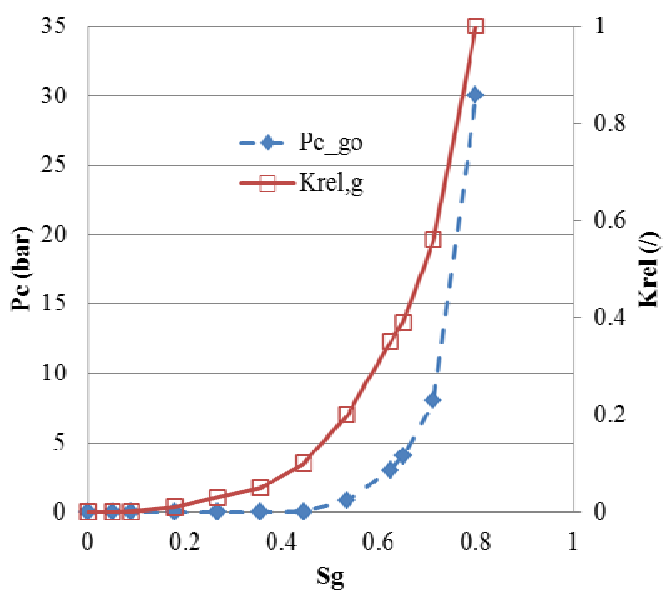

Figure 9-4. Relative permeabilities and capillary pressures: (a) Water Saturation, (b) Gas saturation, and (c) Oil Saturation.

\subsection{Results}

\subsubsection{Results of oil depletion at the MTU test site}

Figure 9-5 shows results of cumulative production at the MTU test site for the three scenarios of

Table 9-2. The cumulative production of oil and gas is greater at the MTU test site than the cumulative production from the three scenarios. Scenario 1, with lowest permeability, has the lowest cumulative production of oil and gas. Results of water cumulative production are very close for the three scenarios, being scenario 3, with greatest permeability, the scenario that produces less water. 
Figure 9-6 shows the evolution of the bore-hole pressure, oil in place, gas in place, and water in place during depletion for the three scenarios. Unfortunately we do not have data during depletion at the MTU test site to compare with. In scenario 3, with greatest permeability, bore-hole pressure decreases more slowly in comparison with scenario 1 . Scenario 3 obtains lowest content of oil, gas, and water in the reservoir (Figure 9-6b-Figure 9-6d respectively). From Figure 9-7 to Figure 9-10 are represented the final state of pressure, oil saturation, gas saturation, and water saturation obtained at time $01 / 01 / 2014$ for the three scenarios. Notice that distributions of these results are different for the three scenarios.

(a)

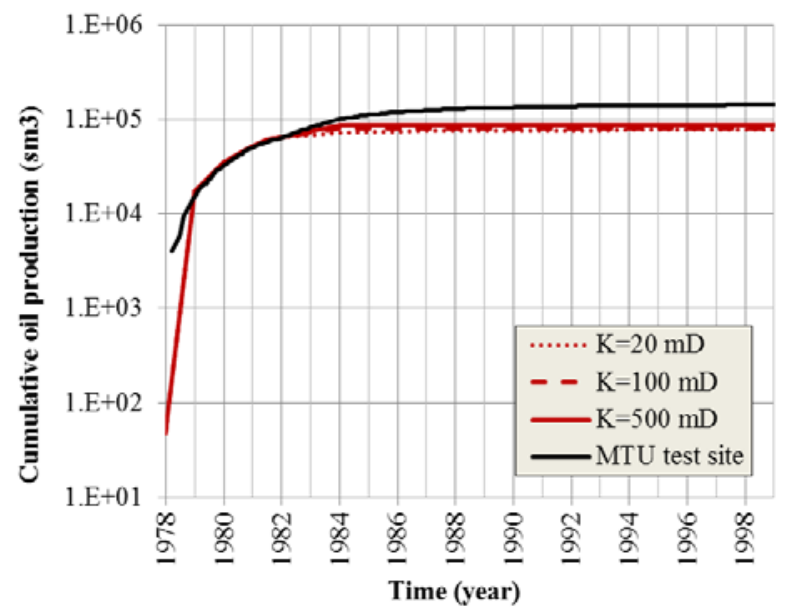

(c)

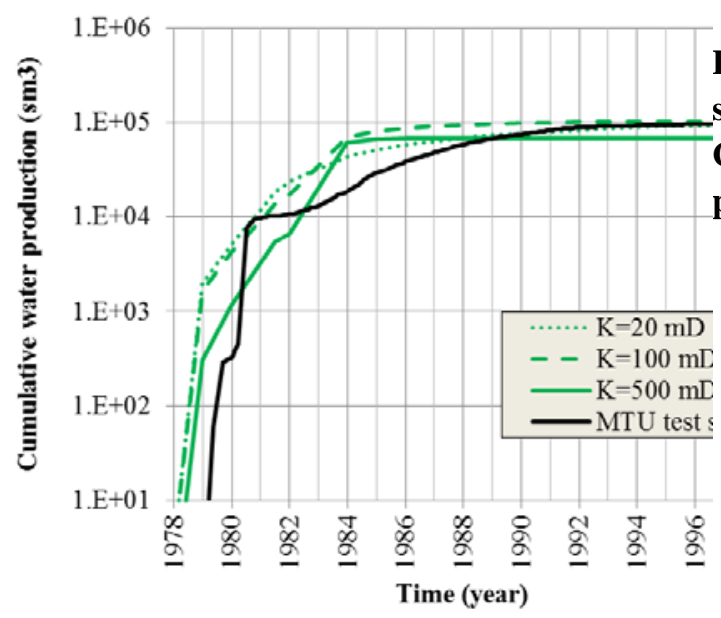

(b)

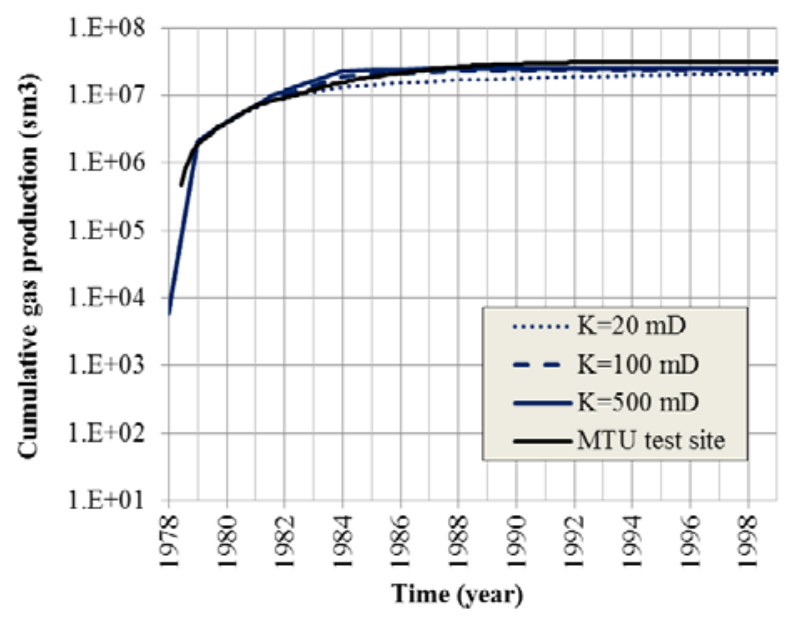

Figure 9-5. Comparison of cumulative productions of scenarios from Table 2 with MTU test site: (a) Cumulative oil production, (b) Cumulative gas production, and (c) Cumulative water production. 
(a)

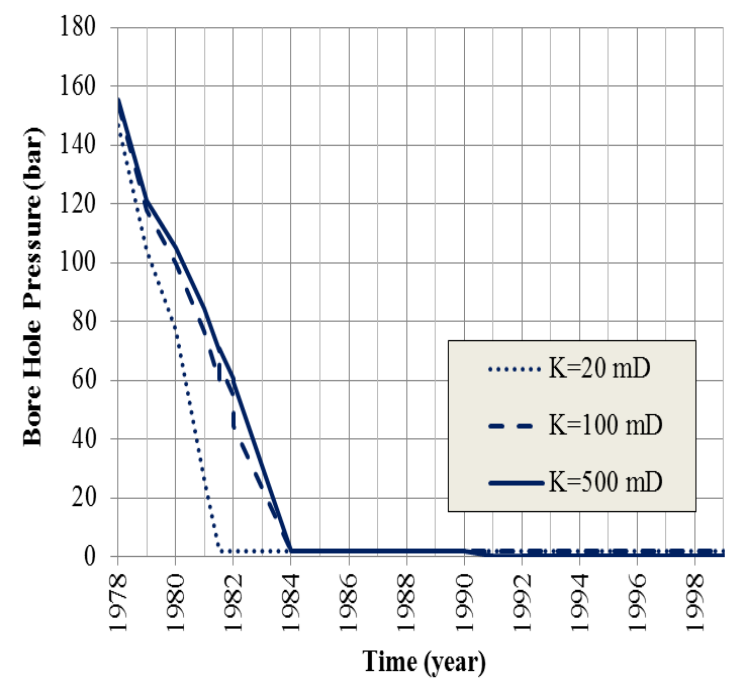

(c)

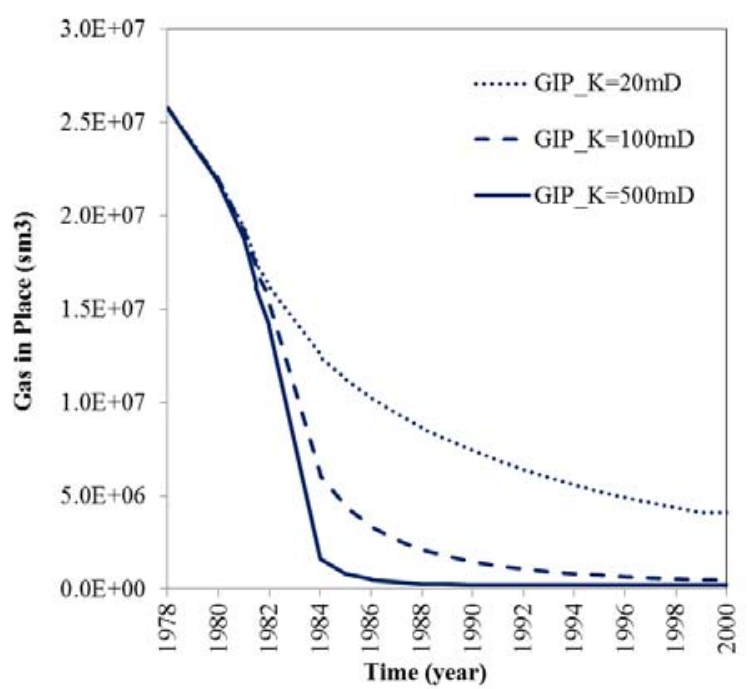

(b)

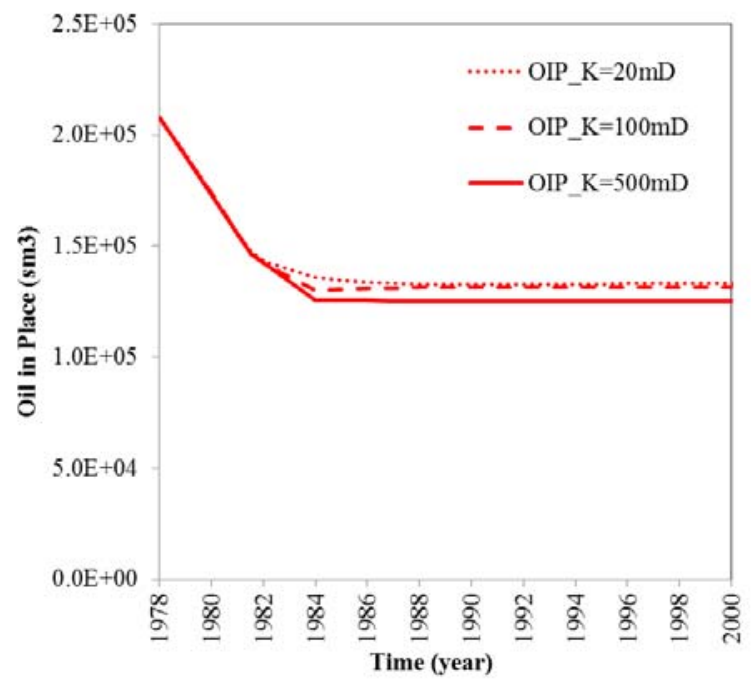

(d)

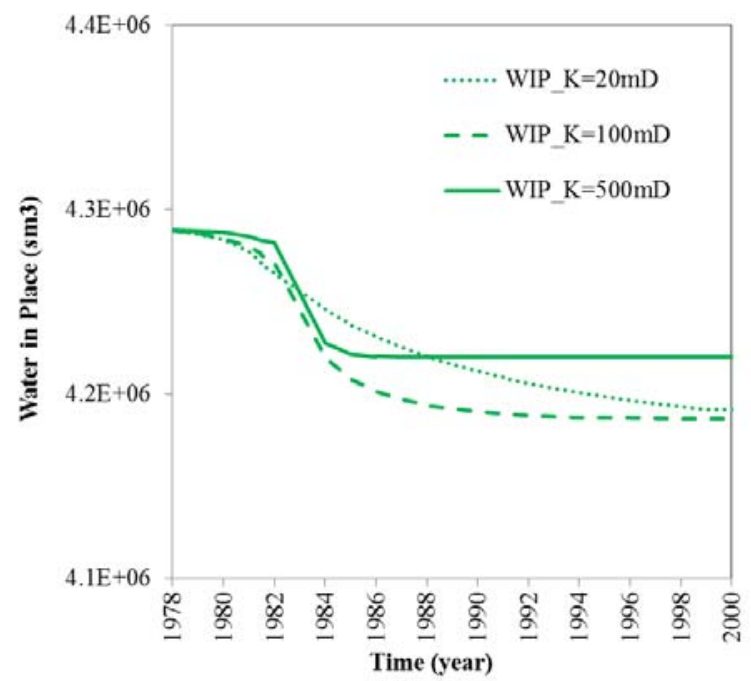

Figure 9-6. Evolution during depletion of: (a) Bore Hole Pressure, (b) Oil in Place, (c) Gas in Place, and (d) Water in Place. 


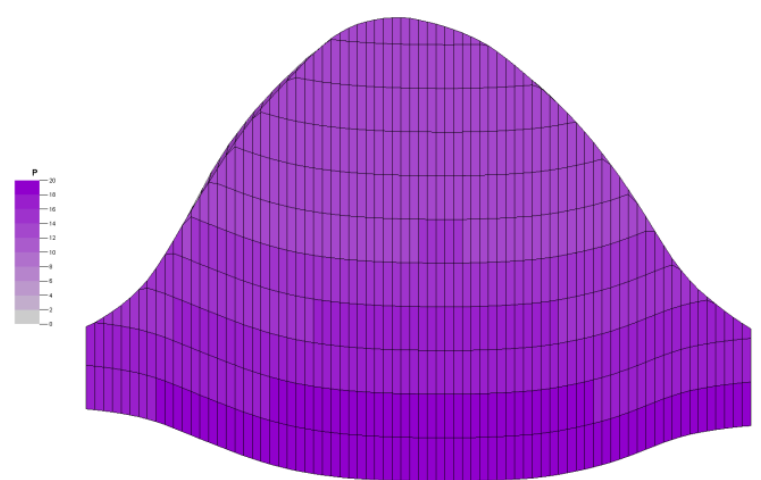

(a) Scenario $1(\mathrm{~K}=20 \mathrm{mD})$

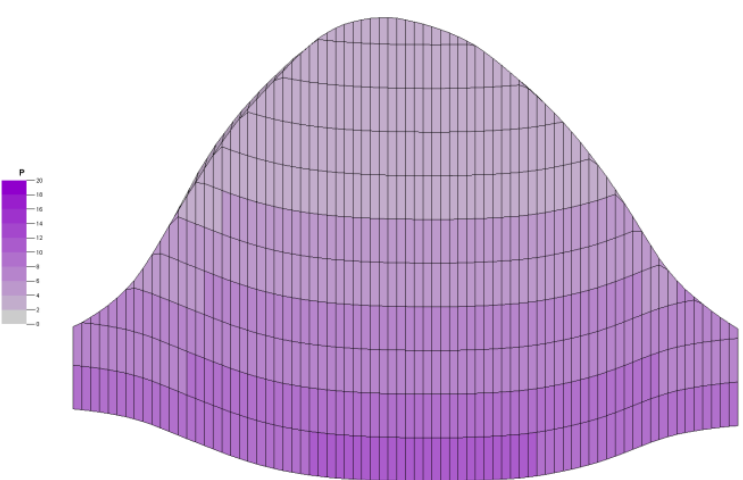

(b) Scenario $2(\mathrm{~K}=100 \mathrm{mD})$

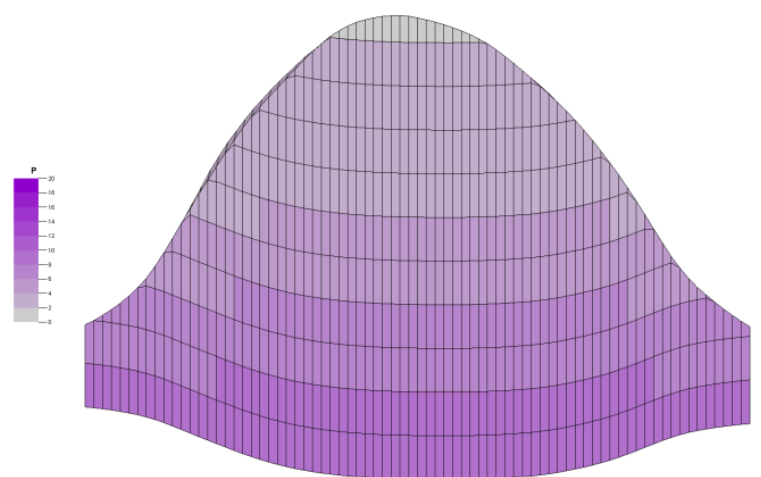

(c) Scenario $3(\mathrm{~K}=500 \mathrm{mD})$

Figure 9-7. Cross-section of pressure distribution at time 1/01/2014 for scenarios from Table 2.

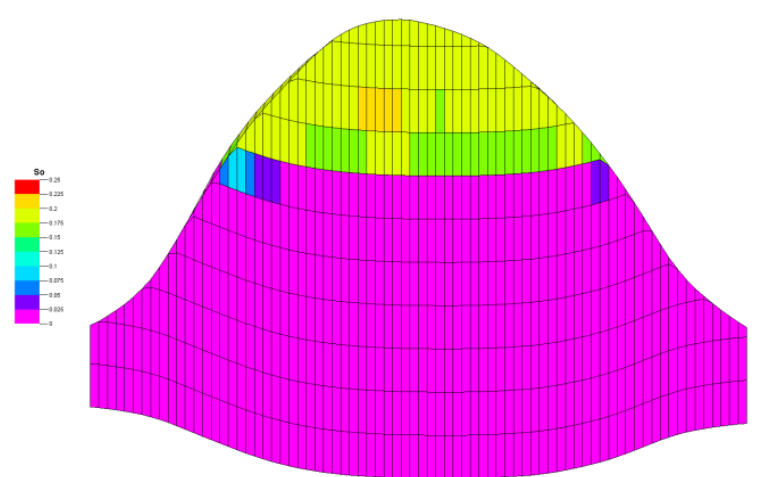

(a) Scenario $1(\mathrm{~K}=20 \mathrm{mD})$

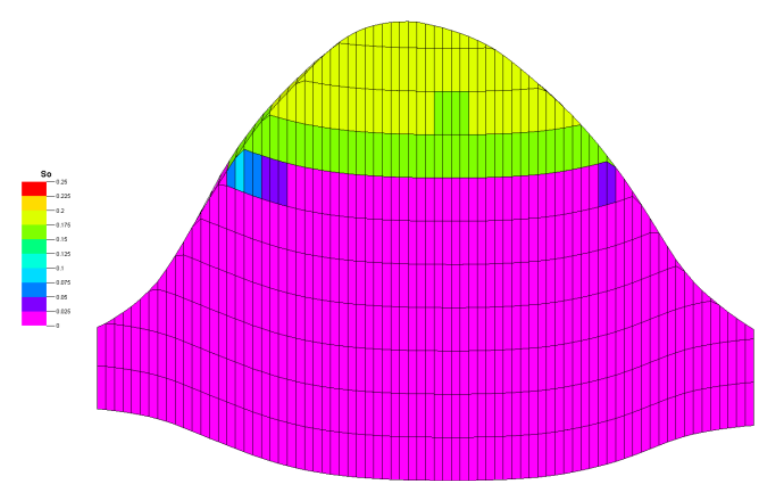

(b) Scenario $2(\mathrm{~K}=100 \mathrm{mD})$

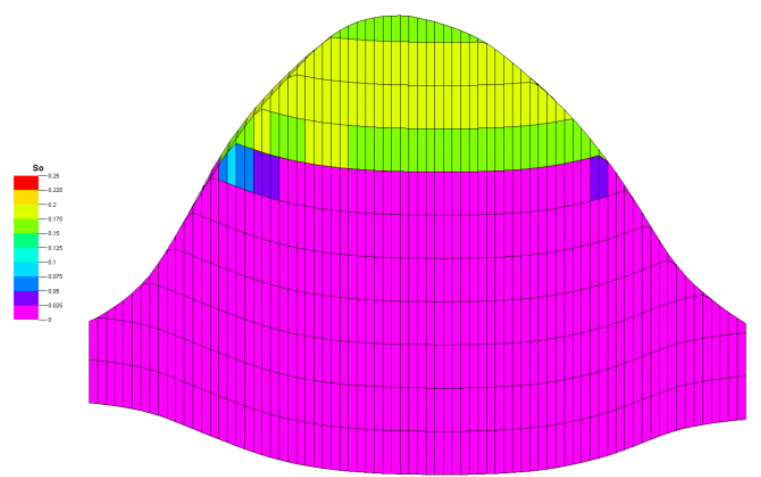

(c) Scenario $3(\mathrm{~K}=500 \mathrm{mD})$

Figure 9-8. Cross-section of oil saturation distribution at time 1/01/2014 for scenarios from Table 2. 


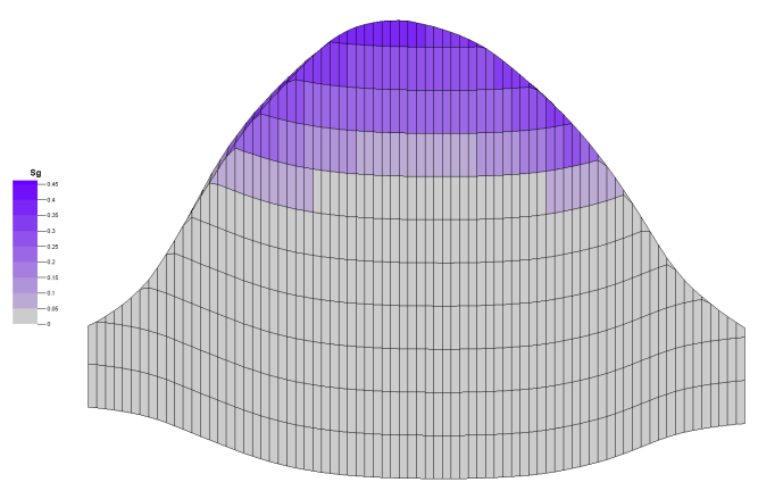

(a) Scenario $1(\mathrm{~K}=20 \mathrm{mD})$

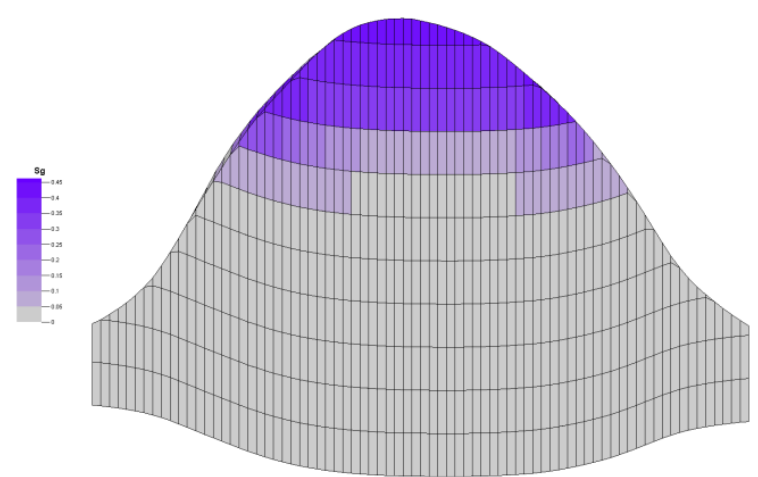

(b) Scenario $2(\mathrm{~K}=100 \mathrm{mD})$

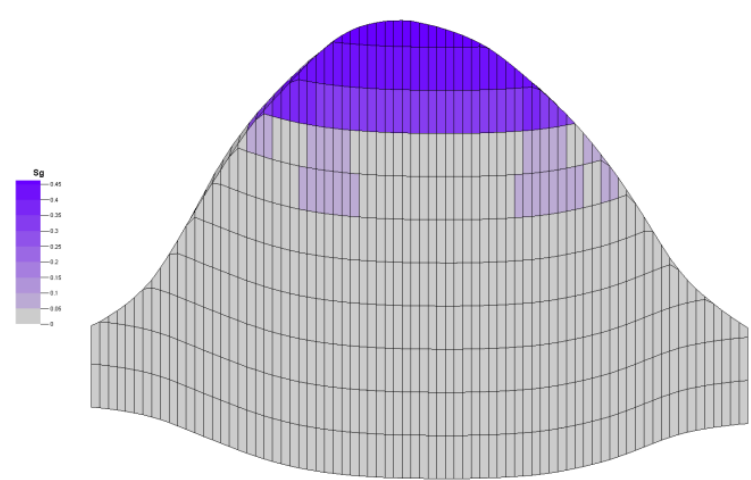

(c) Scenario $3(\mathrm{~K}=500 \mathrm{mD})$

Figure 9-9. Cross-section of gas saturation distribution at time 1/01/2014 for scenarios from Table 2.

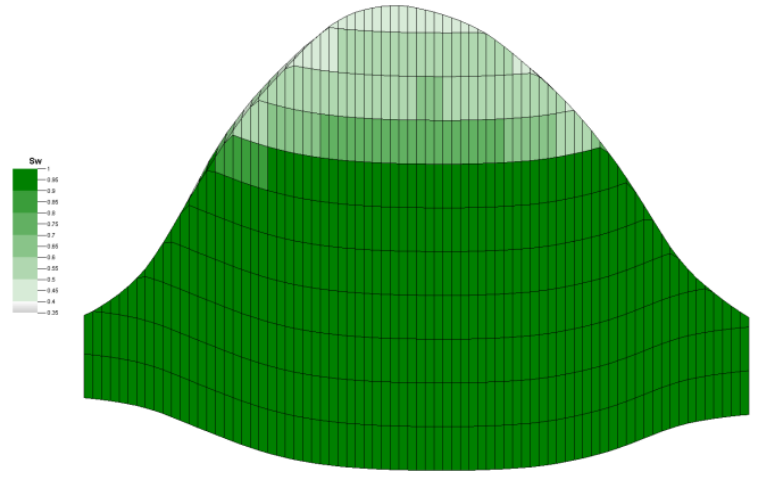

(a) Scenario $1(\mathrm{~K}=20 \mathrm{mD})$

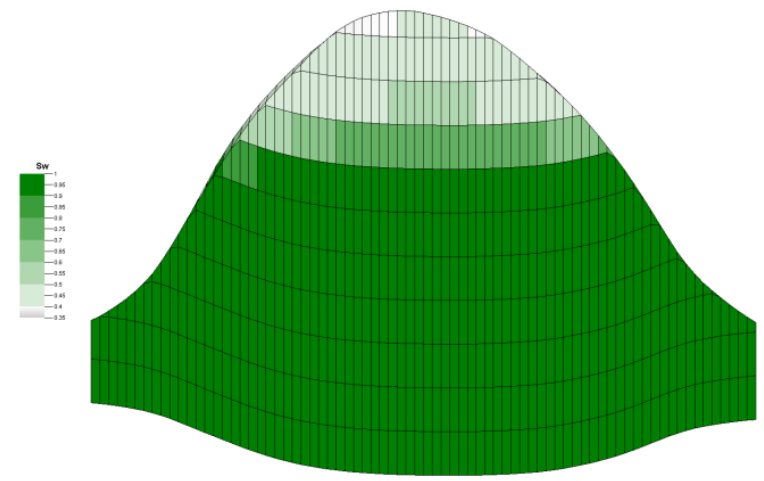

(b) Scenario $2(\mathrm{~K}=100 \mathrm{mD})$

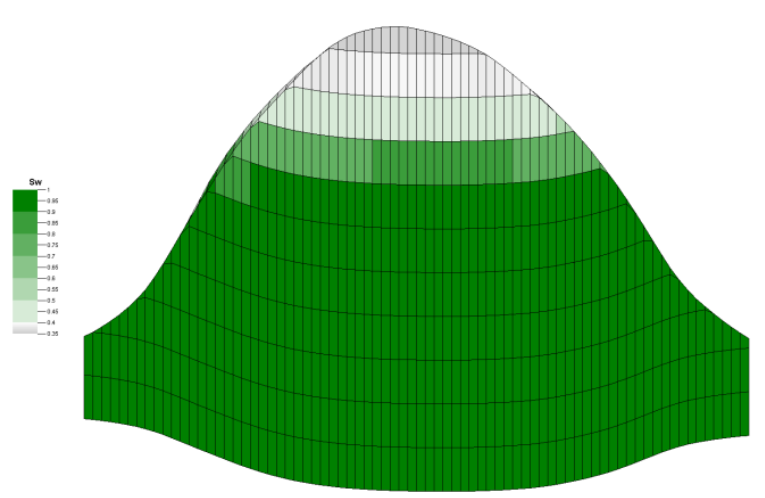

(c) Scenario $3(\mathrm{~K}=500 \mathrm{mD})$

Figure 9-10. Cross-section of water saturation distribution at time 1/01/2014 for scenarios from Table 2. 


\subsubsection{Results of $\mathrm{CO}_{2}$ injection at the $\mathrm{MTU}$ test site}

Table 9-5 provides the total amount of $\mathrm{CO}_{2}$ injected for the different scenarios. Between the maximum and minimum amount injected (scenario $\mathrm{Q}=5 \mathrm{~kg} / \mathrm{s}-\mathrm{K}=100 \mathrm{mD}$ and scenario $\mathrm{Q}=10 \mathrm{~kg} / \mathrm{s}-\mathrm{K}=500$ $\mathrm{mD}$ respectively) there is a difference of storage of $23.8 \%$.

Table 9-5. Cumulative injected gas obtained after 5 years of simulation (1/01/2019).

\begin{tabular}{ccc}
\hline $\begin{array}{c}\text { Injection } \\
\text { rate }(\mathrm{kg} / \mathrm{s})\end{array}$ & $\begin{array}{c}\text { Permeability } \\
(\mathrm{mD})\end{array}$ & $\begin{array}{c}\text { Cumulative Injected } \\
\text { Gas }\left(\mathrm{sm}^{3}\right)\end{array}$ \\
\hline \multirow{3}{*}{10} & 20 & $7.97 \mathrm{E}+07$ \\
& 100 & $8.95 \mathrm{E}+07$ \\
& 500 & $7.80 \mathrm{E}+07$ \\
\hline \multirow{2}{*}{5} & 20 & $8.09 \mathrm{E}+07$ \\
& 100 & $9.90 \mathrm{E}+07$ \\
& 500 & $8.10 \mathrm{E}+07$ \\
\hline
\end{tabular}

Figure 9-11 shows results of cumulative injected gas for the three permeabilities and injection rates. The amount stored increases when the injection rate is decreased from $10 \mathrm{~kg} / \mathrm{s}$ to $5 \mathrm{~kg} / \mathrm{s}$ rates (Figure 25a, $d$ and e). A lower injection rate allows longer times of injection. Figure 9-11b shows that the injection rate of $5 \mathrm{~kg} / \mathrm{s}$ starts to decrease at the beginning of 2015 , whereas an injection rate of $10 \mathrm{~kg} / \mathrm{s}$ ends around July 2014. Similarly, this is also observed in scenarios with $\mathrm{K}=500 \mathrm{mD}$ and $\mathrm{K}=20 \mathrm{mD}$ (Figures not included in the report). A lower injection rate reaches the maximum pressure later on time, delaying the stop of the well. In Figure 9-11c we see that the maximum pressure for $\mathrm{Q}=5 \mathrm{~kg} / \mathrm{s}$ is reached around July 2015, whereas for Q=10 kg/s is reached around December 2014. 
(a)

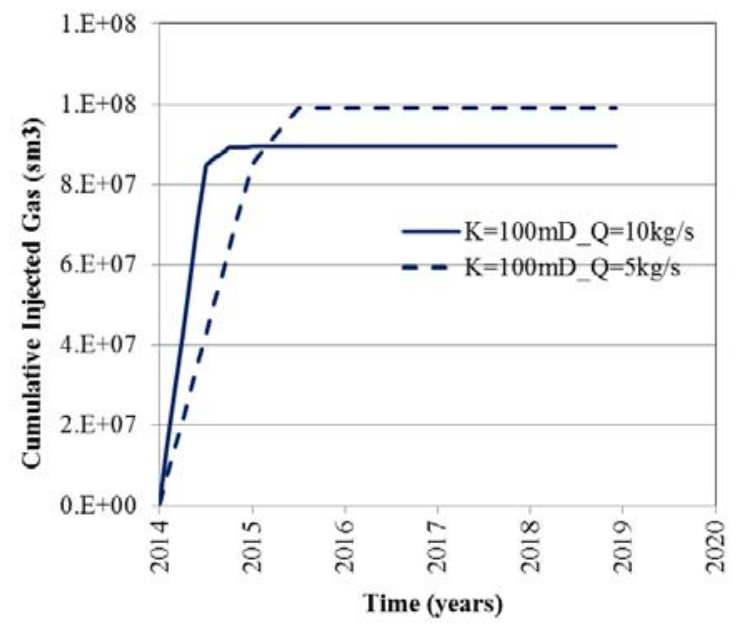

(b)

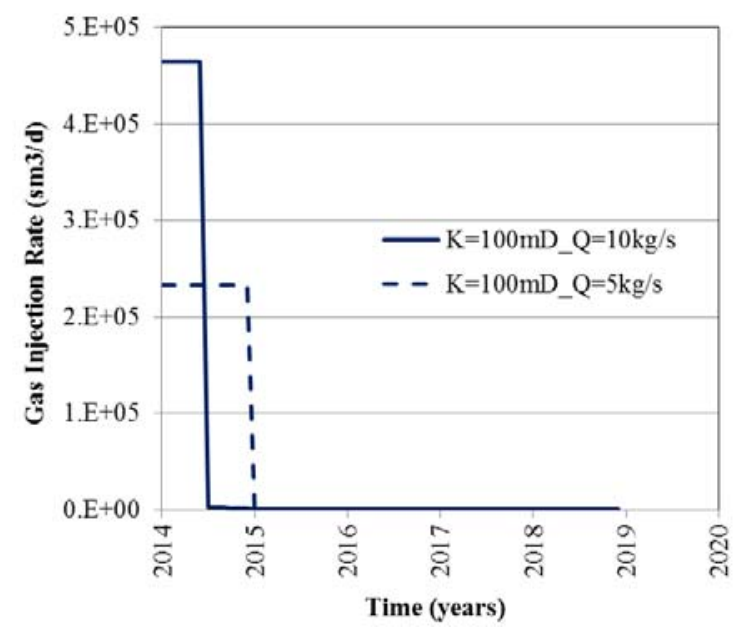

(c)

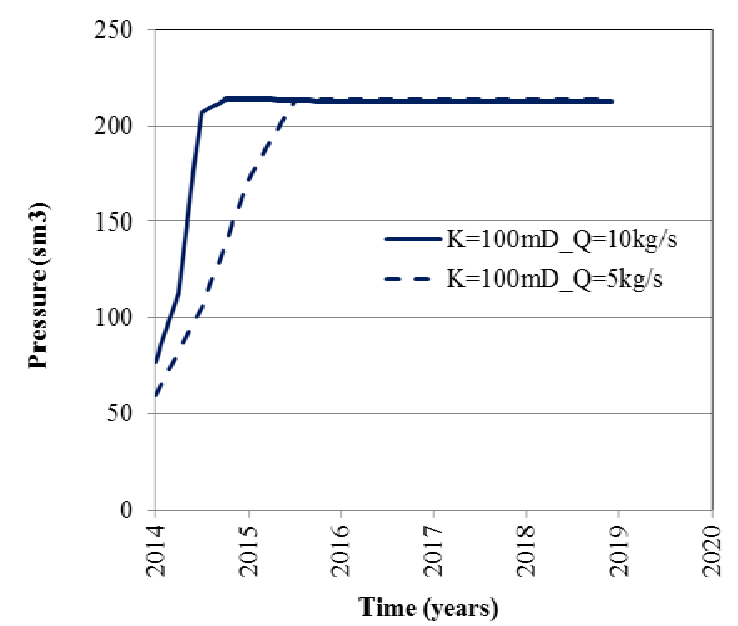

(d)

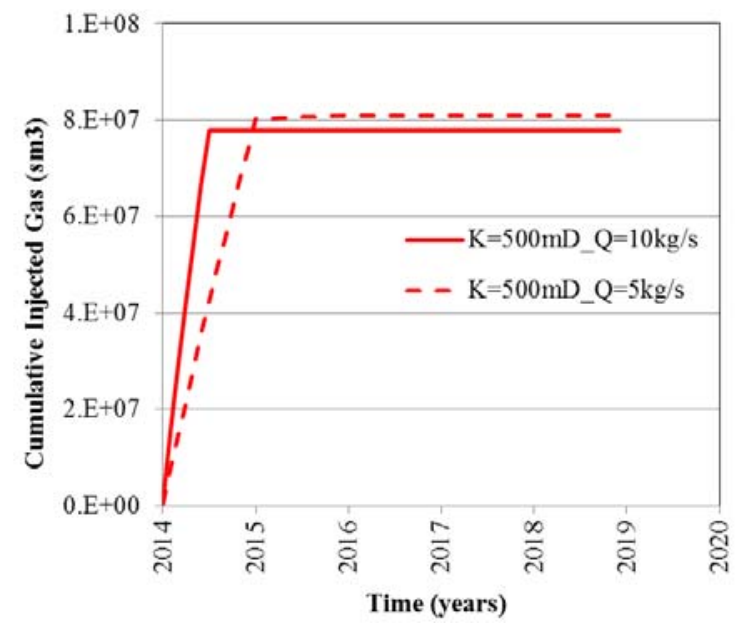

(e)

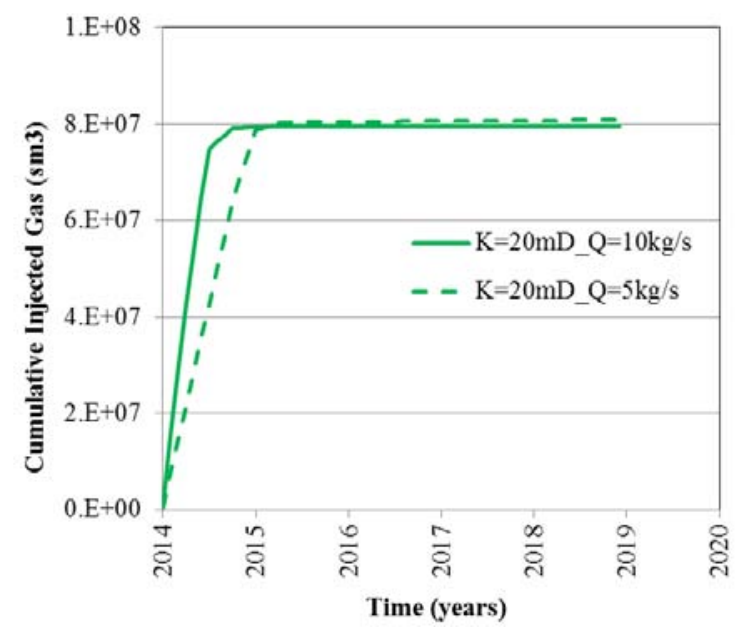

Figure 9-11. Results of $\mathrm{CO}_{2}$ injection at the MTU test site. (a) Cumulative injected gas, (b) Gas injection rate, and (c) Pressure field of scenario Q2. (d) and (e) Cumulative injected gas of scenarios Q3 and Q1 respectively.

Figure 9-12 shows that a greater amount of $\mathrm{CO}_{2}$ is stored in the reservoir for a permeability $\mathrm{K}=100 \mathrm{mD}$. Scenario $\mathrm{K}=100 \mathrm{mD}$ obtained greater production of water during depletion of the reservoir 
(Figure 9-5c), hence less water was present in the reservoir at the end of depletion (Figure 9-6d) and consequently more volume is available to store $\mathrm{CO}_{2}$.

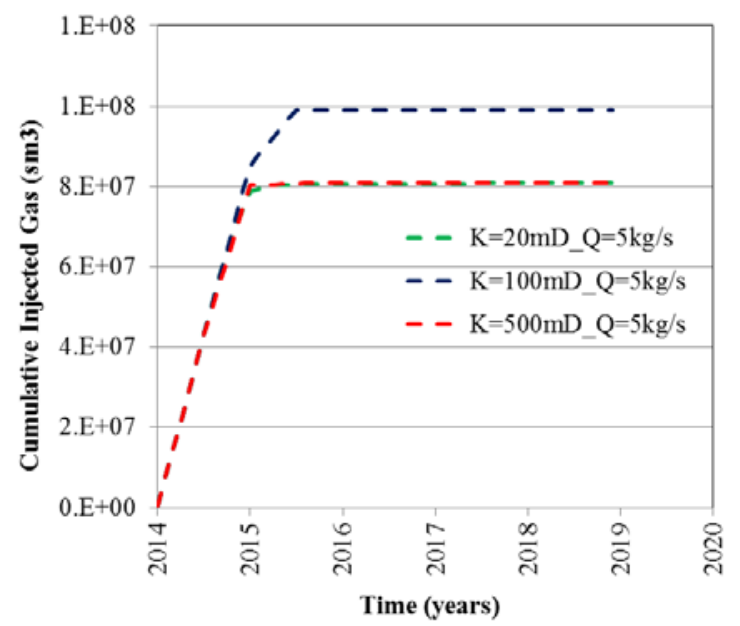

Figure 9-12. Results of $\mathrm{CO}_{2}$ injection at the MTU test site for an injection rate $\mathrm{Q}=5 \mathrm{~kg} / \mathrm{s}$.

\subsection{Conclusions}

We analyzed the variability of $\mathrm{CO}_{2}$ mass stored in the MTU test site based upon several initial conditions obtained from different scenarios of depletion, which had different permeability. For the three injection scenarios considered here, it was observed that lower injection rates reached maximum pressure later on time increasing the cumulative injected gas at the reservoir.

\section{Performance Assessment}

\subsection{Summary of skills learned}

Several skills have been gained by the two graduate students involved in this project. These doctoral candidates have acquired extensive knowledge in the areas of subsurface characterization, numerical and analytical modeling of multiphase domains, stochastic optimization of GS projects, and uncertainty analysis. 


\subsection{Presentation and Publication of Work}

The following is a list of work presented or publicized under this project:

Cody, B., A. González-Nicolás, D. Baù, CCS Site Optimization by Applying a Multi-objective Evolutionary Algorithm to Semi-Analytical Leakage Models, Abstract H21H-02, Fall meeting, AGU 2011, San Francisco, California, U.S., 5-9 Dec 2011

Cody, B., A. González-Nicolás, D. Baù. Analyzing Potential Improvements to a Semi-Analytical $\mathrm{CO}_{2}$ Leakage Algorithm, XXXII American Geophysical Union Hydrology Days, Fort Collins, Colorado, US, 21-23 Mar 2012.

Cody, B., A. González-Nicolás, D. Baù. Multi-site $\mathrm{CO}_{2}$ Sequestration Optimization using a Dynamic Programming Approach, XXXI American Geophysical Union Hydrology Days, Fort Collins, Colorado, US, 21-23 Mar 2011.

Cody, B., A. González-Nicolás, D. Baù. Optimization of Geological Carbon Sequestration using SemiAnalytical Leakage Models linked to a Multi-objective Evolutionary Algorithm, XIX International Conference on Computational Methods in Water Resources (CMWR 2012), Urbana, Illinois, 17-21 June 2012.

Cody, B., A. González-Nicolás, D. Baù. Stochastic Optimization of the Geological Sequestration of Carbon Dioxide, American Geophysical Union Hydrology Days 2013, Fort Collins, Colorado, US, 25-27 Mar 2013.

González-Nicolás, A., B. Cody, D. Baù. Carbon geological sequestration: effects of parameter uncertainty on fluid overpressure and $\mathrm{CO}_{2}$ leakage, XXXII American Geophysical Union Hydrology Days, Fort Collins, Colorado, US, 21-23 Mar 2012. 
González-Nicolás, A., B. Cody, D. Baù. Estimation of the Sealing Properties of MTU-site (Michigan) for Geological Carbon Storage, American Geophysical Union Hydrology Days 2013, Fort Collins, Colorado, US, 25-27 Mar 2013.

González-Nicolás, A., B. Cody, D. Baù. Influence of Uncertain Parameters on the Leakage of $\mathrm{CO}_{2}$ to Overlying Formations, Abstract H51G-1278, Fall meeting, AGU 2011, San Francisco, California, U.S., 5-9 Dec 2011.

González-Nicolás, A., B. Cody, D. Baù. Numerical simulation of $\mathrm{CO}_{2}$ into deep saline aquifers, XXXI American Geophysical Union Hydrology Days, Fort Collins, Colorado, US, 21-23 Mar 2011.

González-Nicolás, A., B. Cody, D. Baù. Stochastic analysis of factors affecting the leakage of $\mathrm{CO}_{2}$ from injected geological basins, XIX International Conference on Computational Methods in Water Resources (CMWR 2012), Urbana-Illinois, 17-21 Jun 2012.

\subsection{Completion of Goals and Objectives}

The construction and presentation of the $\mathrm{CO}_{2}$ Sequestration Simulation and Multi-objective Optimization Software (COSMOS) tool has fulfilled the first objective, Formulate and implement an integrated simulation-optimization framework to provide rigorous scientific support to the design of costoptimal, effective and safe carbon capture and sequestration (CCS) systems. COSMOS has the ability to:

1) Allow for users to easily input site data, simulation parameters, and optimization parameters.

2) Display sequestration site characteristics such as permeable caprock locations and vertical subsurface profiles

3) Display injection scheme information such as injection well locations and flow rates.

4) Display pressure pulse and $\mathrm{CO}_{2}$ plume propagation during simulation. 
5) Create and display optimal trade-off information for the given site data and optimization parameters. The three competing objectives will be 1) maximize the total mass of $\mathrm{CO}_{2}$ sequestered, 2) minimize total project cost, and 3) minimize the leakage risk.

6) Allow for the user to specify a target value for one objective then display the twodimensional optimal trade-off curve between the two remaining competing objectives.

7) Display injection scheme information for any point on the optimal trade-off plots

In addition, the second objective, Provide training opportunities for two graduate students in order to improve the human capital and skills required for implementing and deploying CCS technologies, has been thoroughly met by the training of Ana and Brent. This is evident by the skills learned and work composed listed in the preceding two chapters.

\subsection{Research Significance}

The research performed under this grant are significant to academic researchers and professionals weighing the benefits, costs, and risks of $\mathrm{CO}_{2}$ sequestration. Project managers in initial planning stages of CCS projects will be able to generate optimal tradeoff surfaces and with corresponding injection plans for potential sequestration sites leading to cost efficient preliminary project planning.

In addition, uncertainties concerning CCS have been researched. Uncertainty topics included Uncertainty Analysis of Continuity of Geological Confining Units using Categorical Indicator Kriging (CIK) and the Influence of Uncertain Parameters on the Leakage of $\mathrm{CO}_{2}$ to Overlying Formations. Reductions in uncertainty will lead to safer CCS projects. 


\section{Cost Status Table}

Table 11-1. Cost status as of December 31, 2012.

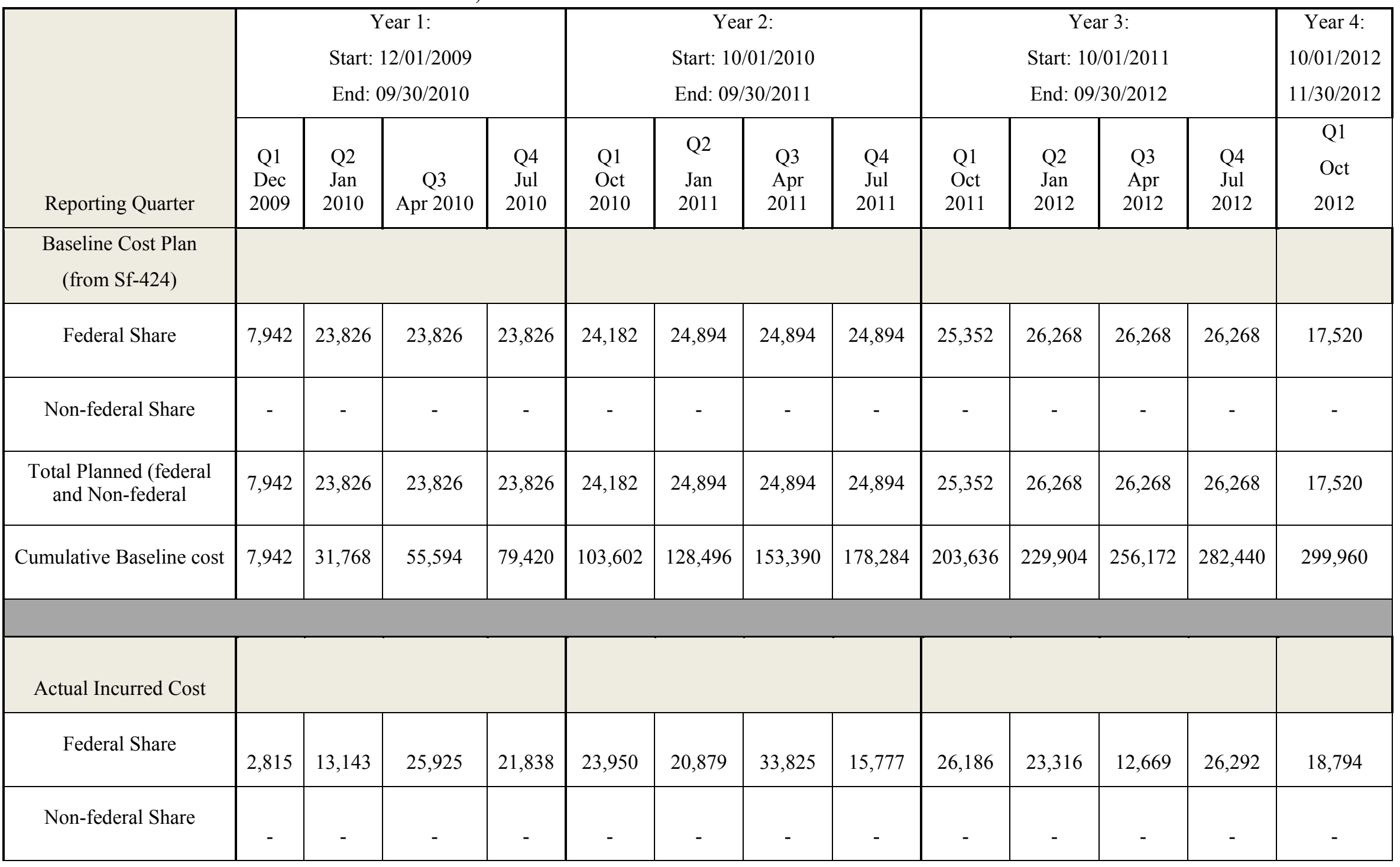




\begin{tabular}{|c|c|c|c|c|c|c|c|c|c|c|c|c|c|}
\hline $\begin{array}{l}\text { Total Planned (federal } \\
\text { and Non-federal }\end{array}$ & 2,815 & 13,143 & 25,925 & 21,838 & 23,950 & 20,879 & 33,825 & 15,777 & 26,186 & 23,316 & 12,669 & 26,292 & 18,794 \\
\hline Cumulative Baseline cost & 2,815 & 15,958 & 41,883 & 63,721 & 87,671 & 108,550 & 142,375 & 158,152 & 184,338 & 207,654 & 220,323 & 246,615 & 265,409 \\
\hline \multicolumn{14}{|l|}{ Variance } \\
\hline Federal Share & 5,127 & 10,683 & 2,099 & 1,988 & 232 & 4,015 & $(8,931)$ & 9,117 & (834) & 2,952 & 13,599 & (24) & $(1,274)$ \\
\hline Non-federal Share & - & - & - & - & - & - & - & - & - & - & - & - & - \\
\hline $\begin{array}{l}\text { Total Planned (federal } \\
\text { and Non-federal }\end{array}$ & 5,127 & 10,683 & $2,099.00$ & 1,988 & 232 & 4,015 & $(8,931)$ & 9,117 & (834) & 2,952 & 13,599 & (24) & $(1,274)$ \\
\hline Cumulative Baseline cost & 5,127 & 15,810 & $13,711.09$ & 15,699 & 15,931 & 19,946 & 11,015 & 20,132 & 19,298 & 22,250 & 35,849 & 35,825 & 34,551 \\
\hline
\end{tabular}




\section{Milestone Table}

Table 12-1. Milestone log status as of December 31, 2012.

\begin{tabular}{|c|c|c|c|c|c|c|c|c|c|c|c|c|c|c|c|c|}
\hline \multirow{3}{*}{$\begin{array}{l}\text { Task } \\
\text { Subtas } \\
\mathrm{k} \#\end{array}$} & \multirow{3}{*}{$\begin{array}{l}\text { Project } \\
\text { Mileston } \\
\text { e } \\
\text { Descripti } \\
\text { on }\end{array}$} & \multicolumn{15}{|c|}{ Project Duration: Start: 12/01/2009; End: 5/31/2013. } \\
\hline & & \multicolumn{4}{|c|}{$\begin{array}{c}\text { Year 1: } \\
\text { Start: } 12 / 01 / 2009 \\
\text { End: } 09 / 30 / 2010\end{array}$} & \multicolumn{4}{|c|}{$\begin{array}{c}\text { Year 2: } \\
\text { Start: } 10 / 01 / 2010 \\
\text { End: } 09 / 30 / 2011\end{array}$} & \multicolumn{5}{|c|}{$\begin{array}{c}\text { Year 3: } \\
\text { Start: } 10 / 01 / 2011 \\
\text { End: 09/30/2012 }\end{array}$} & $\begin{array}{c}\text { Year 4: } \\
\text { Start: } \\
10 / 01 / 2 \\
012 \\
\text { End: } \\
11 / 30 / 2 \\
012\end{array}$ & $\begin{array}{c}\text { No- } \\
\text { Cost } \\
\text { Extensi } \\
\text { on: } \\
\text { Start: } \\
12 / 01 / 2 \\
012 \\
\text { End: } \\
5 / 31 / 20 \\
13\end{array}$ \\
\hline & & $\begin{array}{l}\text { Q1 } \\
\text { De } \\
\text { c } \\
20 \\
09\end{array}$ & $\begin{array}{l}\text { Q2 } \\
\text { Jan } \\
20 \\
10\end{array}$ & $\begin{array}{l}\text { Q3 } \\
\text { Ap } \\
\text { r } \\
\\
20 \\
10\end{array}$ & $\begin{array}{l}\mathrm{Q} 4 \\
\mathrm{Ju} \\
20 \\
10\end{array}$ & $\begin{array}{l}\text { Q1 } \\
\text { Oc }\end{array}$ & $\begin{array}{l}20 \\
11\end{array}$ & $\begin{array}{l}\mathrm{Q} \\
\mathrm{A} \\
\mathrm{r} \\
2 \\
1\end{array}$ & $\begin{array}{l}\text { Q } \\
\mathrm{J} u\end{array}$ & $\begin{array}{l}\text { Q1 } \\
\text { Oc }\end{array}$ & & $\begin{array}{l}2 \\
a n \\
0 \\
2\end{array}$ & $\begin{array}{l}\text { Q3 } \\
\text { Ap } \\
\text { r } \\
20 \\
12\end{array}$ & $\begin{array}{l}\text { Q4 } \\
\text { Jul } \\
20 \\
12\end{array}$ & $\begin{array}{c}\text { Q1 } \\
\text { Oct } \\
2012\end{array}$ & \\
\hline 1 & 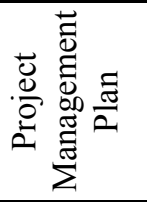 & 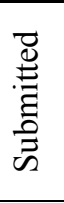 & 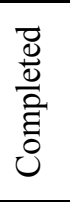 & & & & & & & & & & & & & \\
\hline 2 & 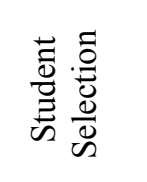 & 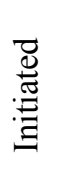 & 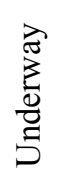 & 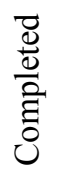 & & & & & & & & & & & & \\
\hline 2 & 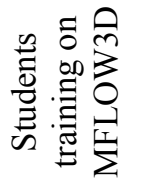 & 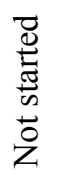 & 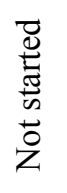 & 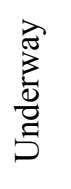 & 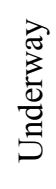 & $\begin{array}{l}\frac{\overrightarrow{0}}{0} \\
\frac{0}{2} \\
\text { : } \\
0\end{array}$ & & & & & & & & & & \\
\hline 3 & $\begin{array}{c}\text { Collectio } \\
\text { n of } \\
\text { MTU } \\
\text { Test-Site } \\
\text { Data }\end{array}$ & 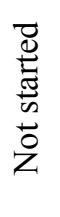 & 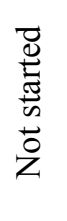 & 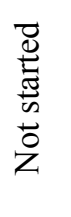 & 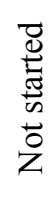 & 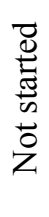 & $\frac{\text { ते }}{\sum_{0}^{0}}$ & 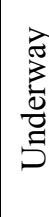 & 怤 & & & & & & & \\
\hline 3 & $\begin{array}{c}\text { Assimila } \\
\text { tion of } \\
\text { MTU } \\
\text { Test-Site } \\
\text { Data }\end{array}$ & 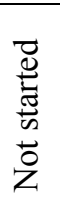 & 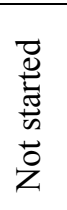 & 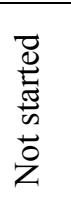 & 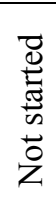 & 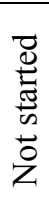 & 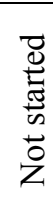 & 㿣 & 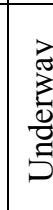 & 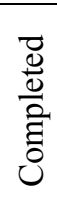 & & & & & & \\
\hline
\end{tabular}




\begin{tabular}{|c|c|c|c|c|c|c|c|c|c|c|c|c|c|c|}
\hline 4 & $\begin{array}{c}\text { CCS } \\
\text { Multi- } \\
\text { objective } \\
\text { framewo } \\
\text { rk }\end{array}$ & 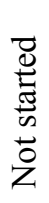 & 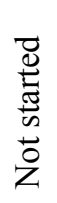 & 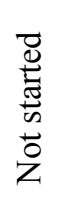 & 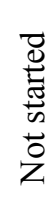 & 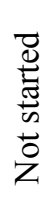 & 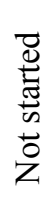 & 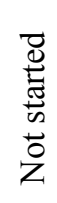 & 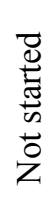 & $\frac{\vec{e}}{\sum_{0}^{0}}$ & 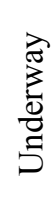 & 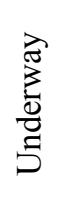 & 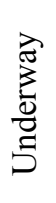 & 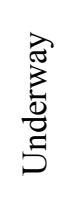 \\
\hline 4 & $\begin{array}{l}\text { Applicat } \\
\text { ion to } \\
\text { the MTU } \\
\text { test site }\end{array}$ & 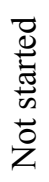 & 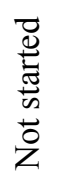 & 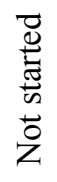 & 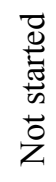 & 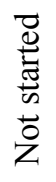 & 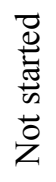 & 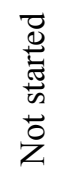 & 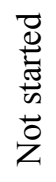 & 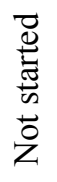 & 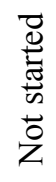 & 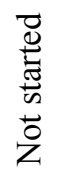 & 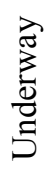 & 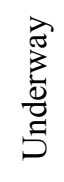 \\
\hline
\end{tabular}




\section{References}

[1] (1977) Log 21101320450000 FullSuite: State Springdale 1-20 (Date 12/14/1977)

[2] (1983) Log 21101365710000 1 CNLDT Litho Density Neutron GR (date 05/06/1983)

[3] Ahmed, T. and D. N. Meehan (2011). Advanced reservoir management and engineering, Gulf Professional Pub.

[4] Avci, C. B. (1994). Evaluation of flow leakage through abandoned wells and boreholes. Water Resources Res., 30 (9), 2565-2578

[5] Baù, D. (2011a). Multi-Objective Optimization Approaches for the Design of Carbon Geological Sequestration Systems, DE-FE0001830 Progress Report III, DOE, National Energy Technology Laboratory, June 2011. Q2

[6] Baù, D. (2011b). Multi-Objective Optimization Approaches for the Design of Carbon Geological Sequestration Systems, DE-FE0001830 Progress Report III, DOE, National Energy Technology Labratory, September 2011. Q3

[7] Baù, D., (2012). Multi-Objective Optimization Approaches for the Design of Carbon Geological Sequestration Systems, DE-FE0001830 Progress Report III, DOE, National Energy Technology Laboratory, September 2012.

[8] Baù, D. (2013a). Multi-Objective Optimization Approaches for the Design of Carbon Geological Sequestration Systems, DE-FE0001830 Progress Report III, DOE, National Energy Technology Laboratory, March 2013. Q1

[9] Cameron, D. A., and Durlofsky, L. J. (2009). Optimization of well placement, $\mathrm{CO}_{2}$ injection rates, and brine cycling for geological carbon sequestration. Intl. Journal of Greenhouse Gas Control, 10, 100-112. 
[10] Celia, M. A., J. M. Nordbotten, B. Court, M. Dobossy, S. Bachu (2011). Field-scale application of a semi-analytical model for estimation of $\mathrm{CO}_{2}$ and brine leakage along old wells, International Journal of Greenhouse Gas Control, 5: 257-269.

[11] Celia, M.A. and Nordbotten, J.M. (2009) Practical modeling approaches for geological storage of carbon dioxide. Ground Water, 47(5), 627-638.

[12] Chatterjee, A., G. K. Mahanti, and N. Pathak (2010) Comparative performance of gravitational search algorithm and modified particle swarm optimization algorithm for synthesis of thinned scanned concentric ring array antenna. Progress in Electromagnetics Research B, Vol. 25, 331348.

[13] Cihan, A., Q. Zhou, and J. Birkholzer. (2011). Analytical solutions for pressure perturbation and fluid leakage through aquitards and wells in multilayered aquifer systems. Water Resources Research 47: W10504. DOI:10.1029/2011WR010721.

[14] Cortis, A., Oldenburg, C. M., and Benson, S. M. (2008). The role of optimality in characterizing $\mathrm{CO}_{2}$ seepage from geologic carbon sequestration sites. Intl. Journal of Greenhouse Gas Control, $2,640-652$

[15] Danesh, A. (1998). PVT and phase behaviour of petroleum reservoir fluids, Elsevier Science.

[16] Gill D. (1977). The Belle River Mills Gas Field: Productive Niagaran Reefs Encased by Sabkha Deposits, Michigan Basin, Michigan Basin Geological Society, Special Papers No.2.

[17] Goda, T., and Sato, K. (2011). Optimization of well placement for geological sequestration of carbon dioxide using adaptive evolutionary Monte Carlo algorithm. Energy Procedia, 4, 42754282

[18] Golden Software (2010). Surfer 10, User Manual (www.goldensoftware.com/products/surfer/surfer.shtml).

[19] Han, S. H., and McPherson, B. J. (2009). Optimizing geologic $\mathrm{CO}_{2}$ sequestration by injection in deep saline formations below oil reservoirs. Energy Conv. and Mgmt., 50, 2570-2582 
[20] Hantush, M. S. (1959). Nonsteady Flow to Flowing Wells in Leaky Aquifers. Journal of Geophysical Res., 64 (8), 1043-1052

[21] Hantush, M. S. (1960). Modification of the Theory of Leaky Aquifers. Journal of Geophysical Res., 65 (11), 3713-3725

[22] Hantush, M.S., Jacob, C.E., 1955. Nonsteady radial flow in an infinite leaky aquifer. Int. Trans. Am. Geophys. Union, 36th Annual Meeting, Part 1, pp. 95-100.

[23] Hassanzadeh H.R. and M. Rouhani (2010). A multi-objective gravitational search algorithm. Second International Conference on Computational Intelligence, Communication Systems and Networks.

[24] Hunt, B. (1985). Flow to a Well in a Multiaquifer System. Water Resources Res., 21 (11), 16371641

[25] Ibrahim M. S., W. D. Pennington, and R. M. Turpening (2010). Crosswell Seismic Imaging of Acoustic and Shear Impedance in a Michigan Reef, The Leading Edge, Society of Exploration Geophysicists, June 2010.

[26] Javandel, I., Tsang, C. F., and Witherspoon, P. A. (1988). Hydrologic Detection of Abandoned Wells Near Proposed Injection Wells for Hazardous Waste Disposal. Water Resources Res., 24 (2), 261-270

[27] Jodry, R.L. 1969. Growth and Dolomitization of Silurian Reefs, St. Clair County, Michigan.Bulletin of the American Association of Petroleum Gelogists, V 53, N 4, pp. 957-981.

[28] Juanes, R., MacMinn, C. W., and Szulczewski, M. L. (2009). The Footprint of the $\mathrm{CO}_{2}$ Plume during Carbon Dioxide Storage in Saline Aquifers: Storage Efficiency for Capillary Trapping at the Basin Scale. Transp Porous Med (2010) 82:19-30.

[29] Kovescek, A. R., and Cakici, M. D. (2005). Geologic storage of carbon dioxide and enhanced oil recovery. II. Cooptimization of storage and recovery. Energy Conv. and Mgmt., 46,1941-1956

[30] Kumar, N. and S.L. Bryant. (2009). Semi-analytical model to determine perforation interval for secure $\mathrm{CO}_{2}$ storage in saline aquifers. Energy Procedia, 1 (2009): 3071-3078. 
[31] Mathias, S.A., Hardisty, P.E., Trudell, M.R., Zimmerman, R.W., 2009. Approximate solutions for pressure buildup during $\mathrm{CO}_{2}$ injection in brine aquifers. Transport in Porous Media, doi:10.1007/s11242-008-9316-7.

[32] Michigan DEQ - Oil and Gas Database. Retrieved May 16, 2013, from http://www.michigan.gov/deq/0,4561,7-135-6132_6828-98518--,00.html

[33] Neuman, S. P., and Whitherspoon, P. A. (1969). Applicability of Curret Theories of Flow in Leaky Aquifers. Water Resources Res., 5 (4), 817-829

[34] Nogues et al. (2012). A methodology to estimate maximum probable leakage along old wells in a geological sequestration operation. Intl. Journal of Greenhouse Gas Control, 7, 39-47.

[35] Nordbotten, J. M., D. Kavetski, M. A. Celia and S. Bachu (2009). Model for $\mathrm{CO}_{2}$ leakage Including Multiple Geological Layers and Multiple Leaky Wells. Environmental Science \& Technology, 43: 743-749.

[36] Nordbotten, J.M., and M.A. Celia (2006). Similarity solutions for fluid injection into confined aquifers. J. Fluid Mech., 561: 307-327.

[37] Nordbotten, J.M., M.A. Celia and S. Bachu (2005a). Injection and Storage of $\mathrm{CO}_{2}$ in Deep Saline Aquifers: Analytical Solution for $\mathrm{CO}_{2}$ Plume Evolution During Injection. Transp Porous Med, 58: $339-360$.

[38] Nordbotten, J.M., M.A. Celia and S. Bachu (2005b). Semi-analytical Solution for $\mathrm{CO}_{2}$ Leakage through an Abandoned Well. Environ. Sci. Technol., 39: 602-611.

[39] Nordbotten, J.M., M.A. Celia and S. Bachu. (2004). Analytical solutions for leakage rates through abandoned wells. Water Resources Research, 40. W04204, doi: 10.1029/2003WR002997.

[40] Oladyshkin et al. (2011). An integrative approach to robust design and probabilistic risk assessment for $\mathrm{CO}_{2}$ storage in geological formations. Comput. Geosci. (2011) 15:565-577

[41] Pentland, William. "The Carbon Conundrum." Forbes.com. 6 October 2008. http://www.forbes.com/2008/10/06/carbon-sequestration-biz-energy-cx_wp_1007capture.html 
[42] Pruess, K. (1991). TOUGH2 - A general-purpose numerical simulator for multiphase fluid and heart flow, Lawrence Berkeley Laboratory Report LBNL-29400, Berkeley, CA.

[43] Quan Y. and J.M. Harris (1997). Seismic attenuation tomography using the frequency shift method, Geophysics, 62 (3), 895-905.

[44] Rashedi, E., H. Nezamabadi-pour, and S. Saryazdi (2009). GSA: A gravitational search algorithm. Information Sciences, Vol. 179, No. 13, 2232-2248.

[45] Schlumberger (2008). ECLIPSE Reference Manual. http://dc184.4shared.com/doc/t_gvT$\mathrm{tM} /$ preview.html

[46] Schlumberger (2010a). Petrel 2010.1, (www.slb.com/content/services/software/geo/petrel/).

[47] Schlumberger, Eclipse technical description, v. 2010.1, Report, Abingdon, U.K., 2010.

[48] Teatini, P., Ferronato, M., Gambolati, G., BaÃ¹, D., Putti, M. (2010). Anthropogenic Venice uplift by seawater pumping into a heterogeneous aquifer system. Water Resour Res 46, W11547.

[49] Theis, C.V. (1935). The relation between lowering of the piezometric surface and the rate and duration of discharge of a well using ground water storage. In: Trans. Am. Geophys. Union, 16th Annual Meeting, Part 2, pp. 519-524.

[50] Trebin, F.A. (1945). Permeability to oil of sandstone reservoir, Gostoptekhizdat, Moscow.

[51] Turpening, R. (2011). Personal communication.

[52] van Genuchten, M.T., 1980. A Closed-form Equation for Predicting the Hydraulic Conductivity of Unsaturated Soils1. Soil Science Society of America Journal, 44(5): 892.

[53] Zhang, Z., and Agarwal, A. (2012). Numerical simulation and optimization of $\mathrm{CO}_{2}$ sequestration in saline aquifers. Computers and Fluids, Article in Press.

[54] Zhou, Q., Birkholzer, J.T., Mehnert, E., Lin, Y.-F. and Zhang, K., 2009. Modeling Basin- and Plume-Scale Processes of $\mathrm{CO}_{2}$ Storage for Full-Scale Deployment. Ground Water, 48(4): 494514. 
[55] Zhou, Q., Birkholzer, J.T., Tsang, C.-F. (2009). A semi-analytical solution for largescale injection-induced pressure perturbation and leakage in a laterally bounded aquifer-aquitard system. Transport in Porous Media 78 (1), 127-148, doi:10.1007/s11242-008-9290-0. 